\title{
Collaborative Studies for Mercury Characterization in Coal and Coal Combustion Products, Republic of South Africa
}

By Allan Kolker, Constance L. Senior, and Chris van Alphen

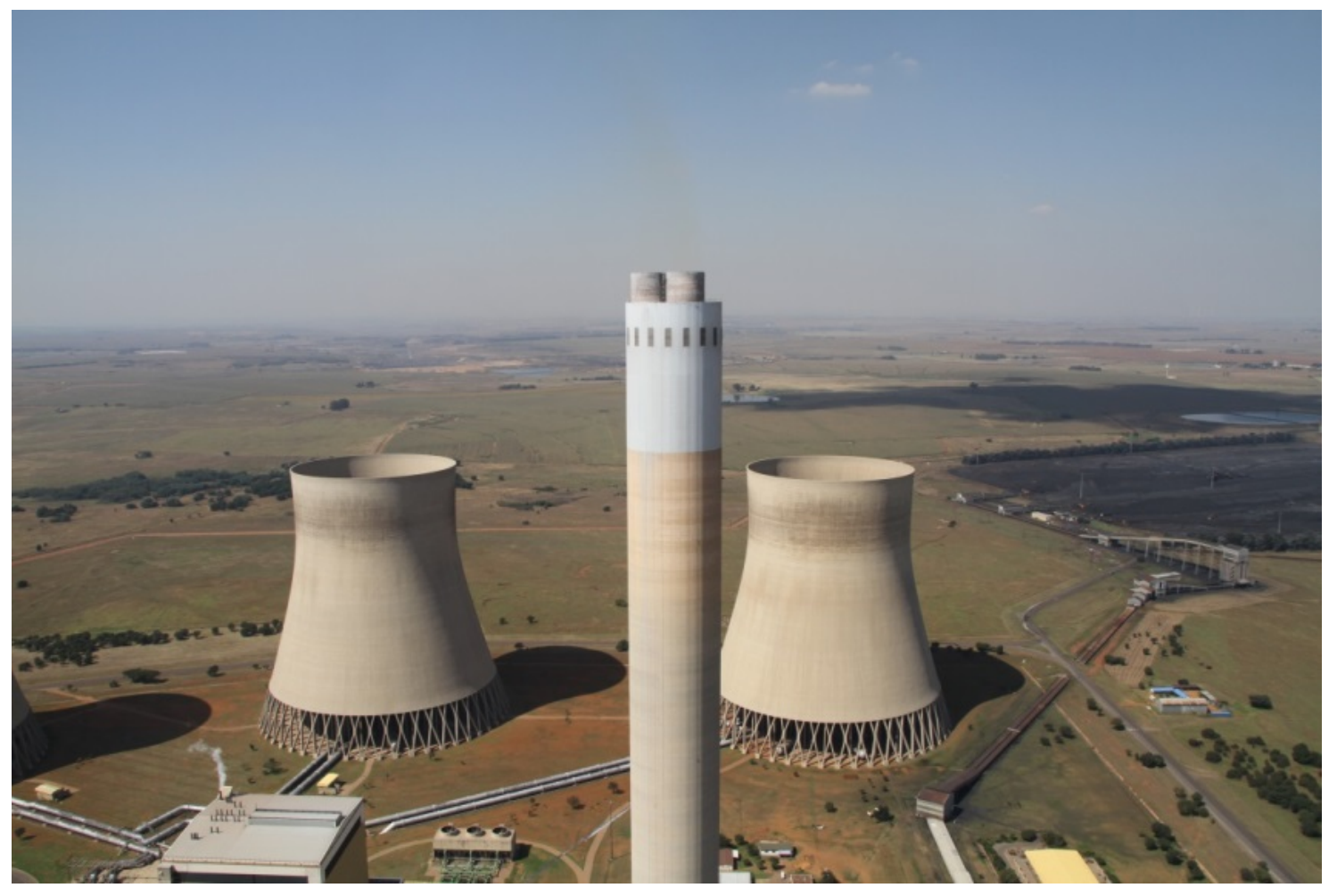

Open-File Report 2014-1153

Version 2.0, May 2016

U.S. Department of the Interior

U.S. Geological Survey 


\title{
U.S. Department of the Interior SALLY JEWELL, Secretary
}

\section{U.S. Geological Survey Suzette M. Kimball, Director}

\author{
U.S. Geological Survey, Reston, Virginia \\ First release: 2014 \\ Revised: May 2016 (ver. 2.0)
}

\begin{abstract}
For more information on the USGS-the Federal source for science about the Earth, its natural and living resources, natural hazards, and the environment-visit http://www.usgs.gov/ or call 1-888-ASK-USGS (1-888-275-8747).
\end{abstract}

For an overview of USGS information products, including maps, imagery, and publications, visit http://store.usgs.gov.

Any use of trade, firm, or product names is for descriptive purposes only and does not imply endorsement by the U.S. Government.

Although this information product, for the most part, is in the public domain, it also may contain copyrighted materials as noted in the text. Permission to reproduce copyrighted items must be secured from the copyright owner.

The material in this publication does not imply the expression of any opinion on the part of the United Nations Environment Programme (UNEP) or the U.S. Geological Survey (USGS) concerning the legal status of any country, territory, city, or area or of its authorities, or concerning delimitation of its frontiers or boundaries. Moreover, the views expressed do not necessarily represent the decision or policy of UNEP, nor does the use of trade names or commercial processes constitute endorsement.

Suggested citation:

Kolker, Allan, Senior, C.L., and van Alphen, Chris, 2014, Collaborative studies for mercury characterization in coal and coal combustion products, Republic of South Africa (ver. 2.0, May 2016): U.S. Geological Survey Open-File Report 2014-1153, 47 p., http://dx.doi.org/10.3133/ofr20141153.

UNEP citation:

United Nations Environment Programme (UNEP), 2014, Collaborative studies for mercury characterization in coal and coal combustion products, Republic of South Africa (version 2.0, May 2016): UNEP Chemicals Branch, Geneva, Switzerland.

ISSN 2331-1258 (online)

Cover photograph by Gunnar Futsaeter, UNEP 


\section{Preface}

This is a report sponsored by the Mercury Control from Coal Combustion Partnership Area of the United Nations Environment Programme (UNEP) Global Mercury Partnership, and can be found on the UNEP Chemicals Branch Web site at: http://www.unep.org/chemicalsandwaste/Mercury/InterimActivities/ Partnerships/Coalcombustion/tabid/3530/language/en-US/Default.aspx. Based on the agreement between the UNEP, Division of Technology, Industry and Economics, Chemicals Branch, and the U.S. Geological Survey (USGS), the USGS has undertaken the project entitled: "Collaborative studies for mercury characterization in coal and coal combustion products, Republic of South Africa." This project report was prepared by the USGS, Eastern Energy Resources Science Center, Reston, Virginia, U.S.A. The work was funded by the European Union, and USGS participation in the study was supported by the USGS Energy Resources Program.

This publication may be produced in whole or in part and in any form for educational or nonprofit purposes without special permission from the USGS or UNEP, provided acknowledgment of the source is made. Material in this report can be freely quoted or reprinted. UNEP and the USGS would appreciate receiving a copy of any publication that uses this report as a source.

No use of this publication may be made for resale or for any other commercial purpose whatsoever without prior permission in writing from the United Nations Environment Programme. 


\section{Preface to Revised Version, 2016}

Reanalysis of the suite of 42 samples of feed coal and 8 density separates discussed in the revised version of this report revealed significant changes to values for trace element determinations by inductively coupled plasma-mass spectrometry (ICP-MS) reported in table 6 of the original (2014) version of this report. Duplicate ICP-MS redeterminations by a commercial laboratory (Activation Laboratories, Ltd. [Actlabs], Ancaster, Ontario, Canada) and by USGS laboratories in Denver are in good agreement. Table 6 of this revised version has been updated to include these new results. In most cases, especially for transition metals, values reported here are lower than those originally reported, and in some cases, the corrected results are less than 50 percent of their original values. The extent to which trace element determinations differ from values originally reported varies by element, and for a given element, there is also considerable variation in the extent of the correction versus results originally reported. For consistency, Actlabs results compose the bulk of table 6, with the exception of USGS reanalysis determinations for chromium, arsenic, and antimony, which are prone to loss in the Activation Laboratories Ultratrace-4 sample digestion procedure used in these determinations. Actlabs and USGS reanalysis results are compared in appendix 1.

Note that results for mercury $(\mathrm{Hg})$ contained in the original report are unaffected by revisions to ICP-MS data included here, because $\mathrm{Hg}$ was determined by atomic absorption spectrophotometry and not by ICPMS. For ease of comparison with other results, $\mathrm{Hg}$ data are now reported on a whole-coal dry basis. Data for halogens (chlorine, fluorine) determined by ion-specific electrode were originally reported on a dry basis and are unchanged in the revision. This revised version also includes the following updates: (1) data for selenium, which were not available for inclusion in the original publication, are now provided in table 6; (2) results for ICP-MS trace element data reported here are expressed on a whole-coal dry basis because this facilitates comparison with published results for coals elsewhere; and (3) the text has been updated to take into account the U.S. Supreme Court decision of June 29, 2015, which puts on hold implementation of U.S. Environmental Protection Agency (EPA) Mercury and Air Toxics Standards (MATS) in the United States. 


\section{Acknowledgments}

This work was performed under an agreement between the United Nations Environment Programme (UNEP), Division of Technology, Industry and Economics, Chemicals Branch, in Geneva, Switzerland, and the U.S. Geological Survey (USGS) in Reston, Virginia, U.S.A. The project partners acknowledge Nick Geboy (Reston) and Alan Koenig and Jamie McCord (Denver) who contributed USGS analytical results. Peter Kariher (Arcadis, U.S.A.) and Jeff Ryan (U.S. Environmental Protection Agency) provided previously collected samples. We thank Gunnar Futsaeter for his assistance as Project Manager for UNEP. We also thank Kristy Langerman of Eskom for her interest and cooperation. 


\section{Contents}

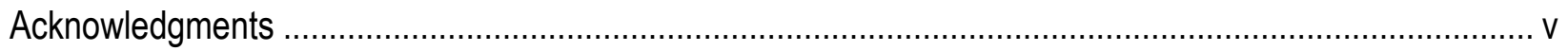

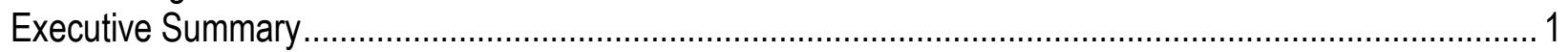

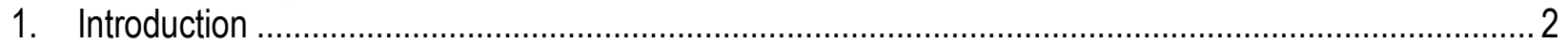

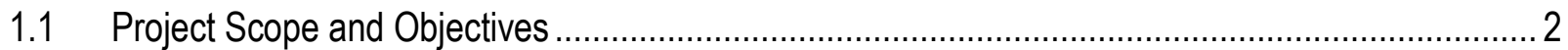

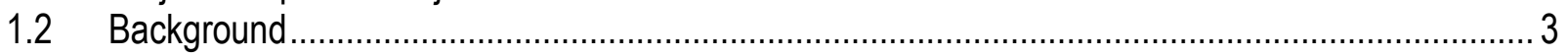

1.3 Technical Overview of Eskom Fleet................................................................................... 4

1.4 Feed Coals and Coal Consumption ………….....................................................................

1.5 Previous Work

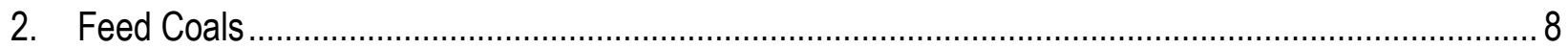

$2.1 \quad$ Feed Coal Characteristics................................................................................................. 8

2.2 Mercury in Eskom Feed Coals .........................................................................................

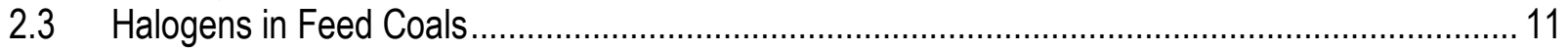

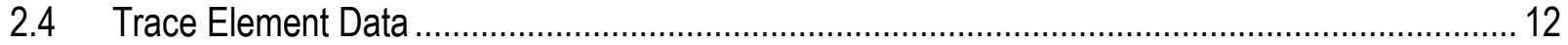

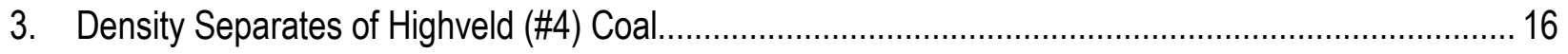

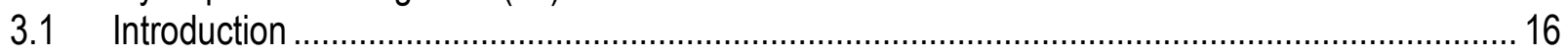

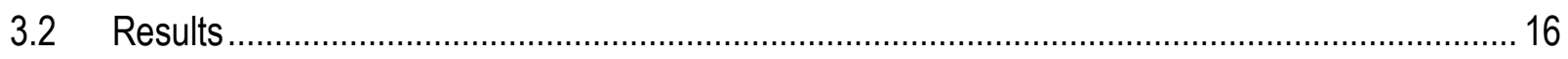

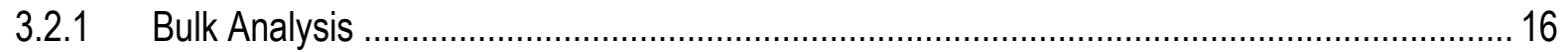

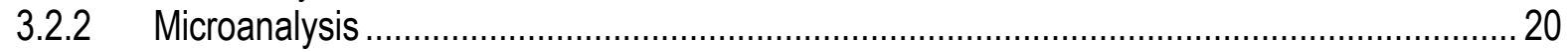

4. Supplemental Results for Duvha and Kendal Power Stations ........................................................... 24

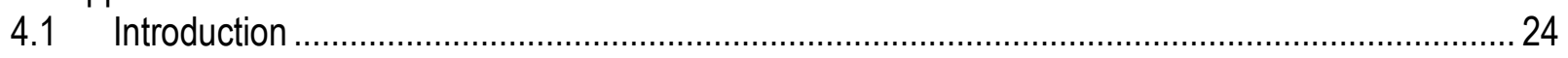

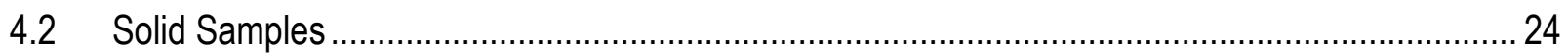

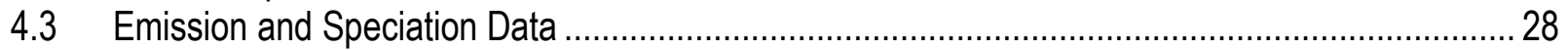

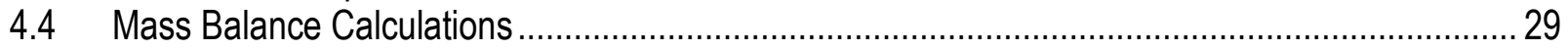

4.5 Comparison with Previous Results..................................................................................... 30

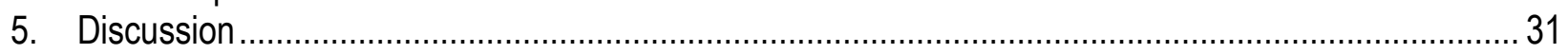

5.1 Potential for Mercury Capture in Coal-fired Power Plants with Conventional Controls..................31

5.2 Potential for Improving Mercury Capture of Eskom Fleet........................................................... 34

5.2.1 Coal Selection and Coal Washing.............................................................................. 34

5.2.2 Optimization of Equipment and Operational Parameters .................................................. 34

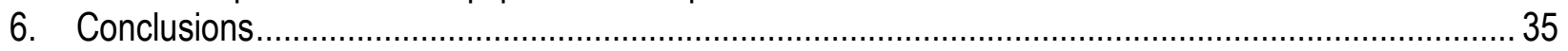

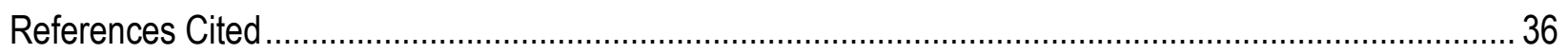

Appendix 1. Analytical Quality Assurance and Inter-laboratory Comparisons ...........................................39

\section{Figures}

1. Map showing Eskom power stations in South Africa …….......................................................... 4

2. Variation in mercury content of feed coals by power station number........................................ 10

3. Variation in American Society for Testing and Materials chlorine content in feed coals by power station number

4. Plot showing ranges for chromium, manganese, nickel, and arsenic in feed coals ..................... 12

5. Plots of ash yield versus pyritic sulfur and mercury for Highveld (\#4) density separates, showing concentration of pyrite and mercury in the high-density cuts.

6. Plot showing increase in mercury and arsenic in separates prepared at increasing separation densities, and corresponding increase in pyrite content 
7. Partitioning of elements chromium, manganese, cobalt, nickel, and molybdenum, indicating a mixed association for these elements.

8. Partitioning of chlorine and fluorine among Highveld \#4 density separates showing that halogens are preferentially concentrated in the low-density fractions indicating an organic affinity

9. U.S. Geological Survey laser ablation inductively coupled plasma-mass spectrometer instrument

10. Backscattered electron image of composite pyrite in density separate sample $14 \mathrm{~F} \ldots \ldots \ldots \ldots \ldots \ldots \ldots . . .22$

11. Laser ablation inductively coupled plasma-mass spectrometry spot analyses for mercury in pyrite from Highveld (\#4) coal density separates.

12. Mercury data for duplicate mill feed coal and fly ash samples collected from Duvha and Kendal power stations in previous United Nations Environment Programme-sponsored sampling ............ 26

13. Chlorine data by boiler for raw mill feed coal samples from Duvha and Kendal power stations collected in 2010 U.S. Environmental Protection Agency-South African Department of Environmental Affairs sampling and chlorine data for samples $6 \mathrm{~A}-\mathrm{D}$ and $3 \mathrm{~A}-\mathrm{C}$ from the group of 42 pulverized feed coal samples provided by Eskom in the present study

14. Estimated mercury removal across particulate control devices at Duvha power station..................29

15. Estimated mercury removal across particulate control devices at Kendal power station .................30

16. Fraction of oxidized mercury at the particulate control device outlet as a function of coal chlorine content: comparison of data from Duvha and Kendal power stations with EPA 1999 Information Collection Request data.

17. Removal of mercury across the particulate control device outlet as a function of coal chlorine content: comparison of data from Duvha and Kendal power stations with EPA 1999 Information

Collection Request data.

18. Effect of sulfuric acid vapor addition on performance of brominated activated carbon for mercury removal across electrostatic precipitator.

A1. Plots showing correspondence between mercury values as determined in USGS Reston and Denver mercury analyzers.

A2. Plot of ash yield determinations ......................................................................................... 45

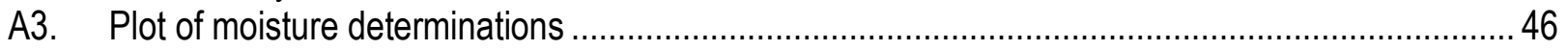

\section{Tables}

1. Description of Eskom coal-fired power plants ........................................................................

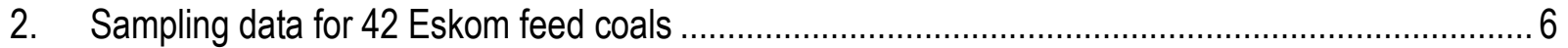

3. Coal washing and coal consumption data for Eskom power stations .........................................

4. Characteristics of 42 Eskom feed coal samples ................................................................... 9

5. Mercury in 42 Eskom feed coal samples (this study) and previous results for feed coals in

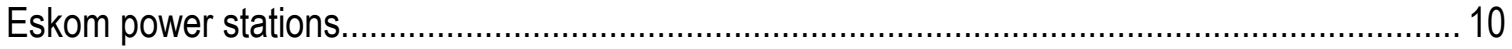

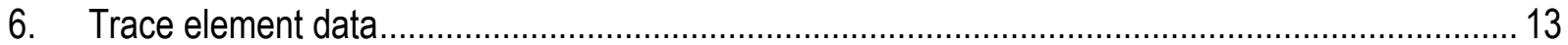

7. Ash yield and mercury contents of coal products predicted from Highveld (\#4) density separates, expressed on a dry basis

8. Laser ablation inductively coupled plasma-mass spectrometer analysis data showing detection limits; calculated mean values for arsenic, molybdenum, mercury, thallium, and lead; and element enrichment factors in pyrite relative to calculated whole coal.. 
9. Mercury analysis, 2010 samples, Duvha and Kendal power stations, analyzed in USGS Reston laboratories.

10. Mercury stack concentrations and speciation, Durha and Kendal power stations ...........................2 28

A1. Replicate mercury analysis, USGS Reston laboratory......................................................... 40

A2. U.S. National Institute of Standards and Technology standard mercury analysis, USGS Reston laboratory

A3. Replicate mercury analyses for density separates, and three feed coal samples showing poor initial correspondence between USGS Reston and Denver laboratories

A4. Comparison of mercury data for $\mathbf{2 0 1 0}$ mill feed coal samples; Kendal and Duvha power stations versus previously unpublished determinations on the same splits .....

A5. Linear regression results comparing values obtained by USGS contract laboratory Actlabs and USGS Denver laboratories in 2015 ICP-MS reruns of Eskom feed coals and density separates described in this report. 


\section{Abbreviations, Chemical Terms, and Definitions}

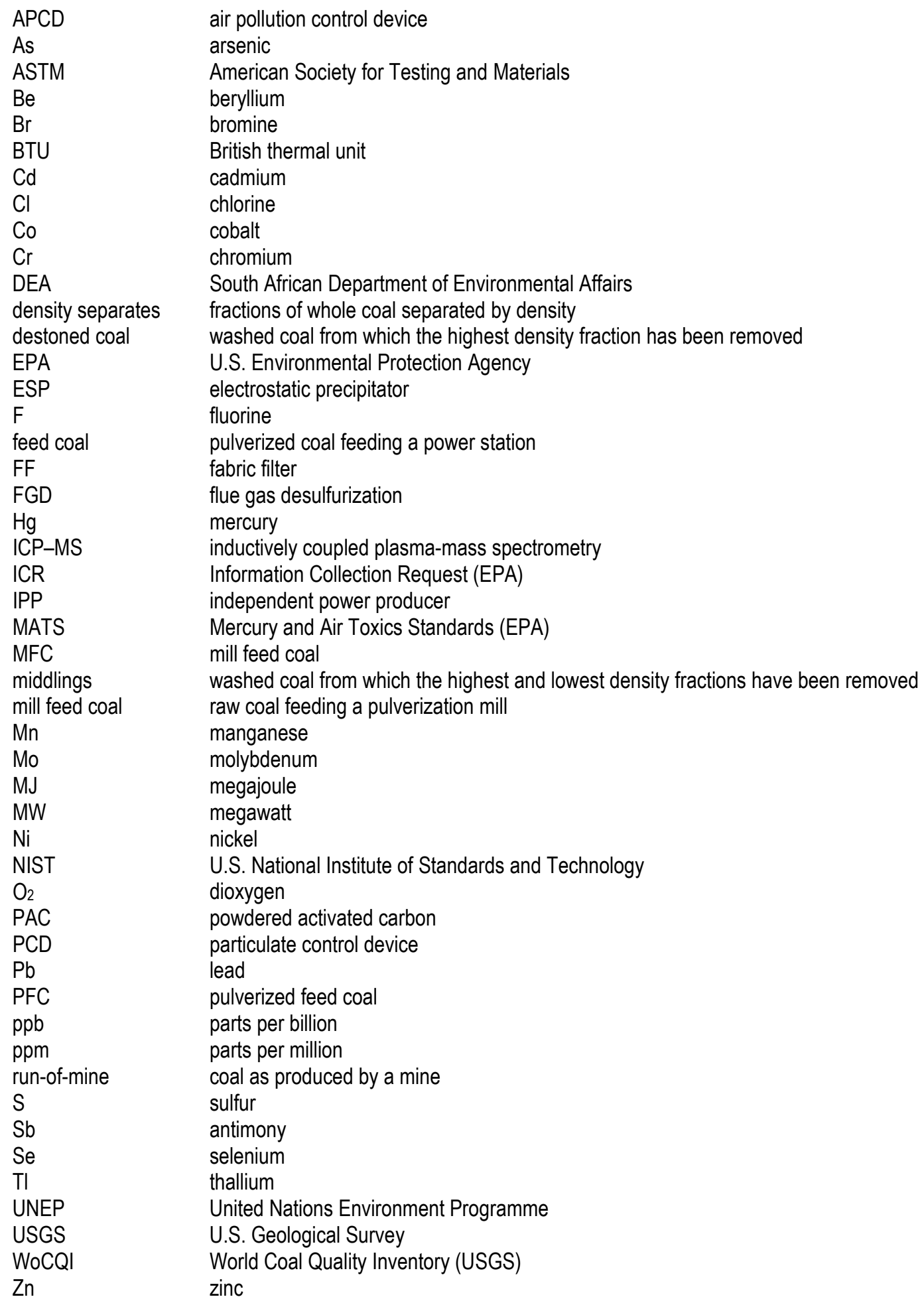




\title{
Collaborative Studies for Mercury Characterization in Coal and Coal Combustion Products, Republic of South Africa
}

\author{
By Allan Kolker, ${ }^{1}$ Constance L. Senior, ${ }^{2}$ and Chris van Alphen ${ }^{3}$
}

\section{Executive Summary}

Mercury $(\mathrm{Hg})$ analyses were obtained in USGS laboratories for 42 new samples of feed coal provided by Eskom, representing all 13 coal-fired power stations operated by Eskom in South Africa. This sampling includes results for three older power stations - Camden, Grootvlei, and Komati-returned to service starting in the late 2000s. Mercury concentrations determined in the present study are similar to or slightly lower than those previously reported, and input $\mathrm{Hg}$ for the three stations returned to service is comparable to that for the other 10 power stations. Results for the Matimba power station burning Waterberg coals show that coal washing currently in use is effective in reducing $\mathrm{Hg}$ levels to the range of the other Eskom power stations. This finding is promising for the future Medupi power station that will also use Waterberg coals and require a similar coal-washing approach. Determination of halogen contents of the 42 feed coals by a contract laboratory confirms that chlorine contents are generally low, and as such, the extent of $\mathrm{Hg}$ self-capture by particulate control devices (PCDs) is rather limited.

Eight density separates of a South African Highveld (\#4) coal were also provided by Eskom for analysis. These samples show a strong mineralogical association of $\mathrm{Hg}$ (and arsenic) with pyrite. For this coal, reduction of pyrite by coal washing is very likely to result in reduced $\mathrm{Hg}$ contents, as well as lowering sulfur emissions. The density separates were used to predict $\mathrm{Hg}$ contents of coal products used in South Africa or exported. These contents range from less than 100 parts per billion (ppb; 0.10 parts per million [ppm]) for washed export coals having ash contents less than 16 percent, to more than $400 \mathrm{ppb}(0.40[\mathrm{ppm}]$ for ash-rich (stone) material that is often discarded. Intermediate $\mathrm{Hg}$ contents are calculated from the density separates for predicted coal products used for power generation in South Africa, such as destoned coal (240 ppb; $0.24 \mathrm{ppm}$ ), middlings ( $270 \mathrm{ppb} ; 0.27 \mathrm{ppm}$ ), and run-of-mine coal (300 ppb; $0.30 \mathrm{ppm}$ ).

A suite of 48 paired samples of pulverization mill feed coal and fly ash collected in a previous (2010) United Nations Environment Programme-sponsored study of emissions from the Duvha and Kendal power stations was obtained for further investigation in the present study. These samples show that in each station, $\mathrm{Hg}$ capture varies somewhat by boiler unit. These results also confirm that units equipped with fabric filters for air pollution control are much more effective in capturing $\mathrm{Hg}$ than those equipped with electrostatic precipitators. In each station, $\mathrm{Hg}$ capture is affected by differences in operating conditions of the boiler and air pollution control devices (APCDs). This variation should be considered in determining emission factors used to

\footnotetext{
${ }^{1}$ U.S. Geological Survey.

${ }^{2}$ ADA Environmental Solutions, Inc., Highlands Ranch, Colorado, U.S.A.

${ }^{3}$ Eskom Holdings, Ltd., Johannesburg, South Africa.
} 
estimate $\mathrm{Hg}$ emissions. Paired sampling of feed coal and fly ash could be used by Eskom to track the performance of its APCDs in removing Hg. Analysis of these samples to assess Hg capture on a unit-by-unit basis would provide a much better estimate of the $\mathrm{Hg}$ emission rate from the plant than simply assigning a fixed emission factor based on the type of PCD, as has been done in previous estimates. Apart from tracking APCD performance individually, changes resulting in improved mercury capture of the Eskom fleet are discussed. These include $\mathrm{Hg}$ reduction through coal selection and washing, as well as through optimization of equipment and operational parameters. Density separates for a Highveld \#4 coal indicate that coal washing is effective in reducing the concentrations of pyrite-associated elements such as $\mathrm{Hg}$. Mercury reduction to the boiler can be achieved by discarding the stone fraction, as is already practiced by Eskom, and by retaining as much of the low-ash export fraction as is practical. A series of plant operational changes leading to increased mercury capture is also presented. For a given mercury input to the boiler, increasing mercury adsorption on unburned carbon is perhaps the simplest operational way to improve mercury capture. This can be accomplished by lowering the air preheater exit temperature, increasing the amount of unburned carbon in the ash, and minimizing the concentration of sulfuric acid vapor in the flue gas. The first two changes have competing influences on boiler efficiency, which may offset one another while increasing $\mathrm{Hg}$ capture. Equipment options for improving $\mathrm{Hg}$ capture include addition of fabric filters, use of halogenated sorbents, and addition of flue gas desulfurization (FGD) scrubbers, listed in order of increasing cost. The capital cost of adding FGD scrubbers to existing plants is probably too high to be justified on the grounds of $\mathrm{Hg}$ removal alone. However, if future regulations require reductions in sulfur dioxide emissions, and FGDs are installed to meet these standards, further reduction in $\mathrm{Hg}$ emissions will be a co-benefit of this installation.

\section{Introduction}

\subsection{Project Scope and Objectives}

Using samples of boiler feed coal and coal preparation fractions provided by Eskom, this study considers mercury $(\mathrm{Hg})$ input to the boiler for Eskom's fleet of 13 utility coal-fired generating stations, and the potential for $\mathrm{Hg}$ emissions reduction by optimizing $\mathrm{Hg}$ capture using conventional air pollution control devices (APCDs), or by coal washing. In addition, samples of pulverization mill feed coal (MFC) and fly ash from Eskom's Kendal and Duvha power stations, collected in 2010 in sampling by the U.S. Environmental Protection Agency (EPA), were obtained for further analysis in the present study. A total of 98 samples were investigated. These include: (1) 42 new samples of pulverized feed coal (PFC) from 13 Eskom coal-fired power stations, including 3 retired stations returned to service starting in the late 2000 s that were not available for sampling in the most recent previous studies (fig. 1). The group of 42 feed coal samples also includes yearly composites for 7 stations, the most recent such data available; (2) 8 density separates of Highveld \#4 coal, one of the most important coals used for power generation in South Africa; and (3) 24 samples of raw pulverization MFC and 24 samples of fly ash, collected in the 2010 study at Kendal and Duvha power stations.

This study does not consider coal-fired power generation for industrial purposes, of which Sasol is the largest contributor, and several small independent power producers (IPPs). Combined power generation by Sasol and the IPPs is a small fraction of Eskom's combined installed capacity; however, large amounts of coal are used by Sasol as feedstock for conversion to liquid fuels. Measurements of stack $\mathrm{Hg}$ emissions are beyond the scope and resources of the 
present study; however, these measurements were obtained in the 2010 study at Kendal and Duvha power stations from which concurrent samples of coal and coal ash were obtained that were investigated here.

More specific information on $\mathrm{Hg}$ in South African feed coal is a key factor in improving $\mathrm{Hg}$ emissions estimates for the South African utility sector (Dabrowski and others, 2008; Leaner and others, 2009; Masekoameng and others, 2010). The present study provides an overview of $\mathrm{Hg}$ input from coal and a starting point for more detailed sampling, such as that by the EPA in support of its Mercury and Air Toxics Standards (MATS) (EPA, 2011). Additional information providing context for the study is given in the remainder of this section. The sections that follow include results for Eskom feed coals (Section 2); density separates of a Highveld (\#4) coal (Section 3); supplemental results for the Kendal and Duvha power stations (Section 4); discussion (Section 5); and conclusions (Section 6).

\subsection{Background}

Mercury is a known neurotoxin with demonstrated adverse human health impacts. Coal combustion is the largest industrial contributor to global $\mathrm{Hg}$ emissions (Pacyna and Pacyna, 2001, AMAP/UNEP, 2013). To address this issue, the United Nations Environment Programme (UNEP) funded the U.S. Geological Survey (USGS) under a UNEP small-scale funding agreement to partner with Eskom, the national electric utility of South Africa. The purpose of the agreement is to characterize the distribution of $\mathrm{Hg}$ in coals used for electric power generation in South Africa, and to provide technical information needed for $\mathrm{Hg}$ emissions reduction in the South African utility sector using available APCDs and (or) coal washing methods, as $\mathrm{Hg}$ specific controls are not contemplated. South Africa is of particular interest because of its status as one of the world's largest coal producers and its reliance on coal (in 2012) for more than 90 percent of its electric power generation (World Coal Association, 2014). Past sampling of South African coals for $\mathrm{Hg}$ analysis is relatively limited, and much of the available results reflect runof-mine samples or coal prepared for export. 


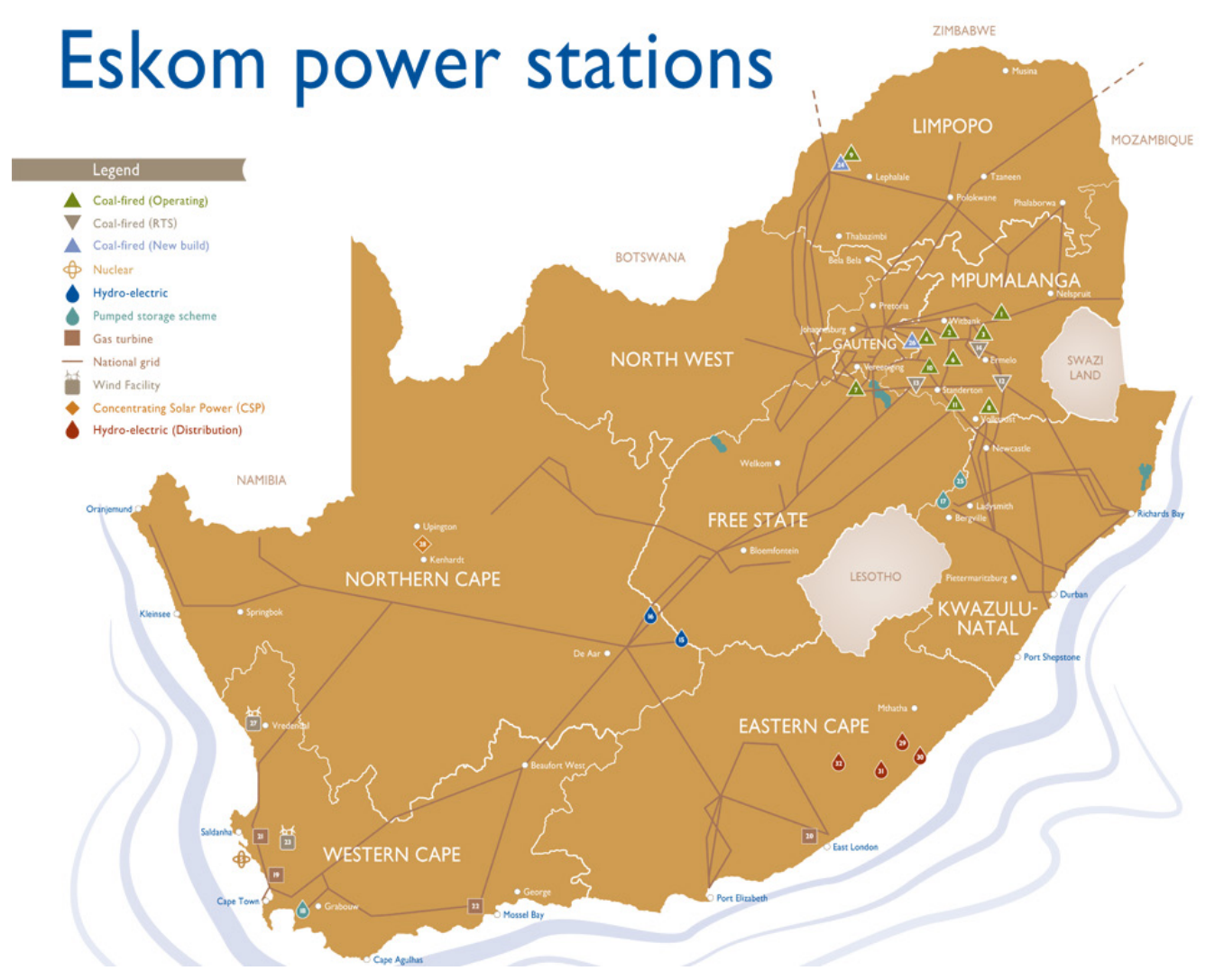

Figure 1. Map showing Eskom power stations in South Africa. Coal-fired stations (green triangles) are concentrated in west-central Mpumalanga Province. Coal-fired stations returned to service (Camden, Grootvlei, Komati) are shown as gray inverted triangles, and future stations (Medupi, Limpopo Province, and Kusile, Mpumalanga Province) are shown as blue triangles. Source: Eskom, www.eskom.co.za.

\subsection{Technical Overview of Eskom Fleet}

Eskom currently operates 87 coal-fired boilers at 13 plants (table 1). Two plants, Medupi and Kusile (a total of 12 boilers), are under construction. None of the operating boilers have flue gas desulfurization (FGD) technology. All boilers have pollution control devices (PCDs), either a fabric filter (FF) or a cold-side electrostatic precipitator (ESP). Some of the plants that have ESPs use flue gas conditioning to reduce the resistivity of the fly ash and make it easier to collect. This conditioning of the fly ash is accomplished by injecting sulfuric acid (sulfuric acid vapor $\left[\mathrm{SO}_{3}\right]$ or sulfuric acid $\left[\mathrm{H}_{2} \mathrm{SO}_{4}\right]$ ) into the flue gas upstream of the ESP. Some of the coal that Eskom fires in the boilers of its power plants is washed (following section). Coal washing removes some of the minerals (ash) in the coal; in addition to reducing the ash content, coal washing has the potential to reduce both the sulfur (S) content and the Hg content, in the case where there is a significant amount of pyrite in the coal and that pyrite contains $\mathrm{Hg}$. 
Table 1. Description of Eskom coal-fired power plants.

[MW, megawatts; PCD, particulate control device; FF, fabric filter; $\mathrm{FGC}$, flue gas conditioning; $\mathrm{SO}_{3}$, sulfuric acid vapor; $\mathrm{SO}_{2}$, sulfur dioxide; ESP, electrostatic precipitator; --, not available; FGD, flue gas desulfurization]

\begin{tabular}{|c|c|c|c|c|c|c|c|c|}
\hline Station & $\begin{array}{c}\text { Plant } \\
\text { capacity } \\
\text { (MW) }\end{array}$ & $\begin{array}{c}\text { No. } \\
\text { boilers }\end{array}$ & $\begin{array}{l}\text { Commission } \\
\text { date }\end{array}$ & Status & $\begin{array}{c}\text { Coal } \\
\text { washing }\end{array}$ & Type of PCD & $\begin{array}{c}\text { FGC with } \\
\mathrm{SO}_{3}\end{array}$ & $\begin{array}{c}\text { Type of } \mathrm{SO}_{2} \\
\text { control }\end{array}$ \\
\hline Arnot & 2,352 & 6 & 1975 & Operating & Partial & $\mathrm{FF}$ & None & None \\
\hline Duvha & 3,600 & 6 & 1980 & Operating & Partial & $\begin{array}{l}\text { ESP } \times 3 \\
\text { FF } \times 3\end{array}$ & Yes & None \\
\hline Hendrina & 2,000 & 10 & 1970 & Operating & Partial & $\mathrm{FF}$ & None & None \\
\hline Kendal & 4,116 & 6 & 1988 & Operating & None & ESP & Yes & None \\
\hline Kriel & 3,000 & 6 & 1979 & Operating & None & ESP & Yes & None \\
\hline Lethabo & 3,708 & 6 & 1985 & Operating & Partial & ESP & Yes & None \\
\hline Majuba & 4,110 & 6 & 1996 & Operating & None & FF & None & None \\
\hline Matimba & 3,990 & 6 & 1988-1993 & Operating & Yes & ESP & Yes & None \\
\hline Matla & 3,600 & 6 & 1983 & Operating & None & ESP & Yes & None \\
\hline Tutuka & 3,654 & 6 & 1985 & Operating & None & ESP & None & None \\
\hline Camden & 1,510 & 8 & 1967 & $\begin{array}{l}\text { Returned to } \\
\text { service }\end{array}$ & None & $\mathrm{FF}$ & None & None \\
\hline Grootvlei & 1,200 & 6 & 1969 & $\begin{array}{l}\text { Returned to } \\
\text { service }\end{array}$ & None & $\begin{array}{l}\text { ESP x } 3 \\
\text { FF x } 3\end{array}$ & None & None \\
\hline Komati & 940 & 9 & 1961 & $\begin{array}{l}\text { Returned to } \\
\text { service }\end{array}$ & None & ESP & Yes & None \\
\hline Medupi & 4,788 & 6 & Future & Construction & -- & $\mathrm{FF}$ & None & $\begin{array}{l}\text { FGD } \\
\text { (technology not } \\
\text { final) }\end{array}$ \\
\hline Kusile & 4,800 & 6 & Future & Construction & -- & $\mathrm{FF}$ & None & $\begin{array}{l}\text { FGD } \\
\text { (technology not } \\
\text { final) }\end{array}$ \\
\hline
\end{tabular}

\subsection{Feed Coals and Coal Consumption}

A suite of 42 samples of pulverized feed coals provided by Eskom includes from 2 to 4 samples from each of the 13 coal-fired electric utility power stations operated by Eskom in South Africa (table 1). This unique sample set would be unobtainable without Eskom's cooperation. The sampling provides an overview of $\mathrm{Hg}$ input to the entire Eskom fleet at selected monthly time points from 2009 to 2012, including nine yearly composites from seven power stations (table 2).

Feed coals utilized by Eskom include washed, partly washed, and unwashed (run-ofmine) coals (table 3). Low-ash, washed fractions of South African coals are primarily produced for export, with the exception of Waterberg coals used in the Matimba power station. Partly washed feed coals utilized by Eskom include all the remaining fractions, the middlings (fractions remaining after export and discard fractions are removed), or a destoned product where only the discard fraction is removed (section 3). 
Table 2. Sampling data for 42 Eskom feed coals. Monthly samples are indicated by month of sampling. Yearly composites are shown in boldface for years indicated. Numbering of feed coal samples corresponds to stations in the order listed and samples A, B, C, or D for each station.

\begin{tabular}{llcllll}
\hline $\begin{array}{c}\text { Station } \\
\text { number }\end{array}$ & \multicolumn{1}{c}{ Station } & $\begin{array}{c}\text { No. of } \\
\text { samples }\end{array}$ & \multicolumn{1}{c}{ A } & \multicolumn{1}{c}{ B } & \multicolumn{1}{c}{ C } & \multicolumn{1}{c}{ D } \\
\hline 1 & Arnot & 2 & June 2009 & June 2012 & & \\
2 & Camden & 4 & Feb. 2009 & April 2010 & Jan. 2011 & $\mathbf{2 0 1 2}$ \\
3 & Duvha & 3 & Dec. 2010 & $\mathbf{2 0 1 2}$ & July 2012 & \\
4 & Grootvlei & 4 & Dec. 2009 & Jan. 2011 & $\mathbf{2 0 1 2}$ & June 2012 \\
5 & Hendrina & 3 & $\mathbf{2 0 1 0}$ & $\mathbf{2 0 1 1}$ & $\mathbf{2 0 1 2}$ & \\
6 & Kendal & 4 & April 2009 & Aug. 2010 & Jan. 2011 & Jan. 2012 \\
7 & Kriel & 3 & March 2009 & Feb. 2009 & April 2011 & \\
8 & Komati & 3 & April 2009 & May 2009 & June 2009 & \\
9 & Lethabo & 3 & Jan. 2009 & Jan. 2011 & $\mathbf{2 0 1 2}$ & \\
10 & Majuba & 4 & Jan. 2009 & Nov. 2010 & March 2011 & $\mathbf{2 0 1 2}$ \\
11 & Matimba & 3 & April 2010 & Nov. 2010 & Feb. 2011 & \\
12 & Matla & 3 & Nov. 2010 & May 2011 & $\mathbf{2 0 1 2}$ & \\
13 & Tutuka & 3 & Jan. 2009 & Dec. 2010 & May 2011 & \\
\hline
\end{tabular}

Coal production in South Africa has traditionally been concentrated in the Highveld region of Mpumalanga Province where the Witbank, Highveld, and Ermelo coals are worked (Pretorius and others, 2002; Peatfield, 2003; Jeffrey, 2005). This production includes minemouth supply of Eskom power stations as well as feedstock for Sasol's coal-to-liquids operations. Reserves of the Witbank and Highveld coals, together with those of the Waterberg coals in Limpopo Province, constitute approximately 70 percent of South Africa's recoverable coal reserves (Jeffrey, 2005). The Witbank and Highveld coals are laterally contiguous; the same coal beds are present in each coal, but their characteristics may differ. Historically, the Witbank \#2 coal has been an important source of low-ash, washed export coal. The Witbank and Highveld \#4 coals are generally of lower quality but are economically important for domestic power generation, and increasingly, as feedstock for washed export product (Bergh and others, 2011). The Witbank \#3 coal is of good quality but relatively thin, and therefore not as economically important as the \#4 coal, whereas the Highveld \#3 is thin, discontinuous, and of poor quality. The \#5 coal is relatively thin, but can be of good quality and has been used as a source of metallurgical coal (Jeffrey, 2005). 
Table 3. Coal washing and coal consumption data for Eskom power stations. Numbering of feed coal samples corresponds to power stations in the order listed.

\begin{tabular}{llcl}
\hline $\begin{array}{c}\text { Station } \\
\text { number }\end{array}$ & \multicolumn{1}{c}{ Station } & $\begin{array}{c}\text { Consumption } \\
\text { (million tons/yr) }\end{array}$ & \multicolumn{1}{c}{ Coal preparation } \\
\hline 1 & Arnot & 6.8 & A partly washed product is fired. \\
2 & Camden & 4.7 & No washing; some sources could be washed. ${ }^{1}$ \\
3 & Duvha & 11.7 & A partly washed product is fired. \\
4 & Grootvlei & 1.6 & No washing; some sources could be washed. ${ }^{1}$ \\
5 & Hendrina & 6.9 & A partly washed product is fired. \\
6 & Kendal & 13.9 & No washing; run-of-mine coal is fired. \\
7 & Kriel & 8.5 & No washing; run-of-mine coal is fired. \\
8 & Komati & 0.7 & No washing; some sources could be washed. ${ }^{1}$ \\
9 & Lethabo & 18.2 & A partly washed product is fired. \\
10 & Majuba & 12.3 & No washing; some sources could be washed. ${ }^{1}$ \\
11 & Matimba & 14.6 & Fully washed; cleanest fractions are fired. \\
12 & Matla & 12.4 & No washing; run-of-mine coal is fired. \\
13 & Tutuka & 10.6 & No washing; some sources could be washed. ${ }^{1}$ \\
\hline
\end{tabular}

${ }^{1}$ Run-of-mine is primarily used, but washed coal is available from various market sources.

Reserves of Witbank coals are declining, providing motivation to investigate use of other coals for power generation and to better understand element partitioning during coal washing. Density separation of a Highveld \#4 coal was tested by Eskom to predict coal quality variation during coal washing, and in the present study, the impact of coal washing on trace element distribution (section 3).

For Waterberg coals, interest has increased in recent years due to the large reserves, and construction underway in Limpopo Province of the 4,764-megawatt (MW) Medupi power station, one of two new power stations being added by Eskom. When completed, the Medupi power station will burn Waterberg coal, as is currently burned by the Matimba power station nearby. Coal washing is needed for Waterberg coals because of finely laminated mudstone present within them (Jeffrey, 2005; Wagner and Tlotleng, 2012). The second new coal-fired power station, the 4,800-MW Kusile station under construction in Mpumalanga Province, will presumably utilize Witbank/Highveld coals. Each of the two new Eskom coal-fired power stations will be among the largest in the world, exceeding the generating capacity of any of the existing power stations (table 1).

\subsection{Previous Work}

The present activity follows from a 2010 investigation conducted under a UNEPsponsored consortium, including Eskom, the South African Department of Environmental Affairs, and the EPA. In the 2010 study, two of Eskom's coal-fired generating stations, Kendal and Duvha, were sampled in detail (Scott, 2011). In this previous study, stack mercury (Hg) speciation measurements were obtained by EPA Method 30B using carbon sorbent traps (EPA, 2008). Reporting for this study emphasized these emissions measurements (Scott, 2011). Pulverization mill feed coal (MFC) and fly ash were also collected in the 2010 study. A portion of these solid samples were analyzed for $\mathrm{Hg}$ using a Lumex instrument upon their return to EPA laboratories, but these results were never published. This archival sample material was obtained from EPA collaborators for further investigation in the present study. 
Average $\mathrm{Hg}$ data for previous (2001) sampling of feed coals from South African power stations are available in Eskom internal reporting (Gericke and others, 2007), providing context for comparing the present results. Subsequent coal sampling (in 2004-2005) was used by Roos (2011) to calculate $\mathrm{Hg}$ emissions for each of the Eskom power stations, assuming published emission factors; unfortunately, however, $\mathrm{Hg}$ data for input coal were not provided with this study. Uncertainties in the values used for the efficiency of the power plants and the heating value of the feed coal made it impossible for us to accurately determine input $\mathrm{Hg}$ by backcalculating from emissions projections given by Roos (2011).

Additional data on $\mathrm{Hg}$ in South African coal are available for run-of-mine coal samples or specific coal products. A suite of 40 South African coal samples representing coal products, including raw, sized, and washed coals (Pretorius and others, 2002), was obtained by the USGS in the early 2000s for the World Coal Quality Inventory (WoCQI; Tewalt and others, 2010). The WoCQI samples include some washed export coals with very low $\mathrm{Hg}$ contents. As might be expected, the WoCQI sample set shows a much wider distribution of $\mathrm{Hg}$ values $(<0.03$ to 0.83 parts per million (ppm; $<30$ to 830 parts per billion [ppb]) than power station feed coals determined in the present study. Other recent results for $\mathrm{Hg}$ in South African coal have been presented in the context of $\mathrm{Hg}$ as one of a number of potentially hazardous elements in coal. Wagner and Hlatshwayo (2005) studied five run-of-mine samples and a middlings split of Highveld \#4 (lower) coal, one of the main producing beds. A mean $\mathrm{Hg}$ value of $0.15 \pm 0.05 \mathrm{ppm}$ $(150 \pm 50 \mathrm{ppb})$ is given for the five run-of-mine samples, within error of USGS-determined $\mathrm{Hg}$ values for the same sample splits (mean of $0.20 \mathrm{ppm} \mathrm{Hg}$ [200 ppb]). For a \#4 Witbank coal with $0.3 \mathrm{ppm}(300 \mathrm{ppb}) \mathrm{Hg}$, Bergh and others (2011) compare froth flotation and density separation approaches to trace element reduction, concluding that the density separation approach is more effective for pyrite-associated elements such as $\mathrm{Hg}$.

For Waterberg coals, expanded use expected in the future will require coal washing. Consequently, there has been interest in the partitioning of trace elements during washing tests. Wagner and Tlotleng (2012) investigated element partitioning in four run-of-mine samples and corresponding density splits of Waterberg coals. These include three samples (benches 3, 4, and 5) from the Grootegeluk Formation and one sample (bench 11) from the underlying Vryheid Formation. All of the run-of-mine coals have high $\mathrm{Hg}$ contents (0.9 to $2.43 \mathrm{ppm}$ [900 to 2,430 ppb]) with the greatest $\mathrm{Hg}$ enrichment in the Vryheid-bench 11 sample. Density splits for the Grootegeluk samples show especially good correlations between $\mathrm{Hg}$ (and arsenic [As]) and pyritic sulfur, but this association is less clear for the Vryheid sample. The results indicate that coal washing is promising for $\mathrm{Hg}$ reduction of Waterberg coals, particularly those in the Grootegeluk Formation, pending commercial-scale trials.

\section{Feed Coals}

\subsection{Feed Coal Characteristics}

Compared to Carboniferous coals of the northern hemisphere, South African coals and Permian coals, in general, have relatively high ash yields and low $\mathrm{S}$ and halogen contents (Falcon, 1986; Synman and Botha, 1993; Wagner and Hlatshwayo, 2005). Characteristics of Eskom feed coals are shown in table 4, with results shown as ranges for each set of power station samples. With the exception of the Lethabo power station, which shows a large range in ash contents and corresponding heating values, each station shows relatively narrow ranges in coal quality parameters. Ash yields in the 30-percent range are typical. Sulfur and pyritic S contents 
are relatively low. Moisture contents are less than 5 percent in all but one sample (5.1 percent in sample 9, from a Lethabo power station). Results for moisture and ash yield provided by Eskom compared with those obtained in the present study show good or acceptable agreement and no systematic differences (appendix 1).

Table 4. Characteristics of 42 Eskom feed coal samples (on an as-determined basis). ${ }^{1}$

[\%, percent; wt. \%, weight percent; BTU/lb, British thermal units per pound]

\begin{tabular}{llccccc}
\hline $\begin{array}{c}\text { Station } \\
\text { number }\end{array}$ & $\begin{array}{c}\text { Station } \\
\text { (No. of samples) }\end{array}$ & $\begin{array}{c}\text { Moisture } \\
\text { [wt. \%] }\end{array}$ & $\begin{array}{c}\text { Ash } \\
\text { [wt. \%] }\end{array}$ & $\begin{array}{c}\text { Sulfur } \\
\text { [wt. \%] }\end{array}$ & $\begin{array}{c}\text { Pyritic sulfur } \\
\text { [wt. \%] }\end{array}$ & $\begin{array}{c}\text { Calorific value }^{2} \\
\text { [BTU/lb] }\end{array}$ \\
\hline 1 & Arnot (2) & $3.8-3.9$ & $24.5-26.6$ & $0.66-0.75$ & $0.30-0.36$ & $9,233-9,396$ \\
2 & Camden (4) & $3.1-3.7$ & $27.6-32.4$ & $0.79-1.18$ & $0.34-0.63$ & $8,516-9,067$ \\
3 & Duvha (3) & $2.1-2.3$ & $29.4-30.5$ & $0.84-0.98$ & $0.40-0.48$ & $9,074-9,402$ \\
4 & Grootvlei (4) & $3.5-3.9$ & $29.4-31.1$ & $1.06-1.23$ & $0.40-0.55$ & $8,284-8,675$ \\
5 & Hendrina (3) & $3.0-3.2$ & $27.1-27.7$ & $1.21-1.27$ & $0.73-0.81$ & $9,312-9,448$ \\
6 & Kendal (4) & $3.0-3.5$ & $31.9-33.8$ & $0.76-0.80$ & $0.36-0.45$ & $7,982-8,402$ \\
7 & Kriel (3) & $3.8-4.2$ & $21.7-24.8$ & $0.66-0.73$ & $0.22-0.27$ & $9,119-9,637$ \\
8 & Komati (3) & $3.9-4.1$ & $29.2-32.3$ & $0.80-1.01$ & $0.46-0.53$ & $8,161-8,653$ \\
9 & Lethabo (3) & $2.9-5.1$ & $39.3-40.9^{3}$ & $0.68-0.84$ & $0.36-0.48$ & $6,579-9,591$ \\
10 & Majuba (4) & $3.3-3.6$ & $27.7-28.5$ & $0.81-1.01$ & $0.38-0.56$ & $8,925-9,039$ \\
11 & Matimba (3) & $2.0-2.4$ & $33.9-34.4$ & $1.21-1.25$ & $0.59-0.66$ & $8,414-8,606$ \\
12 & Matla (3) & $2.2-4.4$ & $25.3-33.3$ & $0.84-1.36$ & $0.43-0.75$ & $8,561-9,113$ \\
13 & Tutuka (3) & $3.6-3.9$ & $28.6-30.2$ & $0.72-1.14$ & $0.53-0.76$ & $8,864-8,905$ \\
\hline
\end{tabular}

${ }^{1}$ Values obtained by USGS contract laboratory. See appendix 1 for comparison with Eskom data.

${ }^{2}$ To convert to megajoule per kilogram, multiply by 0.0023259 .

${ }^{3}$ Eskom ash value used for sample 9C (appendix 1).

\subsection{Mercury in Eskom Feed Coals}

Results for $\mathrm{Hg}$ in the 42 samples of Eskom feed coal in the present study are given in table 5 in comparison to past determinations. Results presented were determined in USGS Reston laboratories and these results are compared with reanalysis in USGS Denver laboratories in appendix 1. Mercury results by power station are shown in figure 2 . Results for $\mathrm{Hg}$ in the 42 feed coals give a mean of $241 \pm 75.1 \mathrm{ppb}$ expressed on a dry basis. ${ }^{4}$ The range in $\mathrm{Hg}$ values (from 125 to $487 \mathrm{ppb}$, dry basis) is similar to that of power station feed coal averages given previously by Gericke and others (2007; from 0.17 to $0.45 \mathrm{ppm}$ [170 to $450 \mathrm{ppb}$ ], basis unspecified).

Without knowing more about the source of coal and variations in the coal supply for each power station, and without more detailed sampling, it is difficult to make specific comparisons. From table 5, it appears that $\mathrm{Hg}$ contents determined in the present study are either similar to those obtained previously (for Arnot, Duvha, Hendrina, Lethabo, Majuba, Matla, and Tutuka) or lower (for Kendal, Kriel, and Matimba). Additionally, the sampling provides results for the Camden, Grootvlei, and Komati stations that have been returned to service since previous determinations, showing these three stations are within the range obtained for the other 10 stations. In none of the power stations has there been a pronounced increase in $\mathrm{Hg}$ input since the previous determinations. Washed Waterberg coal used to supply the Matimba power station shows that the process is effective in attaining $\mathrm{Hg}$ levels comparable to stations supplied by other coals.

\footnotetext{
${ }^{4}$ Mercury results are expressed in ppb where possible due to greater precision. To compare results given in ppm: $1 \mathrm{ppm}=1,000 \mathrm{ppb}$.
} 
Table 5. Mercury in 42 Eskom feed coal samples (this study) and previous results for feed coals in Eskom power stations (in parts per million, on a dry basis).

\begin{tabular}{lllcc}
\hline $\begin{array}{c}\text { Station } \\
\text { number }\end{array}$ & \multicolumn{1}{c}{ Station } & \multicolumn{1}{c}{$\begin{array}{c}\text { This study } \\
\text { (samples A, B, C, D) }\end{array}$} & $\begin{array}{c}\text { Composite } \\
\text { year(s) }\end{array}$ & $\begin{array}{c}\text { Gericke and } \\
\text { others }(\mathbf{2 0 0 7})^{2}\end{array}$ \\
\hline 1 & Arnot & $0.17,0.12$ & & 0.17 \\
2 & Camden & $0.21,0.26,0.22, \mathbf{0 . 2 0}$ & 2012 & N.A. \\
3 & Duvha $^{3}$ & $0.22, \mathbf{0 . 1 8}, 0.19$ & 2012 & 0.23 \\
4 & Grootvlei & $0.39,0.29, \mathbf{0 . 3 5}, 0.33$ & 2012 & N.A. \\
5 & Hendrina & $\mathbf{0 . 2 9 , 0 . 2 4 , \mathbf { 0 . 2 2 }}$ & $2010-2012$ & 0.21 \\
6 & Kendal & $0.22,0.21,0.19,0.22$ & & 0.44 \\
7 & Kriel & $0.13,0.13,0.15$ & & $0.29,0.38$ \\
8 & Komati & $0.24,0.21,0.25$ & & N.A. \\
9 & Lethabo & $0.42,0.49, \mathbf{0 . 1 6}$ & 2012 & 0.36 \\
10 & Majuba & $0.30,0.24,0.29, \mathbf{0 . 2 2}$ & 2012 & 0.29 \\
11 & Matimba & $0.23,0.26,0.20$ & & 0.45 \\
12 & Matla & $0.29,0.24, \mathbf{0 . 2 1}$ & 2012 & 0.29 \\
13 & Tutuka & $0.19,0.32,0.22$ & & 0.29 \\
\hline
\end{tabular}

${ }^{1}$ Values shown in boldface indicate yearly composites. Other results are monthly samples.

${ }^{2}$ Multiyear average Hg content as reported by Scott (2011); basis unspecified.

${ }^{3}$ Excludes results for 2010 samples from Duvha and Kendal stations presented in section 4.

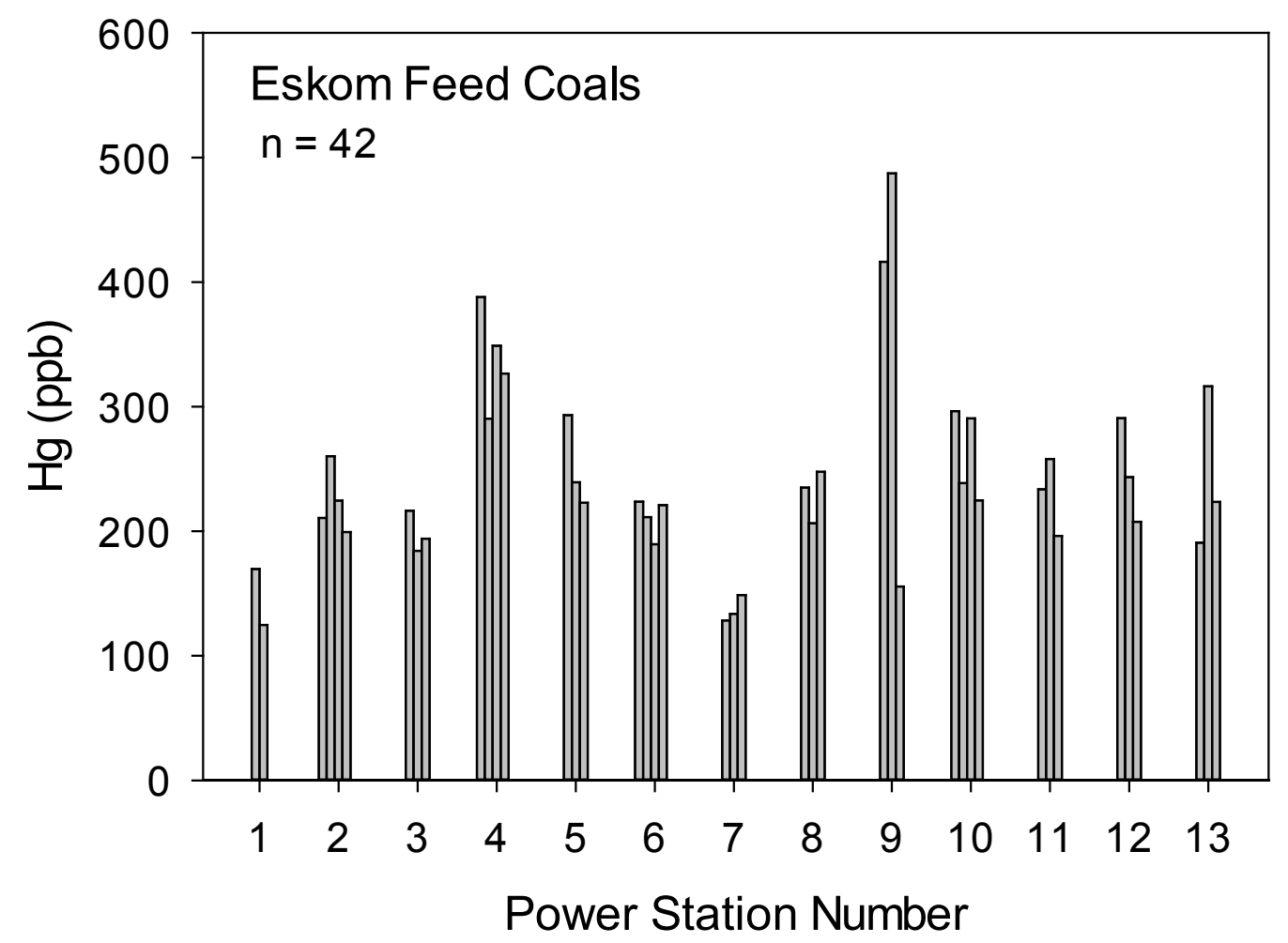

Figure 2. Variation in mercury $(\mathrm{Hg})$ content of feed coals (in parts per billion [ppb] on a dry basis) by power station number. Samples and power stations are as listed in table 2. n, number of samples. 


\subsection{Halogens in Feed Coals}

Chlorine $(\mathrm{Cl})$ is generally the most abundant halogen in coal. At flue gas temperatures, the $\mathrm{Cl}$ content of coal strongly influences $\mathrm{Hg}$ speciation, converting elemental $\mathrm{Hg}$ present at boiler temperatures to oxidized forms that can react to form $\mathrm{Hg}-\mathrm{Cl}$ complexes or compounds (Senior, 2015). These $\mathrm{Hg}-\mathrm{Cl}$ complexes or compounds can be captured by APCDs or taken up by halogen-doped sorbents (section 5). The proportion of oxidized $\mathrm{Hg}$ formed in combustion systems increases with increasing $\mathrm{Cl}$, and, therefore, the presence of moderate (at least several hundred ppm) $\mathrm{Cl}$ contents is advantageous for $\mathrm{Hg}$ capture. On a mass equivalent basis, bromine $(\mathrm{Br})$ is considered more effective than $\mathrm{Cl}$ in promoting $\mathrm{Hg}$ capture.

Halogens in the feed coals were measured using American Society for Testing and Materials (ASTM) methods (ASTM, 2013a,b) by a commercial laboratory. Measured halogen contents in the Eskom feed coals are generally low ( $\mathrm{Cl} \leq 100$ to $200 \mathrm{ppm}$, dry basis), with the exception of the Hendrina (\#5) power station in which 2010, 2011, and 2012 composite samples show variable $\mathrm{Cl}$ contents of uncertain origin (fig. 3); values in excess of $200 \mathrm{ppm}$ (samples 5A and $5 \mathrm{~B}$ ) are not considered to be representative. Fluorine (F) contents are variable, and in some cases, comparable to those obtained for $\mathrm{Cl}$ (table 6). No ASTM method exists for Br, but by using the same digestion and measurement approach (oxygen bomb combustion and ion selective electrode), Br contents were found to be below the detection limit (20 ppm) in all cases. Given the importance of $\mathrm{Br}$ in promoting $\mathrm{Hg}$ capture and the fact that $\mathrm{Br}$ contents in U.S. coals are typically from 2 to 4 percent of Cl contents (Vosteen and others, 2010; Kolker and Quick, 2015), a more sensitive method for $\mathrm{Br}$ determination is needed.

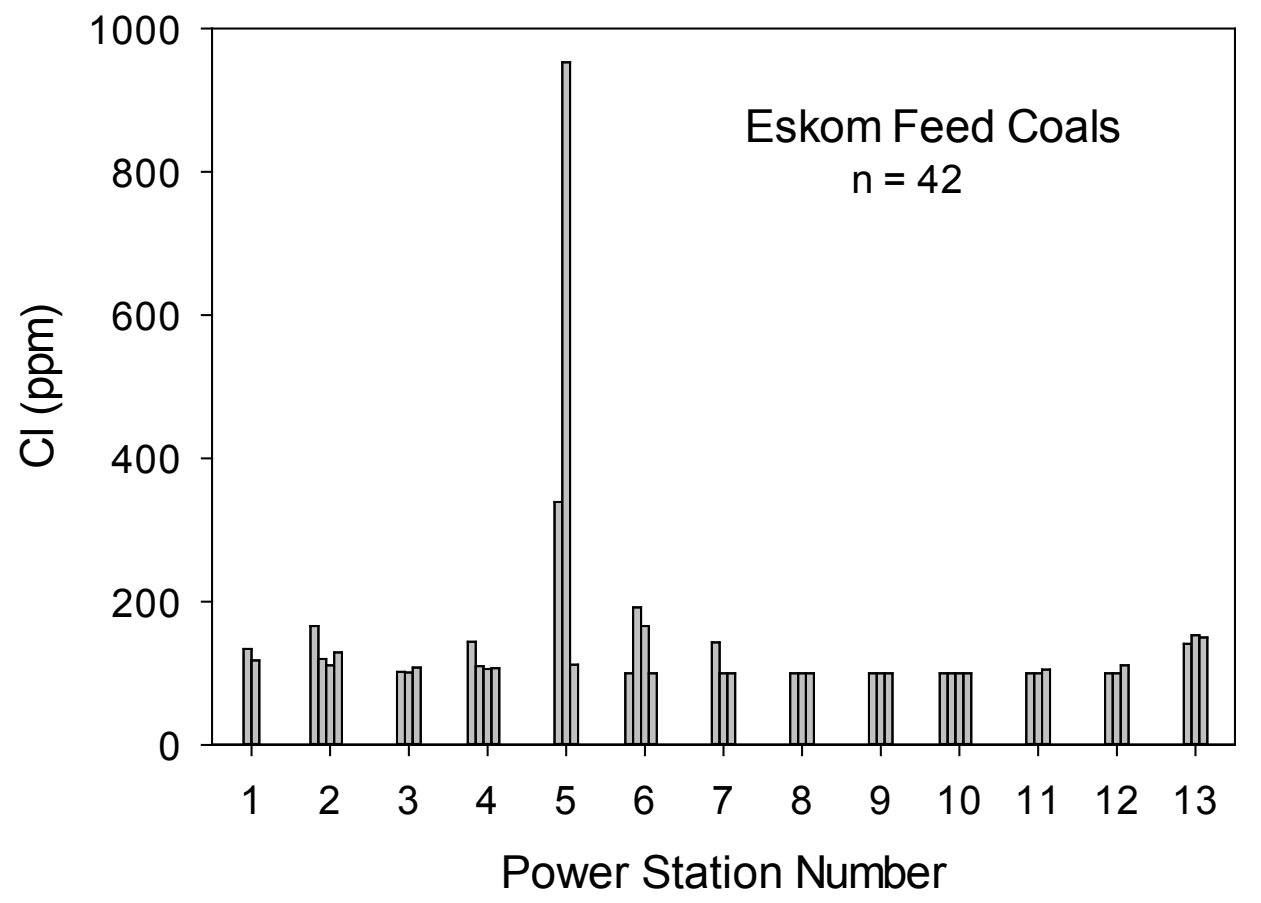

Figure 3. Variation in American Society for Testing and Materials chlorine (Cl) content in feed coals by power station number, reported on a dry basis. Power stations are as listed in table 2. Samples having values below the detection limit (100 parts per million [ppm]) are plotted at the detection limit ( $\mathrm{n}$, number of samples). 


\section{$2.4 \quad$ Trace Element Data}

Trace element results for the 42 feed coals (this section) and 8 density separates (section 3 ) are given in table 6 . For the feed coals, results for a range of elements, including beryllium (Be), chromium $(\mathrm{Cr})$, manganese $(\mathrm{Mn})$, cobalt (Co), nickel (Ni), As, molybdenum (Mo), cadmium $(\mathrm{Cd})$, antimony $(\mathrm{Sb})$, thallium $(\mathrm{Tl})$, and lead $(\mathrm{Pb})$, are relatively uniform (table 6; fig. 4). Relative to global averages, South African coals are higher in $\mathrm{Cr}$ and $\mathrm{Mn}$, and lower or much lower in As, Cd, and Sb (Bergh and others, 2011; Wagner and Tlotleng, 2012). Wagner and Hlatshwayo (2005) also found that $\mathrm{Pb}$, and zinc ( $\mathrm{Zn}$ ) were depleted in Highveld coals relative to global averages. For Waterberg coals (samples 11A-C), Mn and $\mathrm{Cr}$ are high as in other South African coals; $\mathrm{Zn}$ and $\mathrm{Pb}$ in these samples are higher than in Witbank and Highveld coals, as also found by Wagner and Tlotleng (2012). Selenium values for the feed coals in the present study are at or below the global average, agreeing well with results for five Highveld samples given by Wagner and Hlatshwayo (2005).

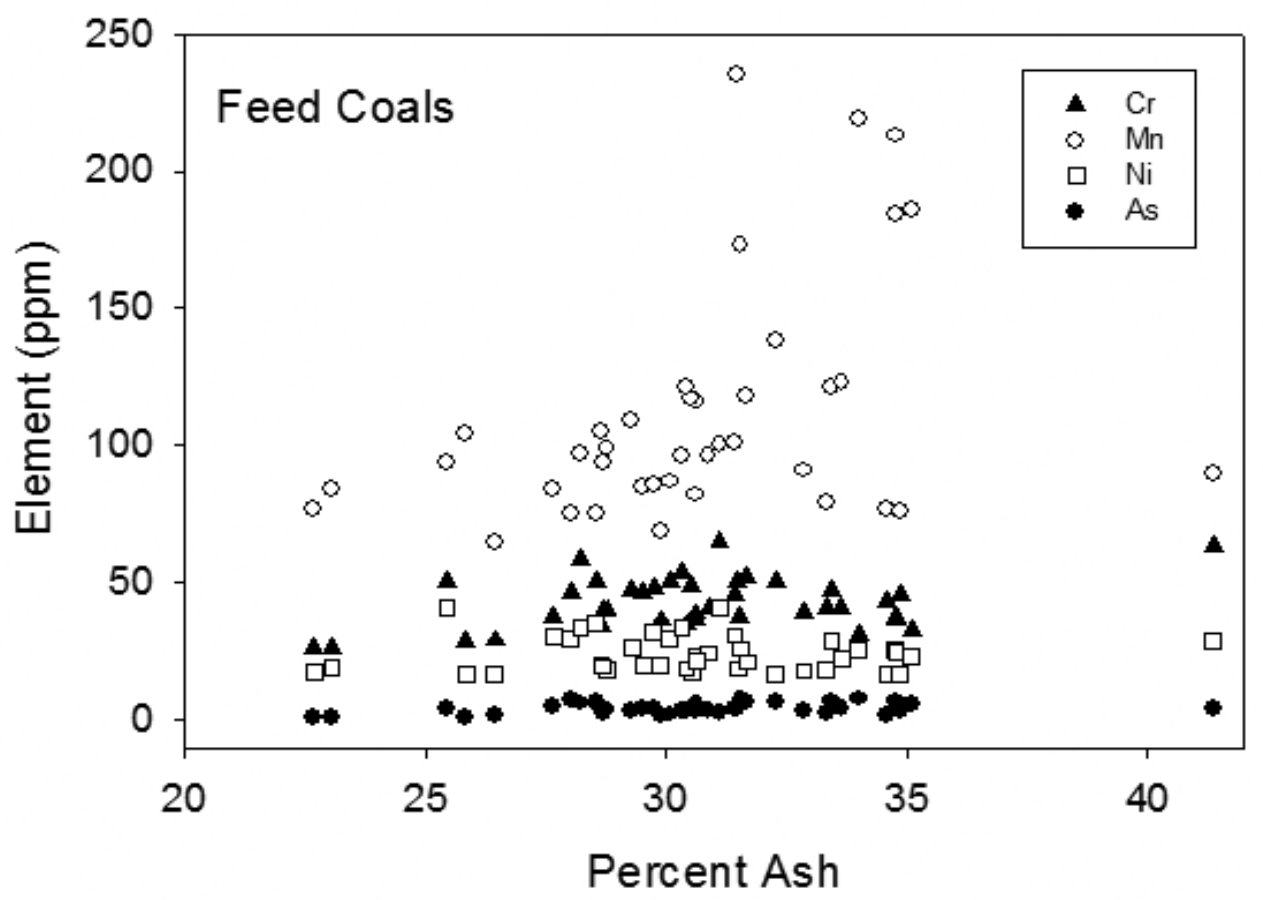

Figure 4. Plot showing ranges for chromium (Cr), manganese (Mn), nickel (Ni), and arsenic (As) in feed coals (in parts per million [ppm] on a dry basis). 
Table 6. Trace element data (in parts per million, on a whole-coal dry basis). ${ }^{1}$

[Be, beryllium; F, fluorine; $\mathrm{Cl}$, chlorine; Cr, chromium; Mn, manganese; Co, cobalt; Ni, nickel; Zn, zinc; As, arsenic; Se, selenium; Mo, molybdenum; Cd, cadmium; $\mathrm{Sb}$, antimony; $\mathrm{Hg}$, mercury; $\mathrm{Tl}$, thallium; $\mathrm{Pb}$, lead. $\mathrm{Cl}$ and $\mathrm{F}$ are proposed to be regulated as acid gases $\mathrm{HCl}, \mathrm{HF} ; \mathrm{Zn}, \mathrm{Mo}$, and $\mathrm{Tl}$ are not proposed to be regulated under EPA Mercury and Air Toxics Standards. Elements are listed in order of atomic number from $4(\mathrm{Be})$ to $82(\mathrm{~Pb})]$

\begin{tabular}{|c|c|c|c|c|c|c|c|c|c|c|c|c|c|c|c|c|}
\hline Sample & $\begin{array}{c}\mathrm{Be}^{2} \\
4 \\
\end{array}$ & $\begin{array}{c}F^{3} \\
9 \\
\end{array}$ & $\begin{array}{l}\mathrm{CI} \\
17 \\
\end{array}$ & $\begin{array}{l}\mathrm{Cr}^{4} \\
24 \\
\end{array}$ & $\begin{array}{c}M n \\
25 \\
\end{array}$ & $\begin{array}{l}\text { Co } \\
27 \\
\end{array}$ & $\begin{array}{l}\mathrm{Ni} \\
28 \\
\end{array}$ & $\begin{array}{l}\mathrm{Zn} \\
30 \\
\end{array}$ & $\begin{array}{l}\text { As } \\
33 \\
\end{array}$ & $\begin{array}{l}\text { Se } \\
34\end{array}$ & $\begin{array}{l}\text { Mo } \\
42 \\
\end{array}$ & $\begin{array}{l}\mathrm{Cd} \\
48 \\
\end{array}$ & $\begin{array}{l}\mathrm{Sb} \\
51\end{array}$ & $\begin{array}{c}\mathrm{Hg} \\
80 \\
\end{array}$ & $\begin{array}{l}\mathrm{Tl} \\
81 \\
\end{array}$ & $\begin{array}{l}\mathrm{Pb} \\
82 \\
\end{array}$ \\
\hline $1 \mathrm{~A}$ & 1.9 & 84 & 134 & 50 & 94 & 12 & 41 & 22 & 2.8 & 1.1 & 1.7 & 0.1 & 0.2 & 0.17 & 0.43 & 17 \\
\hline 1B & 2.6 & 113 & 118 & 38 & 84 & 10 & 31 & 23 & 3.2 & 1.1 & 1.4 & 0.1 & 0.2 & 0.12 & 0.45 & 23 \\
\hline $2 \mathrm{~A}$ & 3.5 & 137 & 166 & 47 & 121 & 8.5 & 29 & 28 & 5.3 & 1.6 & 2.1 & 0.1 & 0.4 & 0.21 & 0.63 & 27 \\
\hline $2 \mathrm{~B}$ & 2.8 & 127 & 120 & 38 & 173 & 9.3 & 26 & 25 & 5.4 & 1.5 & 2.6 & 0.1 & 0.3 & 0.26 & 0.71 & 27 \\
\hline $2 \mathrm{C}$ & 2.7 & 130 & 111 & 39 & 116 & 6.6 & 24 & 20 & 4.4 & 1.2 & 1.9 & $<0.1$ & 0.2 & 0.22 & 0.53 & 21 \\
\hline $2 \mathrm{D}$ & 2.5 & 118 & 129 & 34 & 105 & 7.3 & 20 & 28 & 3.6 & 1.2 & 1.9 & 0.1 & 0.4 & 0.20 & 0.33 & 18 \\
\hline $3 \mathrm{~A}$ & 2.4 & 215 & 102 & 65 & 100 & 8.6 & 41 & 26 & 3.8 & 1.0 & 2.2 & 0.1 & 0.3 & 0.22 & 0.47 & 21 \\
\hline $3 B$ & 2.4 & 208 & 101 & 50 & 87 & 7.1 & 30 & 23 & 3.2 & 1.0 & 1.9 & 0.1 & 0.3 & 0.18 & 0.37 & 20 \\
\hline $3 \mathrm{C}$ & 2.5 & 239 & 108 & 54 & 96 & 8.0 & 34 & 25 & 3.4 & 1.0 & 2.1 & 0.1 & 0.3 & 0.19 & 0.42 & 23 \\
\hline $4 \mathrm{~A}$ & 3.2 & 158 & 144 & 51 & 138 & 4.4 & 17 & 14 & 6.1 & 1.4 & 2.0 & $<0.1$ & 0.3 & 0.39 & 0.34 & 26 \\
\hline $4 B$ & 2.7 & 149 & 110 & 49 & 117 & 4.8 & 18 & 12 & 3.8 & 1.4 & 1.8 & $<0.1$ & 0.3 & 0.29 & 0.20 & 22 \\
\hline $4 \mathrm{C}$ & 3.0 & 153 & 106 & 50 & 235 & 4.7 & 19 & 15 & 4.3 & 1.6 & 0.89 & $<0.1$ & 0.3 & 0.35 & 0.18 & 23 \\
\hline $4 \mathrm{D}$ & 3.3 & 189 & 107 & 52 & 118 & 7.6 & 21 & 17 & 6.2 & 1.5 & 2.1 & $<0.1$ & 0.3 & 0.33 & 0.26 & 27 \\
\hline $5 \mathrm{~A}$ & 2.5 & 37 & 339 & 46 & 75 & 8.9 & 29 & 18 & 5.9 & 1.0 & 1.8 & 0.1 & 0.2 & 0.29 & 0.71 & 18 \\
\hline $5 B$ & 3.6 & 75 & 953 & 51 & 75 & 9.9 & 36 & 26 & 5.4 & 1.0 & 2.3 & $<0.1$ & 0.2 & 0.24 & 0.77 & 18 \\
\hline $5 \mathrm{C}$ & 2.6 & 117 & 112 & 58 & 97 & 9.9 & 34 & 24 & 5.3 & 1.0 & 1.7 & $<0.1$ & 0.2 & 0.22 & 0.63 & 18 \\
\hline $6 \mathrm{~A}$ & 3.4 & 175 & $<100$ & 41 & 79 & 4.9 & 19 & 12 & 2.4 & 1.6 & 1.7 & $<0.1$ & 0.3 & 0.22 & 0.23 & 19 \\
\hline $6 \mathrm{~B}$ & 3.2 & 168 & 192 & 39 & 91 & 5.5 & 18 & 20 & 3.6 & 1.2 & 1.8 & $<0.1$ & 2.3 & 0.21 & 0.34 & 19 \\
\hline $6 C$ & 2.7 & 166 & 166 & 43 & 77 & 4.2 & 17 & 14 & 2.5 & 1.1 & 1.4 & $<0.1$ & 0.3 & 0.19 & 0.22 & 17 \\
\hline $6 \mathrm{D}$ & 2.8 & 47 & $<100$ & 45 & 76 & 4.5 & 17 & 11 & 2.8 & 1.3 & 1.6 & 0.1 & 0.4 & 0.22 & 0.23 & 16 \\
\hline $7 \mathrm{~A}$ & 1.7 & 164 & 143 & 27 & 84 & 3.4 & 19 & 3.5 & 1.3 & 1.0 & 1.2 & $<0.1$ & 0.2 & 0.13 & 0.08 & 12 \\
\hline $7 B$ & 1.6 & 97 & $<100$ & 26 & 77 & 3.0 & 17 & 3.3 & 1.0 & 0.8 & 0.99 & $<0.1$ & 0.2 & 0.13 & 0.07 & 9.2 \\
\hline $7 \mathrm{C}$ & 1.7 & 158 & $<100$ & 29 & 104 & 3.3 & 17 & 6.0 & 1.3 & 0.9 & 1.1 & $<0.1$ & 0.3 & 0.15 & 0.12 & 8.5 \\
\hline $8 \mathrm{~A}$ & 2.1 & 95 & $<100$ & 41 & 96 & 6.7 & 24 & 30 & 2.9 & 1.1 & 1.0 & $<0.1$ & 0.2 & 0.20 & 0.33 & 18 \\
\hline $8 B$ & 1.9 & 98 & $<100$ & 35 & 121 & 6.1 & 19 & 20 & 2.2 & 1.2 & 1.3 & $<0.1$ & 0.2 & 0.21 & 0.28 & 18 \\
\hline
\end{tabular}


Table 6. Trace element data (in parts per million, on a whole-coal dry basis). ${ }^{1}$-Continued

[Be, beryllium; F, fluorine; Cl, chlorine; Cr, chromium; Mn, manganese; Co, cobalt; Ni, nickel; Zn, zinc; As, arsenic; Se, selenium; Mo, molybdenum; Cd, cadmium; $\mathrm{Sb}$, antimony; $\mathrm{Hg}$, mercury; $\mathrm{Tl}$, thallium; $\mathrm{Pb}$, lead. $\mathrm{Cl}$ and $\mathrm{F}$ are proposed to be regulated as acid gases $\mathrm{HCl}, \mathrm{HF} ; \mathrm{Zn}, \mathrm{Mo}$, and $\mathrm{Tl}$ are not proposed to be regulated under EPA Mercury and Air Toxics Standards. Elements are listed in order of atomic number from $4(\mathrm{Be})$ to $82(\mathrm{~Pb})]$

\begin{tabular}{|c|c|c|c|c|c|c|c|c|c|c|c|c|c|c|c|c|}
\hline Sample & $\begin{array}{c}\mathrm{Be}^{2} \\
4\end{array}$ & $\begin{array}{c}F^{3} \\
9\end{array}$ & $\begin{array}{l}\mathrm{Cl} \\
17\end{array}$ & $\begin{array}{c}\mathrm{Cr}^{4} \\
24\end{array}$ & $\begin{array}{c}M n \\
25\end{array}$ & $\begin{array}{l}\text { Co } \\
27\end{array}$ & $\begin{array}{l}\mathrm{Ni} \\
28\end{array}$ & $\begin{array}{l}\mathrm{Zn} \\
30\end{array}$ & $\begin{array}{l}\text { As } \\
33\end{array}$ & $\begin{array}{l}\text { Se } \\
34\end{array}$ & $\begin{array}{l}\text { Mo } \\
42\end{array}$ & $\begin{array}{l}C d \\
48\end{array}$ & $\begin{array}{l}\mathrm{Sb} \\
51\end{array}$ & $\begin{array}{l}\mathrm{Hg} \\
80\end{array}$ & $\begin{array}{l}\mathrm{TI} \\
81\end{array}$ & $\begin{array}{c}\mathrm{Pb} \\
82\end{array}$ \\
\hline $8 \mathrm{C}$ & 2.0 & 98 & $<100$ & 41 & 123 & 7.6 & 22 & 20 & 3.1 & 1.2 & 1.7 & $<0.1$ & 0.2 & 0.25 & 0.42 & 17 \\
\hline $9 \mathrm{~A}$ & 2.6 & 124 & $<100$ & 67 & 107 & 5.6 & 25 & 21 & 4.0 & 1.6 & 1.6 & $<0.1$ & 0.3 & 0.42 & 0.31 & 24 \\
\hline $9 B^{5}$ & 2.6 & 119 & $<100$ & 64 & 90 & 4.9 & 29 & 15 & 3.7 & 1.4 & 1.7 & $<0.1$ & 0.3 & 0.49 & 0.27 & 21 \\
\hline $9 \mathrm{C}$ & 2.3 & 189 & $<100$ & 53 & 80 & 4.4 & 15 & 14 & 4.8 & 1.0 & 1.4 & $<0.1$ & 0.3 & 0.16 & 0.22 & 20 \\
\hline $10 \mathrm{~A}$ & 2.2 & 157 & $<100$ & 47 & 85 & 4.0 & 20 & 10 & 3.3 & 1.3 & 2.2 & $<0.1$ & 0.2 & 0.30 & 0.22 & 16 \\
\hline $10 \mathrm{~B}$ & 2.7 & 145 & $<100$ & 40 & 99 & 4.9 & 18 & 19 & 3.5 & 1.2 & 1.5 & $<0.1$ & 0.3 & 0.24 & 0.27 & 17 \\
\hline $10 \mathrm{C}$ & 2.5 & 173 & $<100$ & 40 & 94 & 4.1 & 20 & 13 & 2.9 & 1.2 & 1.9 & $<0.1$ & 0.2 & 0.29 & 0.24 & 20 \\
\hline $10 \mathrm{D}$ & 2.7 & 186 & $<100$ & 47 & 109 & 4.6 & 26 & 14 & 3.0 & 1.3 & 2.1 & $<0.1$ & 0.2 & 0.22 & 0.28 & 20 \\
\hline $11 \mathrm{~A}$ & 3.0 & 217 & $<100$ & 37 & 184 & 11 & 25 & 55 & 5.4 & 1.2 & 2.8 & 0.2 & 0.6 & 0.23 & 0.57 & 26 \\
\hline $11 \mathrm{~B}$ & 2.8 & 89 & $<100$ & 33 & 186 & 10 & 24 & 52 & 4.9 & 1.3 & 2.6 & 0.2 & 0.5 & 0.26 & 0.57 & 26 \\
\hline $11 \mathrm{C}$ & 3.1 & 205 & 105 & 37 & 213 & 11 & 25 & 58 & 5.4 & 1.5 & 2.9 & 0.2 & 0.5 & 0.20 & 0.61 & 28 \\
\hline $12 A^{5}$ & 1.5 & 152 & $<100$ & 36 & 69 & 4.7 & 20 & 9.8 & 2.1 & 1.1 & 1.7 & $<0.1$ & 0.3 & 0.29 & 0.23 & 18 \\
\hline $12 B^{5}$ & 1.6 & 154 & $<100$ & 29 & 65 & 4.8 & 17 & 9.3 & 1.8 & 0.8 & 1.6 & $<0.1$ & 0.3 & 0.24 & 0.21 & 15 \\
\hline $12 \mathrm{C}$ & 2.9 & 189 & 111 & 31 & 219 & 12 & 25 & 70 & 5.3 & 1.2 & 2.9 & 0.2 & 0.5 & 0.21 & 0.61 & 24 \\
\hline $13 \mathrm{~A}$ & 3 & 86 & 141 & 37 & 82 & 6.8 & 22 & 15 & 2.5 & 1.2 & 1.4 & $<0.1$ & 0.2 & 0.19 & 0.30 & 20 \\
\hline $13 \mathrm{~B}$ & 3.3 & 106 & 153 & 48 & 86 & 10 & 32 & 20 & 3.3 & 1.2 & 1.5 & $<0.1$ & 0.2 & 0.32 & 0.44 & 18 \\
\hline $13 \mathrm{C}$ & 3.9 & 93 & 150 & 45 & 101 & 9.7 & 31 & 25 & 3.3 & 1.2 & 1.5 & $<0.1$ & 0.2 & 0.22 & 0.51 & 19 \\
\hline $14 A^{6}$ & 0.8 & 311 & 540 & 31 & 29 & 9.3 & 15 & 3.0 & 0.5 & 0.5 & 1.7 & $<0.1$ & 0.5 & 0.06 & $<0.05$ & 2.6 \\
\hline $14 \mathrm{~B}$ & 1.4 & 239 & 1084 & 39 & 43 & 5.2 & 16 & 4.7 & 0.9 & 1.0 & 1.5 & $<0.1$ & 0.6 & 0.06 & 0.06 & 7.1 \\
\hline $14 \mathrm{C}$ & 1.6 & 171 & 1037 & 34 & 62 & 2.8 & 15 & 4.3 & 1.0 & 1.0 & 1.6 & $<0.1$ & 0.6 & 0.10 & 0.07 & 6.8 \\
\hline $14 \mathrm{D}$ & 1.7 & 140 & 770 & 33 & 74 & 2.0 & 14 & 4.4 & 1.2 & 1.0 & 2.1 & $<0.1$ & 0.4 & 0.25 & 0.11 & 7.5 \\
\hline $14 \mathrm{E}$ & 2.6 & 154 & 807 & 59 & 67 & 2.5 & 18 & 4.9 & 1.7 & 1.2 & 3.2 & $<0.1$ & 0.3 & 0.32 & 0.22 & 10 \\
\hline $14 \mathrm{~F}$ & 1.8 & 129 & 573 & 50 & 59 & 2.7 & 21 & 8.3 & 2.9 & 1.5 & 4.1 & $<0.1$ & 0.4 & 0.62 & 0.25 & 10 \\
\hline $14 \mathrm{G}^{7}$ & 2.9 & 120 & 536 & 65 & 55 & 2.4 & 24 & 15 & 3.2 & 1.5 & 2.9 & $<0.1$ & 0.4 & 0.45 & 0.28 & 12 \\
\hline $14 \mathrm{H}^{7}$ & 1.8 & 140 & 428 & 70 & 51 & 8.7 & 41 & 21 & 4.4 & 1.3 & 3.5 & $<0.1$ & 0.5 & 0.47 & 0.51 & 11 \\
\hline
\end{tabular}

(see footnotes on next page) 
Table 6. Trace element data (in parts per million, on a whole-coal dry basis). ${ }^{1}$-Continued

${ }^{1}$ Emissions proposed for regulation under U.S. EPA Mercury and Air Toxics Standards (EPA, 2011) are shown in boldface.

${ }^{2}$ The following elements were determined using ICP-MS by Actlabs, Ancaster, Ontario, Canada: $\mathrm{Be}, \mathrm{Mn}, \mathrm{Co}, \mathrm{Ni}, \mathrm{Zn}, \mathrm{Se}, \mathrm{Mo}, \mathrm{Cd}, \mathrm{Tl}, \mathrm{Pb}$

${ }^{3}$ The following elements were determined using ion-selective electrode by Geochemical Testing, Inc., Somerset, Pa., U.S.A.: F, Cl.

${ }^{4}$ The following elements were determined using ICP-MS by USGS in reanalysis of values originally reported in OF-2014-1153: Cr, As, Sb.

${ }^{5}$ Mercury values for samples $9 \mathrm{~B}, 12 \mathrm{~A}$, and 12B are averages of multiple analyses (appendix 1).

${ }^{6}$ Fourteen-series samples are Highveld \#4 density separates (section 3). Mercury values for these samples are averages of multiple analyses (appendix 1).

${ }^{7}$ USGS value was used for Mo in 14H; USGS and Actlabs values were averaged for $\mathrm{Zn}$ in 14G. 


\section{Density Separates of Highveld (\#4) Coal}

\subsection{Introduction}

In addition to power station feed coals, Eskom provided eight sized density separates of Highveld \#4 coal from test preparation in heavy media. These samples are especially relevant as they represent one of the most important coals used for domestic power generation and an increasing proportion of the export market from prepared product. The density separates were prepared from a 1-mm-size split in heavy media ranging from 1.4 to 2.0 grams per cubic centimeter $\left(\mathrm{g} / \mathrm{cm}^{3}\right)$. These include float fractions for densities $\left(\mathrm{g} / \mathrm{cm}^{3}\right) 1.4,1.5,1.6,1.7,1.8,1.9$, and 2.0, corresponding to samples $14 \mathrm{~A}$ to $\mathrm{G}$, and the sink fraction for 2.0 (sample $14 \mathrm{H}$ ). Inclusion of these samples in the present study provides an indication of the partitioning behavior of trace elements during coal washing. Simple calculations using the separates allow prediction of coal quality variations and element partitioning in coal products used in South Africa on a commercial scale. Washed export coals have the lowest ash yields and $\mathrm{Hg}$ contents. Feed coals utilized by Eskom (table 3) may include all the remaining fractions (middling+discard), or the middlings only, from which both the export fraction and a discard fraction have been removed. If the yield of the export fraction is too low, then Eskom may burn an unwashed run-of-mine coal, or commonly, a destoned product in which the most ash-rich fraction (discard) has been removed. Eskom emphasizes the importance of removing the stone (discard) fraction. In most cases, coarse pyrite remaining in the raw coal is removed during pulverization, as pyrite rejects.

\subsection{Results}

\subsubsection{Bulk Analysis}

For the eight density separates, the separation process is effective in concentrating pyrite in the highest density $\left(2.0 \mathrm{~g} / \mathrm{cm}^{3}\right)$ fractions, either as float or sink. Bulk Hg contents of the separates are well correlated with the amount of pyrite (as pyritic sulfur) present, and with ash yield (fig. 5). Arsenic enrichment goes along with $\mathrm{Hg}$, but overall As contents in South African coals are relatively low compared to world averages, especially in the separates (Ketris and Yudovich, 2009; fig. 6 ). Conversely, Cr, Mn, Co, Ni, Mo, and Sb show enrichment in the lowdensity float fractions (table 6; fig. 7), despite the fact that some of these elements ( $\mathrm{Mn}, \mathrm{Co}, \mathrm{Ni}$, and Mo) are measurable in pyrite (following section). These elements have mixed associations, likely including an organic association in addition to pyrite. Although high Cr contents are characteristic of South African coals, the fact that $\mathrm{Cr}$ is enriched in the low-density float fractions suggests that chromite $\left(\mathrm{FeCr}_{2} \mathrm{O}_{4}\right.$, density 5.09) is not the host, despite the proximity of the Witbank coals to the Bushveld Complex, a prominent source of chromite (Cameron, 1977; Hulbert and Von Gruenewaldt, 1985). The Bushveld Complex greatly predates Karoo sediments hosting these coal beds, but it would have to be exposed in Permian time to contribute sediments during coal formation. To explain moderate $\mathrm{Cr}$ enrichment in Highveld coals, Wagner and Hlatshwayo (2005) suggest that $\mathrm{Cr}$ from primary sources, such as chromite, was subsequently dissolved and redistributed, which would explain the uniform $\mathrm{Cr}$ enrichment. 

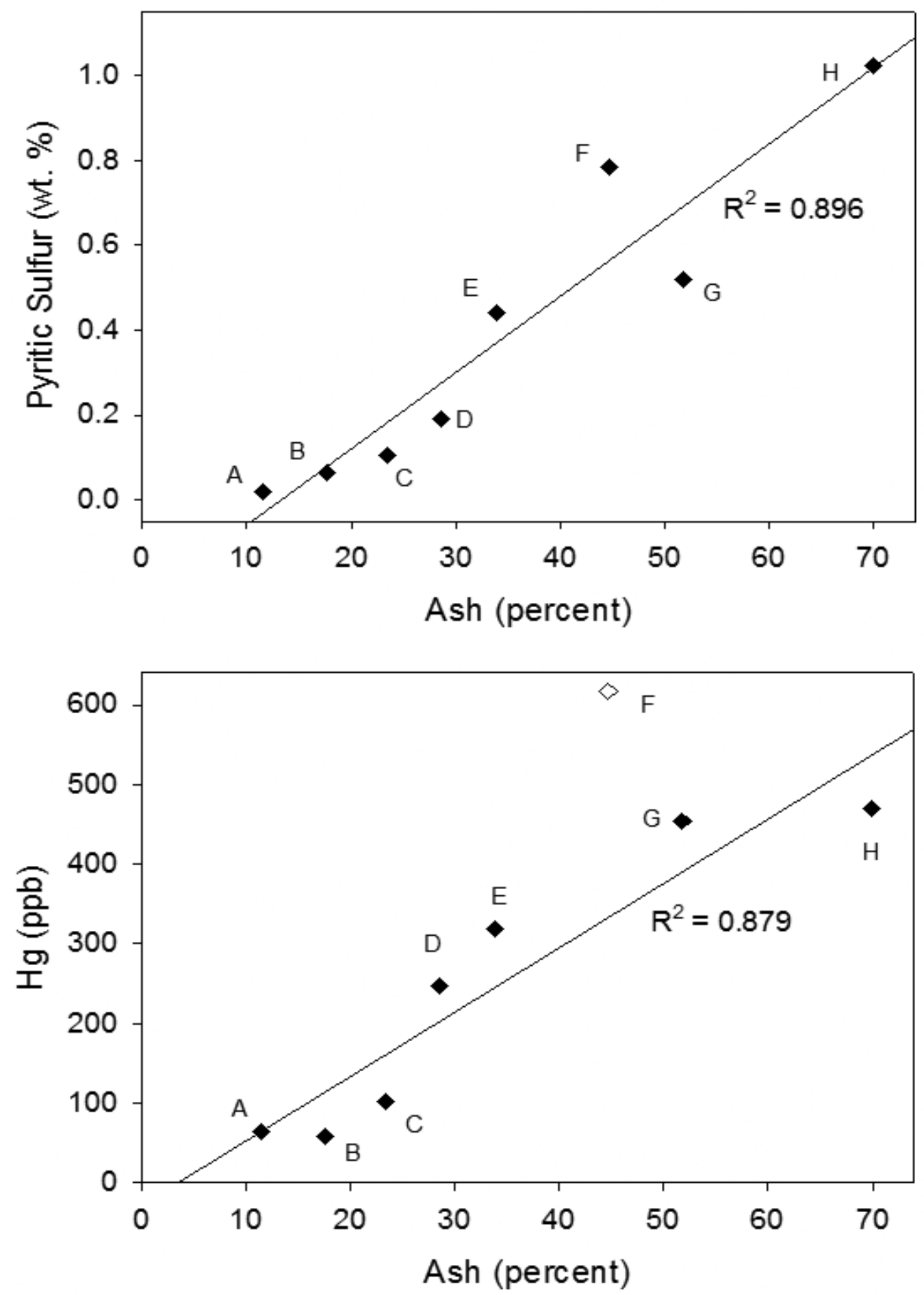

Figure 5. Plots of ash yield versus pyritic sulfur (upper plot; in weight percent [wt. \%]) and mercury (lower plot) for Highveld (\#4) density separates, showing concentration of pyrite and mercury $(\mathrm{Hg})$ in the highdensity cuts (in parts per billion [ppb], on a dry basis; $\mathrm{R}^{2}$, correlation). Corresponding densities are noted in text. Sample 14F (open symbol) is omitted from linear regression in bottom plot. 


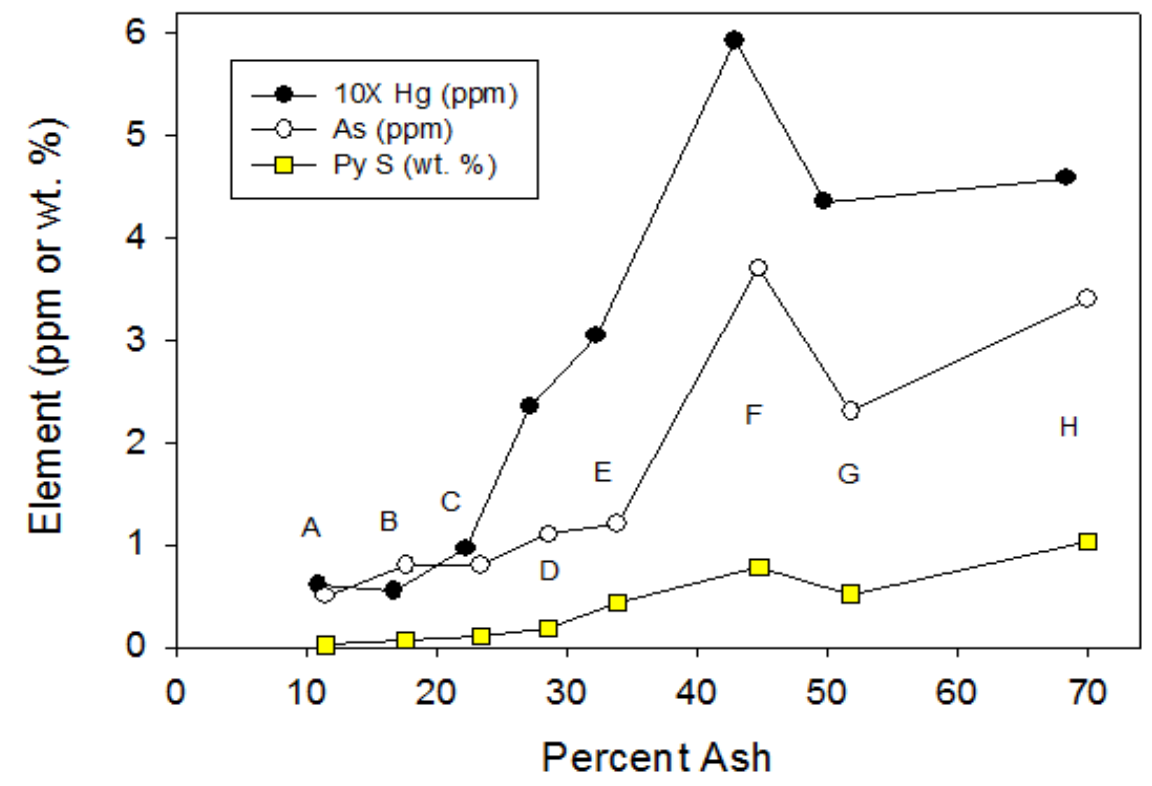

Figure 6. Plot showing increase in mercury $(\mathrm{Hg})$ and arsenic (As) in separates prepared at increasing separation densities, and corresponding increase in pyrite content (as pyritic sulfur [Py S]; in parts per million [ppm] or weight percent [wt. \%]) on a dry basis.

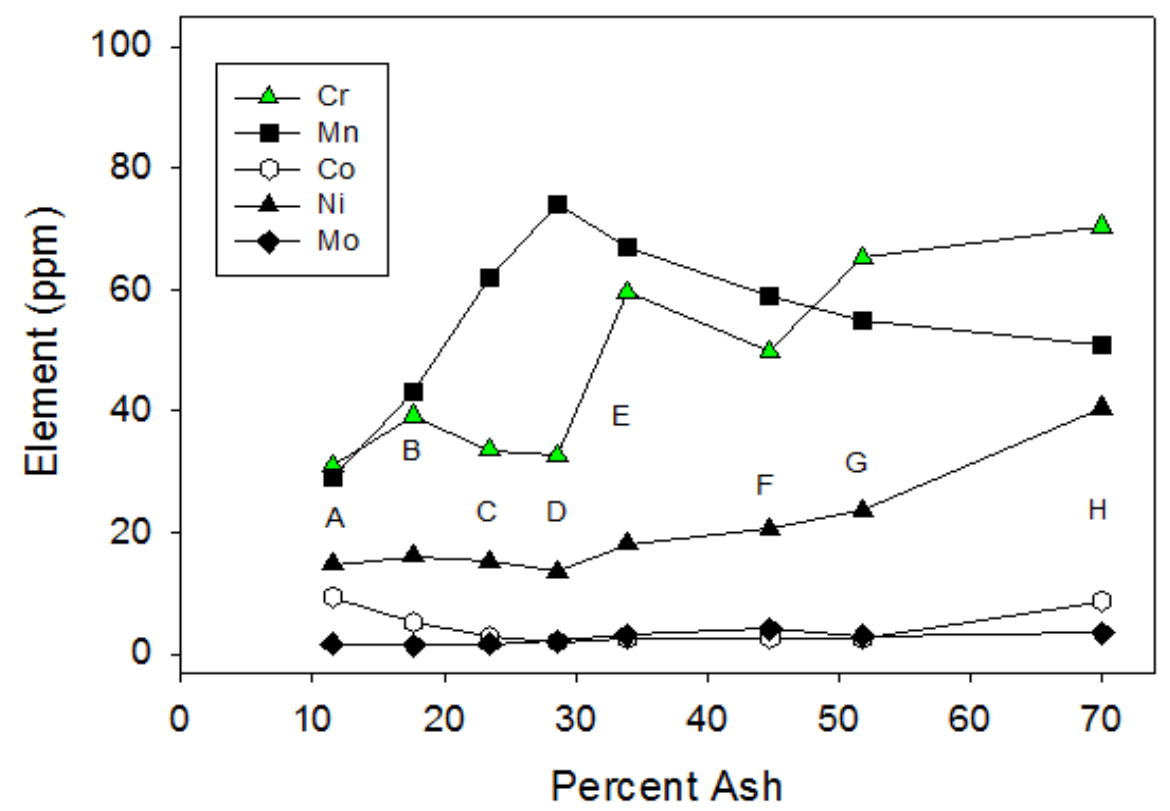

Figure 7. Partitioning of elements chromium ( $\mathrm{Cr}$ ), manganese (Mn), cobalt (Co), nickel (Ni), and molybdenum (Mo), indicating a mixed association for these elements (in parts per million [ppm] on a dry basis). 
Unlike $\mathrm{Hg}, \mathrm{Cl}$ and $\mathrm{F}$ in the Highveld $\# 4$ separates are concentrated in the low-ash fractions, consistent with binding of halogens to organic portions of the coal (Huggins and Huffman, 1995) as the dominant mode of occurrence (fig. 8). Compared to Highveld whole coals, halogen values for the separates are high, possibly a result of zinc chloride heavy liquids used in their preparation. However, results for $\mathrm{Zn}$ do not show enrichment in the separates relative to whole coals, and the observed $\mathrm{Cl}$ enrichment decreases with increasing density, opposite of the trend expected as the proportion of heavy liquid in heavy liquid-water mixtures increases.

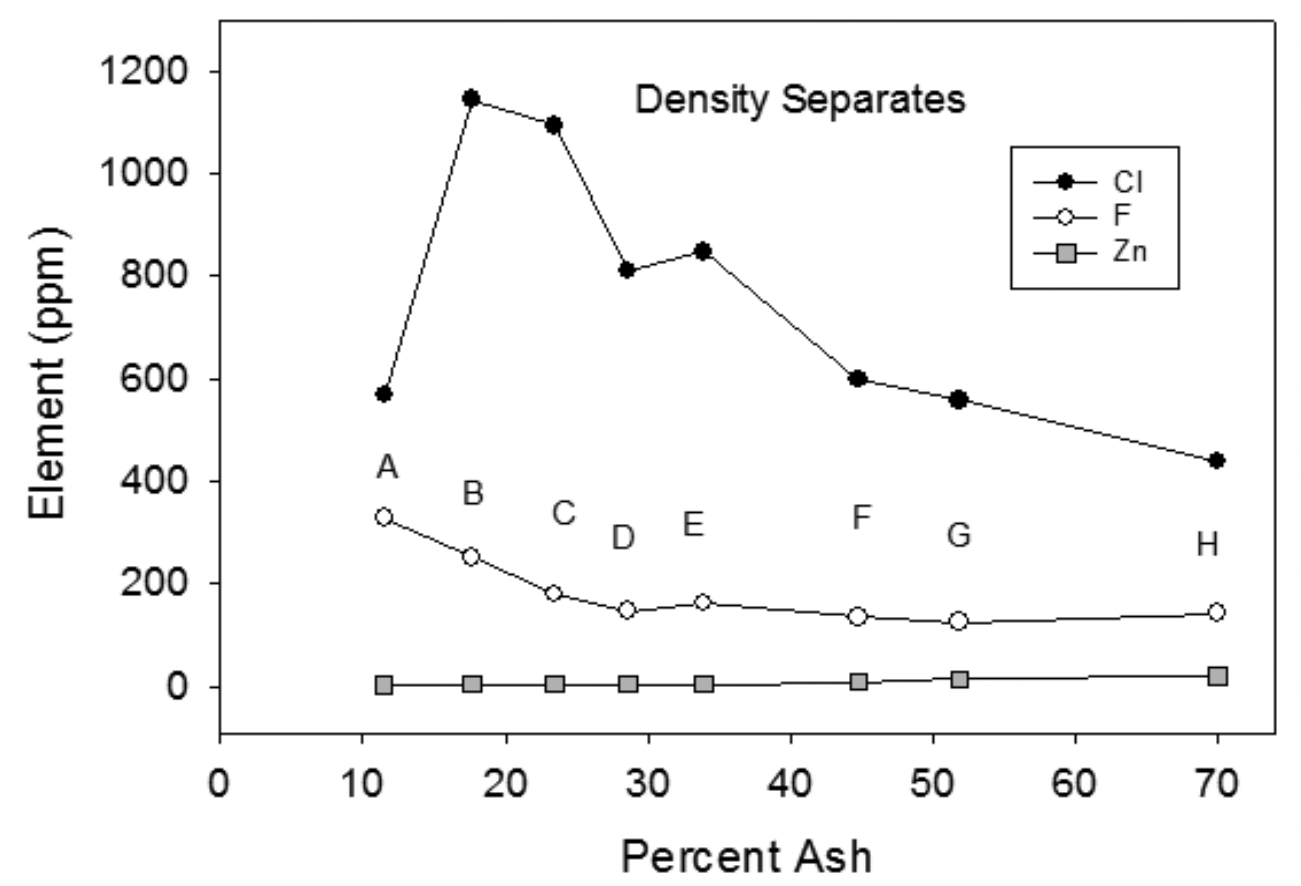

Figure 8. Partitioning of chlorine $(\mathrm{Cl})$ and fluorine $(\mathrm{F})$ among Highveld \#4 density separates showing that halogens are preferentially concentrated in the low-density fractions indicating an organic affinity (in parts per million [ppm] on a dry basis; Zn, zinc).

Combinations of the density fractions can be used to predict characteristics of coal products used in South Africa or exported. These include: (1) export; (2) destoned; (3) middling; (4) run-of-mine; (5) middling plus discard; and (6) stone (discard), listed in order of increasing ash yield predicted from the density fractions (table 7). Mercury contents calculated for these products range from approximately $50 \mathrm{ppb}$ for export coal to more than $450 \mathrm{ppb}$ for stone. While these results are limited to a single-size fraction of a single coal, they are illustrative of the difference in quality of coals prepared for export and those used for domestic power generation. In practice, the middlings fraction may have a higher ash yield than run-of-mine coal (Wagner and Hlatshwayo, 2005), but the standard for export coal is to contain no more than 16 percent ash (Snyman and Botha, 1993), as the density separates predict. Past USGS analysis of export quality Highveld coals confirms $\mathrm{Hg}$ contents of $50 \mathrm{ppb}$ or less are attained (Tewalt and others, 2010). 
Table 7. Ash yield and mercury contents of coal products predicted from Highveld (\#4) density separates, expressed on a dry basis. Mercury $(\mathrm{Hg})$ results used are shown in appendix 1.

[wt. \%, weight percent; ppb, parts per billion]

\begin{tabular}{llccc}
\hline \multicolumn{1}{c}{ Product } & \multicolumn{1}{c}{$\begin{array}{c}\text { Samples } \\
\text { (averaged) }\end{array}$} & $\begin{array}{c}\text { Ash } \\
(\text { wt. \%) }\end{array}$ & $\begin{array}{c}\mathrm{Hg} \\
(\mathbf{p p b})\end{array}$ & $\begin{array}{c}\text { Approximate cut } \\
\text { point }\end{array}$ \\
\hline Export & $14 \mathrm{~A}$ & 11.5 & 6 & Cut at 1.4 \\
Destoned & $14 \mathrm{~A}-\mathrm{F}$ & 26.6 & 235 & Cut at 1.9 \\
Middling & $14 \mathrm{~B}-\mathrm{F}$ & 29.7 & 269 & 1.4 to 1.9 \\
Run-of-mine & $14 \mathrm{~A}-\mathrm{H}$ & 35.2 & 291 & No washing \\
Middling+discard & $14 \mathrm{~B}-\mathrm{H}$ & 38.6 & 324 & $>1.4$ \\
Stone (discard) & $14 \mathrm{G}, \mathrm{H}$ & 60.9 & 461 & $>2.1$ \\
\hline
\end{tabular}

\subsubsection{Microanalysis}

Polished mounts of each density separate were prepared for characterization by microanalysis methods. Pyrite grains for laser ablation inductively coupled plasma-mass spectrometry (ICP-MS) were identified and checked for compositional variation using backscattered electron imaging and wavelength-dispersive elemental mapping, with a JEOL JXA 8900R electron microprobe instrument at the USGS in Reston. This analysis showed no discernable compositional variation. Laser ablation ICP-MS spot analysis was then conducted at the USGS Central Minerals and Environmental Resources laser ablation ICP-MS facility in Denver (fig. 9). Pyrites were ablated using spot sizes of 25 micrometers $(\mu \mathrm{m})$ or $20 \mu \mathrm{m}$ as necessary, giving detection limits for $\mathrm{Hg}$ of $0.49 \mathrm{ppm}(490 \mathrm{ppb})$ and $0.74 \mathrm{ppm}(740 \mathrm{ppb})$, respectively. The larger spot sizes give better detection limits because more material is ablated, but the smaller spot size allows finer intergrowths to be determined (fig. 10). USGS synthetic sulfide standard MASS-1 (Wilson and others, 2002) was used as the primary calibration standard. MASS-1 is known to be homogeneous to a resolution of $20 \mu \mathrm{m}$.

Three distinct pyrite forms were observed. The bulk of the analyses are for complex composite grains that likely have a multistage history (fig. 10). In addition, framboidal pyrite and cleat pyrite were observed, typically the earliest and latest pyrite generations, respectively, in coal (Kolker, 2012). The number of cleat and framboidal pyrites analyzed was not sufficient to determine if these are compositionally distinct from the large composite grains. A total of 263 points on 21 pyrite grains was determined, including 163 determinations at $20 \mu \mathrm{m}$ and 100 at $25 \mu \mathrm{m}$. Results for $\mathrm{Hg}$ show a heterogeneous spatial distribution with typical values ranging from the detection limits to about 3 ppm $(3,000 \mathrm{ppb})$, with a few higher values (fig. 11). 


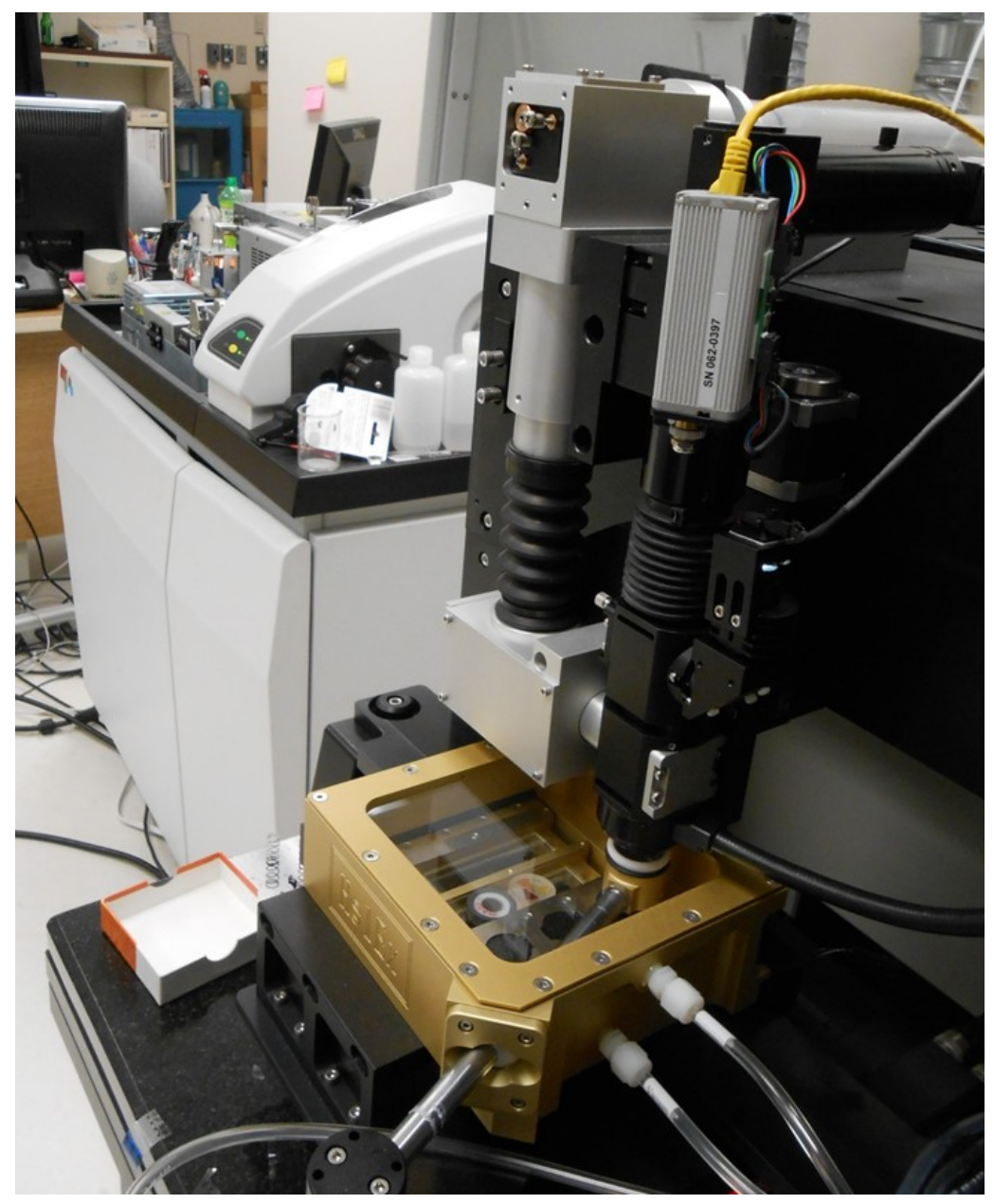

Figure 9. U.S. Geological Survey laser ablation (foreground) inductively coupled plasma-mass spectrometer (background) instrument.

In addition to $\mathrm{Hg}$, minor or trace elements detected in pyrite by laser ablation include $\mathrm{Mn}$, $\mathrm{Co}, \mathrm{Ni}, \mathrm{Cu}$ (copper), Zn, As, Se, Mo, Tl, Pb, and Bi (bismuth) (table 8). Detection limits for each spot size vary by element as do the proportion of analyses that exceed the detection limit. Mean concentrations were calculated for conditions where at least 50 percent of the analyses resulted in detection of an element, by substituting 55 percent of the detection limit for nondetects (Sanford and others, 1993). For each spot size, means were calculated for $\mathrm{As}, \mathrm{Mo}, \mathrm{Hg}, \mathrm{Tl}$, and $\mathrm{Pb}$ in pyrite (table 8). Element enrichment factors were determined for pyrite relative to whole-coal values obtained by averaging all eight separates (dry basis). Including data for both the 25- and 20micron-spot sizes, pyrite is enriched by factors of 20.3 to 33.2 (As), 13.5 to 17.4 (Mo), 3.9 to 8.4 $(\mathrm{Hg}), 29.5$ to $36.4(\mathrm{Tl})$, and 2.1 to $4.4(\mathrm{~Pb})$ relative to the respective calculated whole-coal values. Results for each element are consistent with variation seen in the bulk samples with progressive increases corresponding to an increase in the proportion of pyrite contained. For $\mathrm{Hg}$, the higher mean value for the 20 -micron data $(2.43 \mathrm{ppm})$ versus the 25 -micron results $(1.14$ $\mathrm{ppm}$ ) reflects heterogeneity of the sample populations and the fact that several (six) $10+-\mathrm{ppm} \mathrm{Hg}$ points are included in the 20 -micron mean. 


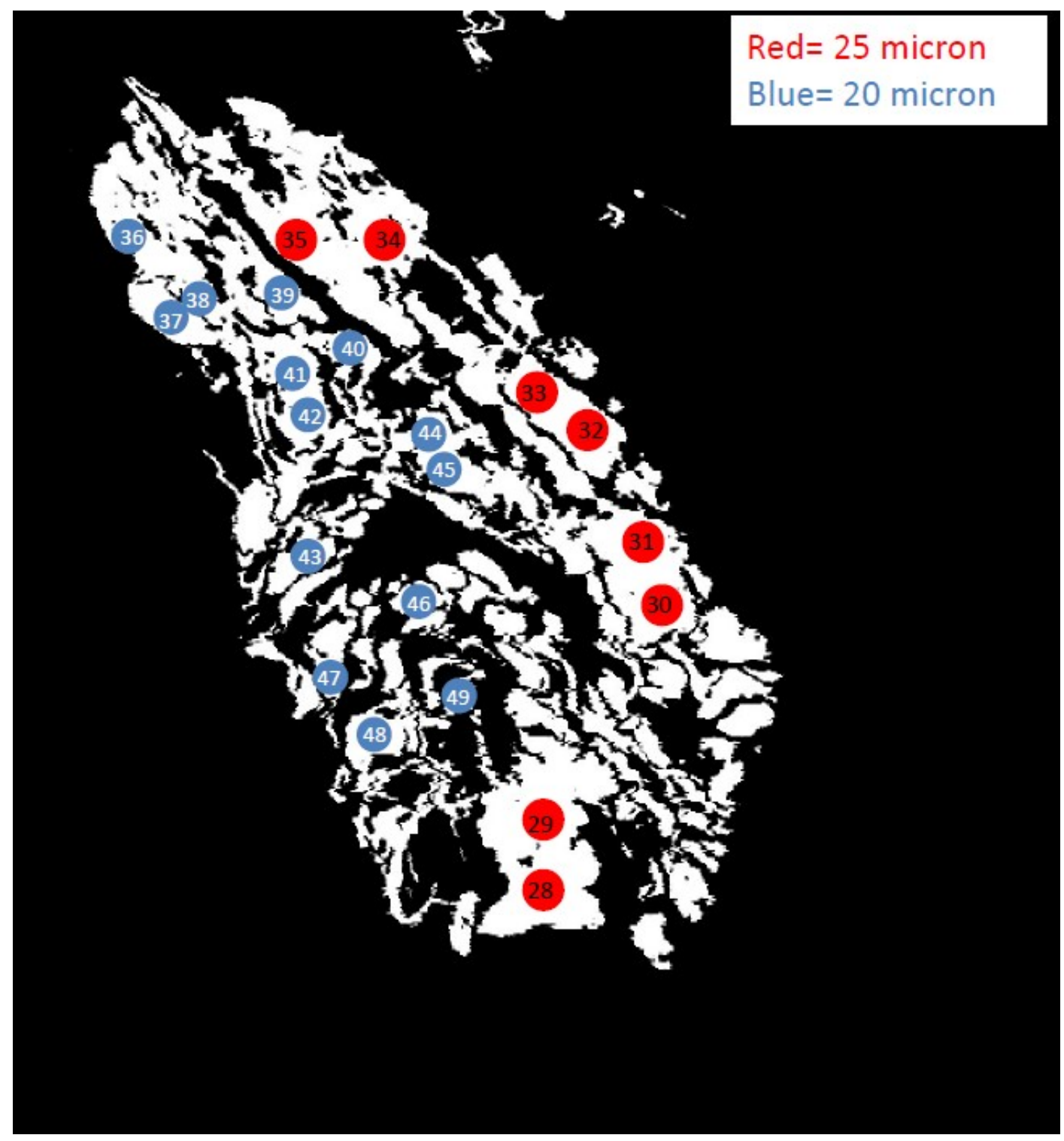

Figure 10. Backscattered electron image of composite pyrite in density separate sample 14F (1.9 float) from Highveld (\#4) coal showing laser ablation spot analysis points using 25-micrometer (red; micron) or 20 -micrometer (blue) laser diameter. Width of field of view is 600 micrometers. 


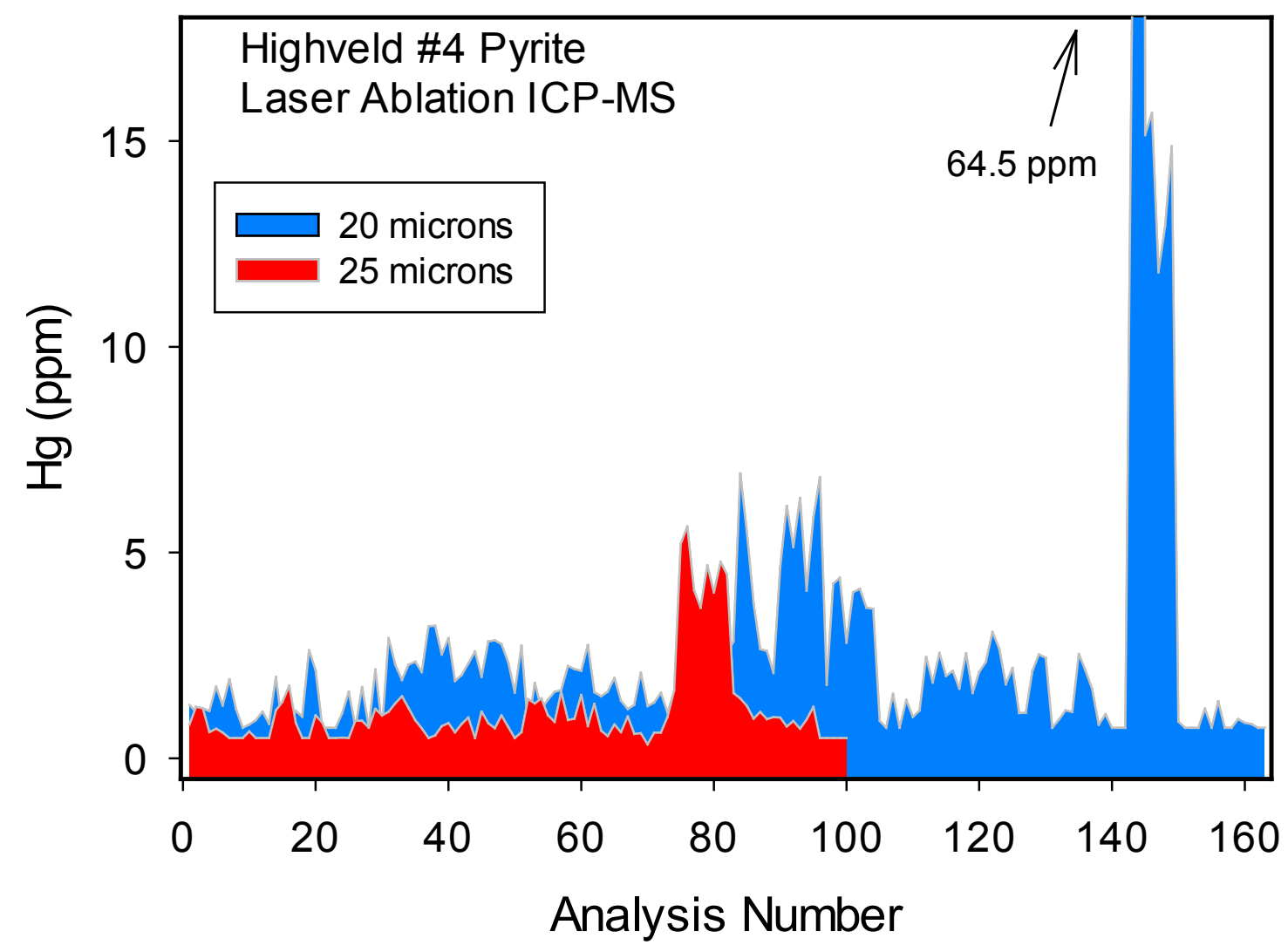

Figure 11. Laser ablation inductively coupled plasma-mass spectrometry (ICP-MS) spot analyses for mercury $(\mathrm{Hg})$ in pyrite from Highveld (\#4) coal density separates. Most analyses range from the detection limits to about 3 parts per million (ppm), but several points exceed $5 \mathrm{ppm}$ and one analysis exceeds $50 \mathrm{ppm}$. Nondetects are plotted at the respective detection limits- $0.49 \mathrm{ppm}$ for 25 -micron data and $0.74 \mathrm{ppm}$ for 20-micron data. These values are baselines for each plot.

Table 8. Laser ablation inductively coupled plasma-mass spectrometer analysis data showing detection limits; calculated mean values for arsenic (As), molybdenum (Mo), mercury (Hg), thallium (TI), and lead $(\mathrm{Pb})(>50$ percent [\%] detected); and element enrichment factors in pyrite relative to calculated whole coal.

[Mn, manganese; Co, cobalt; Ni, nickel; Se, selenium; ppm, parts per million; n, number of analyses; ---, not determined]

\begin{tabular}{|c|c|c|c|c|c|c|c|c|c|}
\hline & $\mathrm{Mn}$ & Co & $\mathrm{Ni}$ & As & Se & Mo & $\mathrm{Hg}$ & TI & $\mathrm{Pb}$ \\
\hline \multicolumn{10}{|c|}{ 20-micrometer spot $(n=163)$} \\
\hline Detection limit (ppm) & 25.2 & 11.6 & 365 & 40.1 & 20.2 & 15.0 & 0.74 & 1.13 & 2.39 \\
\hline Percent detects & $40 \%$ & $42 \%$ & $21 \%$ & $56 \%$ & $29 \%$ & $69 \%$ & $85 \%$ & $72 \%$ & $63 \%$ \\
\hline Mean (ppm) & --- & --- & --- & $66.4^{1}$ & --- & 45.3 & $2.43^{1}$ & 6.92 & $36.9^{1}$ \\
\hline Calculated whole coal ${ }^{2}$ & & & & 2.0 & & 2.6 & 0.29 & $0.19^{3}$ & 8.4 \\
\hline Enrichment factor & & & & 33.2 & & 17.4 & 8.4 & 36.3 & 4.4 \\
\hline
\end{tabular}


Table 8. Laser ablation inductively coupled plasma-mass spectrometer analysis data showing detection limits; calculated mean values for arsenic (As), molybdenum (Mo), mercury (Hg), thallium (TI), and lead $(\mathrm{Pb})$ (>50 percent [\%] detected); and element enrichment factors in pyrite relative to calculated whole coal.-Continued

\begin{tabular}{|c|c|c|c|c|c|c|c|c|c|}
\hline & $\mathrm{Mn}$ & Co & $\mathrm{Ni}$ & As & Se & Mo & $\mathrm{Hg}$ & $\mathrm{TI}$ & $\mathrm{Pb}$ \\
\hline \multicolumn{10}{|c|}{25 -micrometer spot $(n=100)$} \\
\hline Detection limit (ppm) & 16.4 & 8.8 & 37.1 & 15.3 & $163^{4}$ & 11.2 & 0.49 & 0.78 & 1.93 \\
\hline Percent detects & $47 \%$ & $28 \%$ & $23 \%$ & $72 \%$ & $9 \%$ & $75 \%$ & $80 \%$ & $68 \%$ & $73 \%$ \\
\hline Mean (ppm) & --- & --- & --- & 40.5 & --- & 35.1 & 1.14 & 5.60 & 17.8 \\
\hline Calculated whole coal ${ }^{2}$ & & & & 2.0 & & 2.6 & 0.29 & $0.19^{3}$ & 8.4 \\
\hline Enrichment factor & & & & 20.3 & & 13.5 & 3.9 & 29.5 & 2.1 \\
\hline
\end{tabular}

${ }^{1}$ Excludes one analysis with 983 ppm As, $64.5 \mathrm{ppm} \mathrm{Hg}$, and 6,319 ppm Pb.

${ }^{2}$ Whole-coal value estimated by averaging eight density separates as in table 7; values in ppm on a dry basis.

${ }^{3}$ Whole-coal value estimated for $\mathrm{Tl}$ includes one non-detect counted as 70 percent of the detection limit

${ }^{4}$ Detection limit for Se varies with instrument conditions and was better for 20-micrometer spot.

Other elements detected: copper, zinc, and bismuth.

\section{Supplemental Results for Duvha and Kendal Power Stations}

\subsection{Introduction}

The EPA measured $\mathrm{Hg}$ emissions from the stacks of the boilers at two power stations (Duvha and Kendal) in 2010 (Scott, 2011). The objective of the testing was to collect representative $\mathrm{Hg}$ emissions data so that emission factors could be derived from these sources. The Duvha power station was selected because three of the six boilers used fabric filters (FFs) and three used ESPs for particulate control. At the Kendal power station, all six boilers used ESPs for particulate control.

For the stack samples, sorbent trap methods based on EPA Method 30B were used. The sorbent traps contain a carbon that captures and retains the total gaseous $\mathrm{Hg}$ in the flue gas. Modifications of the basic Method 30B equipment and procedures can be made to measure gaseous-elemental and gas-oxidized $\mathrm{Hg}$ species separately. Method 30B is not designed to quantify particulate-bound $\mathrm{Hg}$ and, therefore, is suitable for measurement downstream of the PCD. The EPA sampling methodology is described in detail by Forte and others (2012).

\subsection{Solid Samples}

Two raw pulverization MFC samples and two fly ash samples were collected in one-time sampling from each of the six boiler units at Duvha and Kendal. A portion of these MFC samples was originally analyzed for $\mathrm{Hg}$ by the EPA (appendix 1). Splits of the samples were obtained in the present study. The concentrations of $\mathrm{Hg}$ in these samples were determined in the USGS Reston laboratory, while the concentrations of halogens in the coal samples were determined by the same USGS contract laboratory, using the same ASTM procedures, as the group of 50 feed coals and density separates provided by Eskom. Table 9 gives the concentrations of $\mathrm{Hg}$ in the coal and ash samples. Good agreement was obtained between USGS analyses and the original EPA analysis, as discussed in appendix 1.

The MFC coal Hg content of the Kendal samples was $249 \pm 81$ ppb (on a dry basis) and the average of the Duvha samples was $207 \pm 55 \mathrm{ppb}$ (on a dry basis). These $\mathrm{Hg}$ values are consistent with those of pulverized boiler feed coal samples received from Eskom for the 
respective plants, which ranged from 190 to $224 \mathrm{ppb}$ for Kendal and 184 to $216 \mathrm{ppb}$ for Duvha (dry basis). Some difference in Hg contents between Kendal and Duvha stations might be expected due to differences in the coal milling process at each station. At Duvha, pyrite is rejected in the milling process whereas at Kendal it is not. However, this difference is not apparent in the present sampling. Mill input coal for units 5 and 6 at Kendal has somewhat elevated $\mathrm{Hg}$ contents (349 to $362 \mathrm{ppb}$, dry basis) but this is not reflected in the ash. Figure 12 displays the MFC coal and fly ash $\mathrm{Hg}$ concentrations as a function of unit number for both plants. Duvha units 4-6 and all the Kendal units have ESPs, while Duvha units 1-3 have FFs (section 4.4).

Chlorine contents of the 24 Duvha and Kendal MFC samples collected in 2010 are shown in figure 13, in comparison with 7 samples from the group of 42 new pulverized feed coal samples provided by Eskom, including 3A to 3C (Duvha) and 6A to 6D (Kendal; table 6). For both groups of samples, results confirm $\mathrm{Cl}$ levels are low; in some cases just above the detection limit of $100 \mathrm{ppm}$, and in most cases below the detection limit. These contents do little to promote $\mathrm{Hg}$ self-capture, as discussed in the following sections.

Table 9. Mercury analysis, 2010 samples, Duvha and Kendal power stations (parts per billion [ppb]), on a dry basis for coal and an as-determined basis for fly ash) analyzed in USGS Reston laboratories. Coal samples are adjusted to a dry basis using moisture determinations from USGS contract laboratory.

\begin{tabular}{lccccccc}
\hline $\begin{array}{c}\text { Power } \\
\text { Station }\end{array}$ & Unit & Sample & Material & $\begin{array}{c}\text { Hg } \\
\text { concentration } \\
{[\mathrm{ppb}]}\end{array}$ & Sample & Material & $\begin{array}{c}\text { Hg } \\
\text { concentration } \\
{[\mathbf{p p b}]}\end{array}$ \\
\hline Kendal & 1 & KFC-1A & Coal & 189 & KFA-1A & Fly ash & 89.3 \\
Kendal & 1 & KFC-1B & Coal & 168 & KFA-1B & Fly ash & 88.3 \\
Kendal & 2 & KFC-2A & Coal & 197 & KFA-2A & Fly ash & 80.5 \\
Kendal & 2 & KFC-2B & Coal & 251 & KFA-2B & Fly ash & 103 \\
Kendal & 3 & KFC-3A & Coal & 199 & KFA-3A & Fly ash & 57.9 \\
Kendal & 3 & KFC-3B & Coal & 205 & KFA-3B & Fly ash & 53.9 \\
Kendal & 4 & KFC-4A & Coal & 188 & KFA-4A & Fly ash & 146 \\
Kendal & 4 & KFC-4B & Coal & 173 & KFA-4B & Fly ash & 157 \\
Kendal & 5 & KFC-5A & Coal & 350 & KFA-5A & Fly ash & 84.9 \\
Kendal & 5 & KFC-5B & Coal & 362 & KFA-5B & Fly ash & 77.3 \\
Kendal & 6 & KFC-6A & Coal & 360 & KFA-6A & Fly ash & 30.1 \\
Kendal & 6 & KFC-6B & Coal & 349 & KFA-6B & Fly ash & 35.2 \\
Duvha & 1 & DFC-1A & Coal & 151 & DFA-1A & Fly ash & 152 \\
Duvha & 1 & DFC-1B & Coal & 137 & DFA-1B & Fly ash & 203 \\
Duvha & 2 & DFC-2A & Coal & 177 & DFA-2A & Fly ash & 615 \\
Duvha & 2 & DFC-2B & Coal & 176 & DFA-2B & Fly ash & 641 \\
Duvha & 3 & DFC-3A & Coal & 158 & DFA-3A & Fly ash & 687 \\
Duvha & 3 & DFC-3B & Coal & 166 & DFA-3B & Fly ash & 678 \\
Duvha & 4 & DFC-4A & Coal & 261 & DFA-4A & Fly ash & 126 \\
Duvha & 4 & DFC-4B & Coal & 306 & DFA-4B & Fly ash & 130 \\
Duvha & 5 & DFC-5A & Coal & 204 & DFA-5A & Fly ash & 208 \\
Duvha & 5 & DFC-5B & Coal & 219 & DFA-5B & Fly ash & 215 \\
Duvha & 6 & DFC-6A & Coal & 279 & DFA-6A & Fly ash & 180 \\
Duvha & 6 & DFC-6B & Coal & 247 & DFA-6B & Fly ash & 200 \\
\hline
\end{tabular}



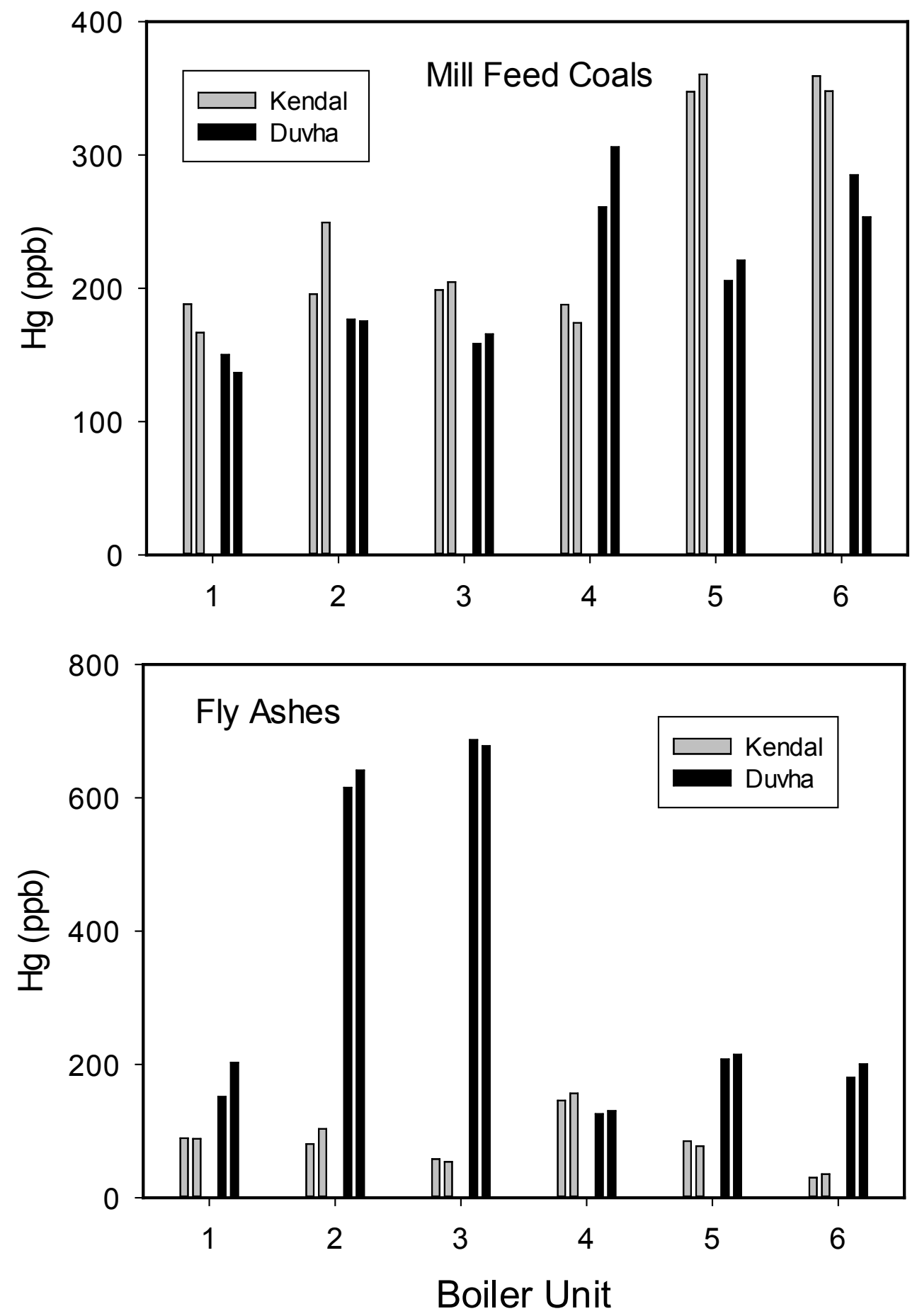

Figure 12. Mercury data (in parts per billion [ppb on a dry basis]) for duplicate mill feed coal (upper plot) and fly ash (lower plot; ppb on an as-determined basis) samples collected from Duvha and Kendal power stations in previous United Nations Environment Programme-sponsored sampling. Duvha units 1-3 are equipped with fabric filters; all other units have electrostatic precipitators. Samples are courtesy of the U.S. Environmental Protection Agency. 


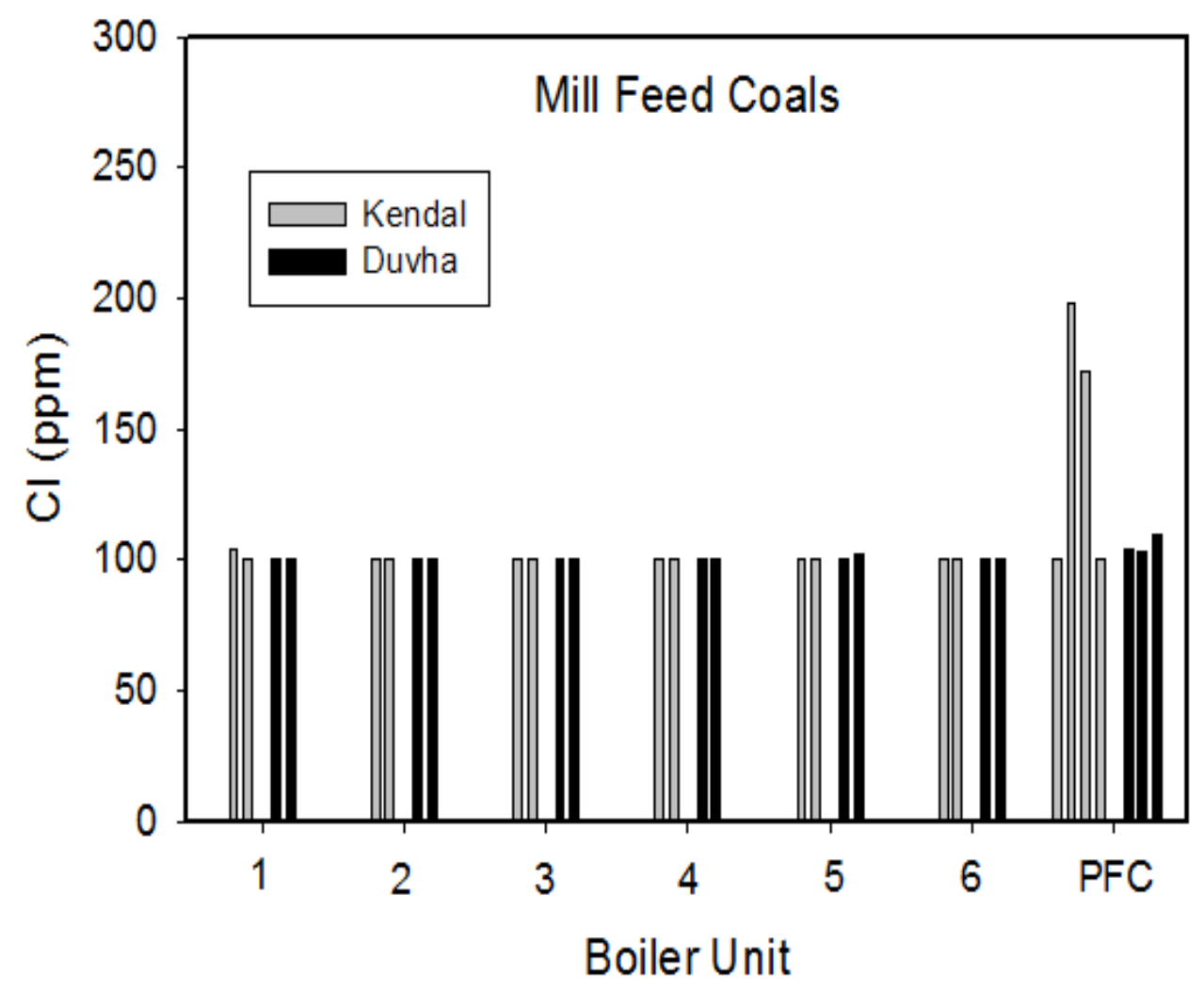

Figure 13. Chlorine $(\mathrm{Cl})$ data by boiler for raw mill feed coal samples from Duvha and Kendal power stations collected in 2010 U.S. Environmental Protection Agency-South African Department of Environmental Affairs sampling (boilers 1-6) and $\mathrm{Cl}$ data for samples $6 \mathrm{~A}-\mathrm{D}$ (Kendal) and $3 \mathrm{~A}-\mathrm{C}$ (Duvha) from the group of 42 pulverized feed coal (PFC) samples provided by Eskom in the present study. $\mathrm{Cl}$ is expressed on a whole-coal dry basis. Results show that for most samples, $\mathrm{Cl}$ content is at or below the detection limit of 100 parts per million (ppm). Samples having $\mathrm{Cl}$ contents below detection are plotted at the detection limit (100 ppm). Results confirm that feed coals used in these power stations have low $\mathrm{Cl}$ contents and, therefore, do little to promote $\mathrm{Hg}$ self-capture by air pollution control devices. 


\subsection{Emission and Speciation Data}

Table 10 reproduces the reported data from Duvha and Kendal power stations on the $\mathrm{Hg}$ concentrations in the stack gas, as well as the fraction of $\mathrm{Hg}$ that was in the oxidized form.

Differences between the Duvha units with FFs and ESPs are apparent. Stack emissions are lower on the units with FFs; a correspondingly high concentration of $\mathrm{Hg}$ is present in the fly ash from the FF units (fig. 12). As discussed below, FFs generally exhibit higher efficiency for $\mathrm{Hg}$ capture than ESPs, which is borne out by the Duvha results. There is also more oxidized Hg at the stack in the Duvha units with FFs compared to the units with ESPs. The results from Kendal, which has ESPs on all six units, are similar to the results from the ESP units at Duvha.

Table 10. Mercury stack concentrations and speciation, Duvha and Kendal power stations. ${ }^{1}$

[Hg, mercury; $\mu \mathrm{g} / \mathrm{m}^{3}$, micrograms per cubic meter; \%, percent; $\mathrm{O}_{2}$, dioxygen]

\begin{tabular}{lccc}
\hline Power station & Unit number & $\begin{array}{c}\text { Average } \mathrm{Hg}, \boldsymbol{\mu g} / \mathbf{m}^{3} @ \\
\mathbf{3} \% \mathrm{O}_{\mathbf{2}}\end{array}$ & $\begin{array}{c}\text { Fraction of oxidized } \\
\mathbf{H g}\left(\% \mathbf{~ H g}^{2+}\right)\end{array}$ \\
\hline Duvha & 1 & 13.81 & $89 \%$ \\
& 2 & 4.65 & $73 \%$ \\
& 3 & 4.09 & $88 \%$ \\
& 4 & 35.49 & $56 \%$ \\
& 5 & 29.01 & $54 \%$ \\
Kendal & 6 & 40.37 & $55 \%$ \\
& 1 & 39.20 & $70 \%$ \\
& 2 & 43.45 & $54 \%$ \\
& 3 & 49.13 & $52 \%$ \\
& 4 & 46.03 & $52 \%$ \\
& 5 & 39.47 & $48 \%$ \\
& 6 & 46.34 & $54 \%$ \\
\hline
\end{tabular}

${ }^{1}$ Source: Scott, 2011. 


\subsection{Mass Balance Calculations}

The fractions of $\mathrm{Hg}$ removed in the PCDs at Duvha and Kendal were estimated from the concentrations of $\mathrm{Hg}$ in the coal and fly ash. For these estimates, it was assumed that: (1) $\mathrm{Hg}$ in the MFC is representative of the PFC; (2) the ash content of the coal is the average of the Eskom PFC samples; and (3) the carryover of fly ash from the boiler is 80 percent, a typical proportion. Figures 14 and 15 show the estimated $\mathrm{Hg}$ collection efficiency of the PCDs at Duvha and Kendal, respectively. The Hg collection efficiency for the ESPs at Kendal ranged from 2 to 22 percent (10 percent average). The average $\mathrm{Hg}$ collection efficiency for the boilers with ESPs at Duvha was 17 percent, while the average $\mathrm{Hg}$ collection efficiency for the boilers with FFs was 72 percent.

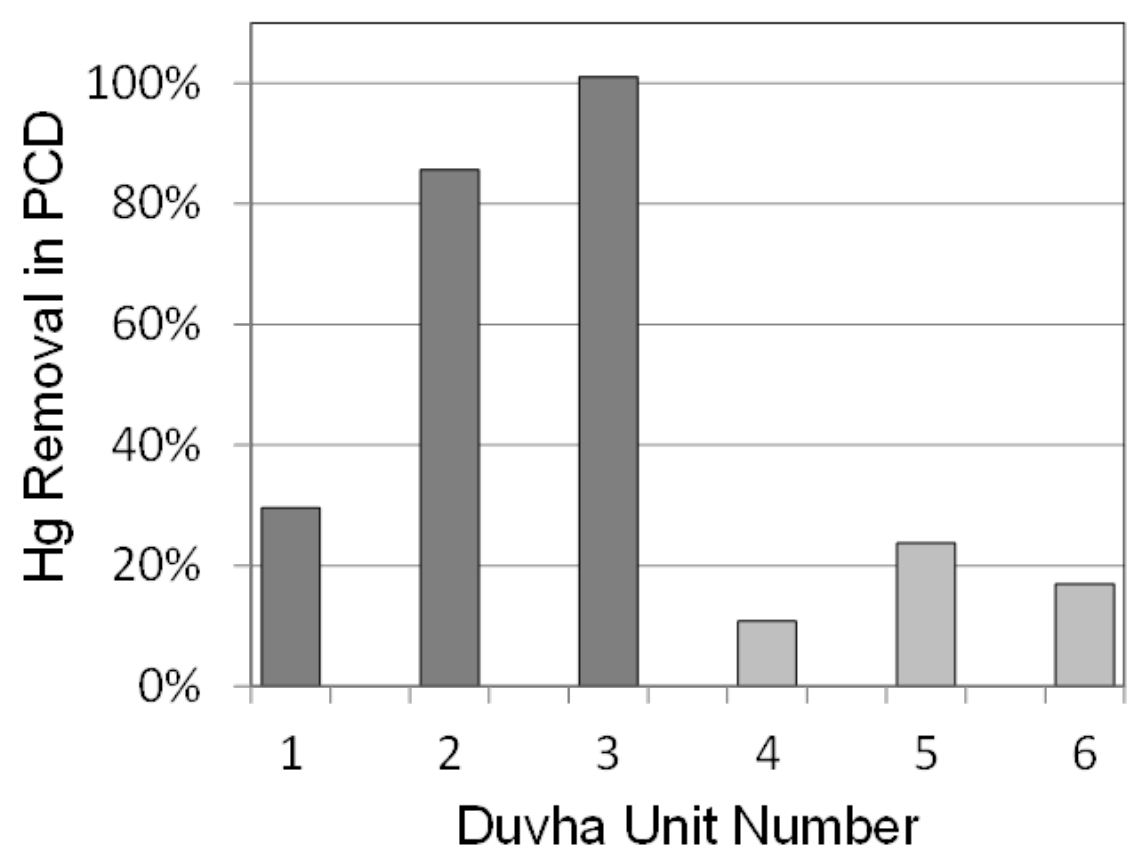

Figure 14. Estimated mercury $(\mathrm{Hg})$ removal across particulate control devices (PCDs) at Duvha power station. Duvha units 1-3 are equipped with fabric filters; all other units have electrostatic precipitators. 


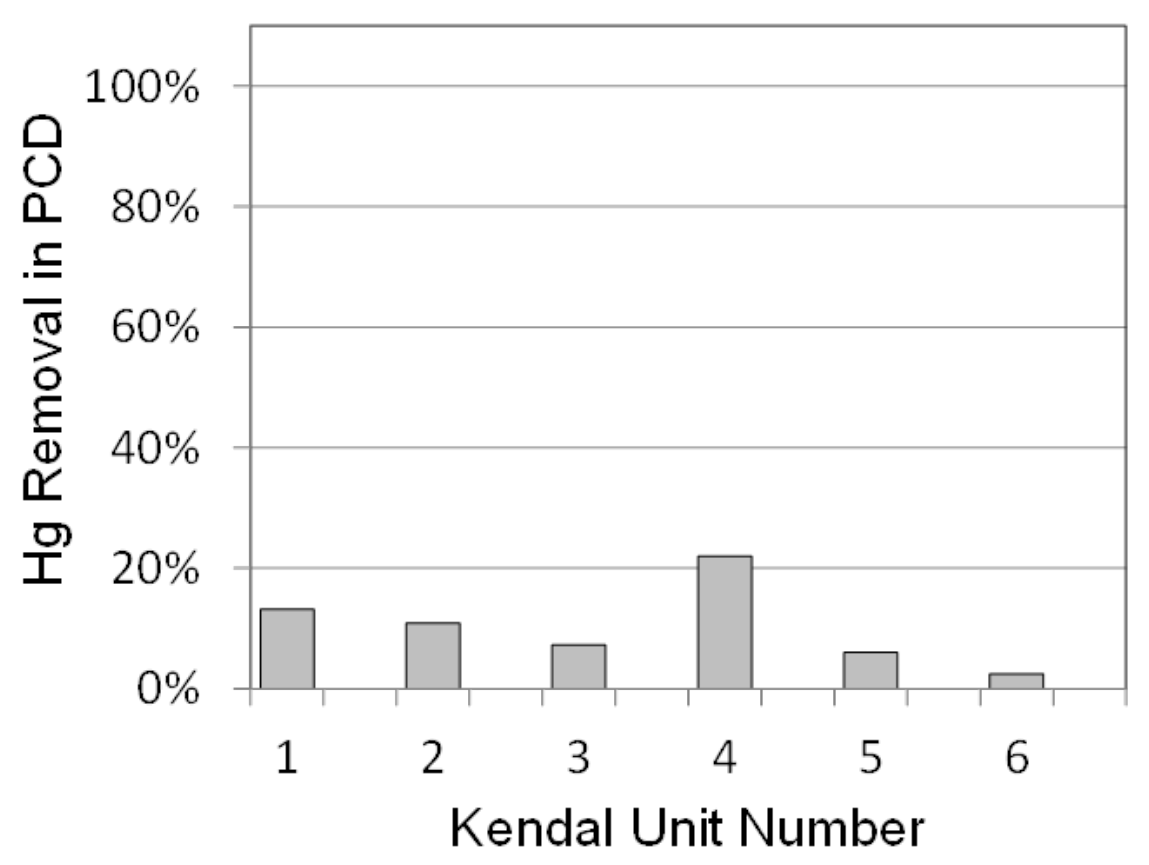

Figure 15. Estimated mercury $(\mathrm{Hg})$ removal across particulate control devices (PCDs) at Kendal power station. All units have electrostatic precipitators.

\subsection{Comparison with Previous Results}

There are clear differences between units with FFs and units with ESPs in terms of $\mathrm{Hg}$ capture in the PCDs, $\mathrm{Hg}$ stack emissions, and the speciation of emitted Hg. The factors that affect $\mathrm{Hg}$ speciation and emission are discussed in more detail in the next section. A preliminary comparison of the Duvha and Kendal results with other coal-fired boilers will be made here, and subsequently discussed in more detail.

In 1999, the EPA Information Collection Request (ICR) collected data from 83 coal-fired power plants in the United States, consisting of coal samples and speciated $\mathrm{Hg}$ measurements at the stack and upstream of the last APCD (Kilgroe and others, 2002). Using these data, one can calculate the fraction of oxidized $\mathrm{Hg}$ at the outlet and the removal efficiency of $\mathrm{Hg}$ for PCDs.

The $\mathrm{Cl}$ content of the coal is one of the primary indicators for $\mathrm{Hg}$ behavior and fate in coal-fired boilers. The speciation of $\mathrm{Hg}$ after the PCD is shown as a function of coal $\mathrm{Cl}$ content in figure 16. Individual data points are from the 1999 ICR, while the bars indicate the range of data from Duvha and Kendal. Generally, the fraction of oxidized $\mathrm{Hg}$ is higher downstream of FFs than ESPs and is a function of the coal $\mathrm{Cl}$ content. The fraction of oxidized $\mathrm{Hg}$ at the outlet of the Duvha units with FFs is consistent with the ICR data. Most of the data from the ESP units fall in the range of 40-55-percent $\mathrm{Hg}^{2+}$, which is consistent with ICR data; the exception is one data point (70-percent $\mathrm{Hg}^{2+}$ ) from the Kendal power station, which is higher than most of the other ESP data.

Mercury removal (fig. 17) across ESPs is generally low for coals with $\mathrm{Cl}$ contents of 100 to $200 \mathrm{ppm}$, and the $\mathrm{Hg}$ removals estimated for the Duvha and Kendal units with ESPs fall in line with the 1999 ICR data. Removal of Hg across FFs is higher than removal across ESPs, as 
can be seen in the figure. The range of estimated $\mathrm{Hg}$ removal across the FFs of the Duhva units is large, but consistent with the 1999 ICR data range.

\section{Discussion}

\subsection{Potential for Mercury Capture in Coal-fired Power Plants with Conventional Controls}

There are only two pathways by which $\mathrm{Hg}$ can be removed from coal-fired boilers: collection of $\mathrm{Hg}$ that has been adsorbed on surfaces (for example, fly ash and sorbents) and absorption of oxidized gaseous $\mathrm{Hg}$ species in aqueous media (for example, FGD, not employed by Eskom). Additionally, factors that influence the capacity for a PCD to remove Hg include: (1) type of PCD, (2) chlorine content of coal, (3) concentration of unburned carbon in fly ash, (4) temperature of $\mathrm{PCD}$, and (5) concentration of sulfuric acid (as $\left.\mathrm{SO}_{3}\right)$ in the flue gas.

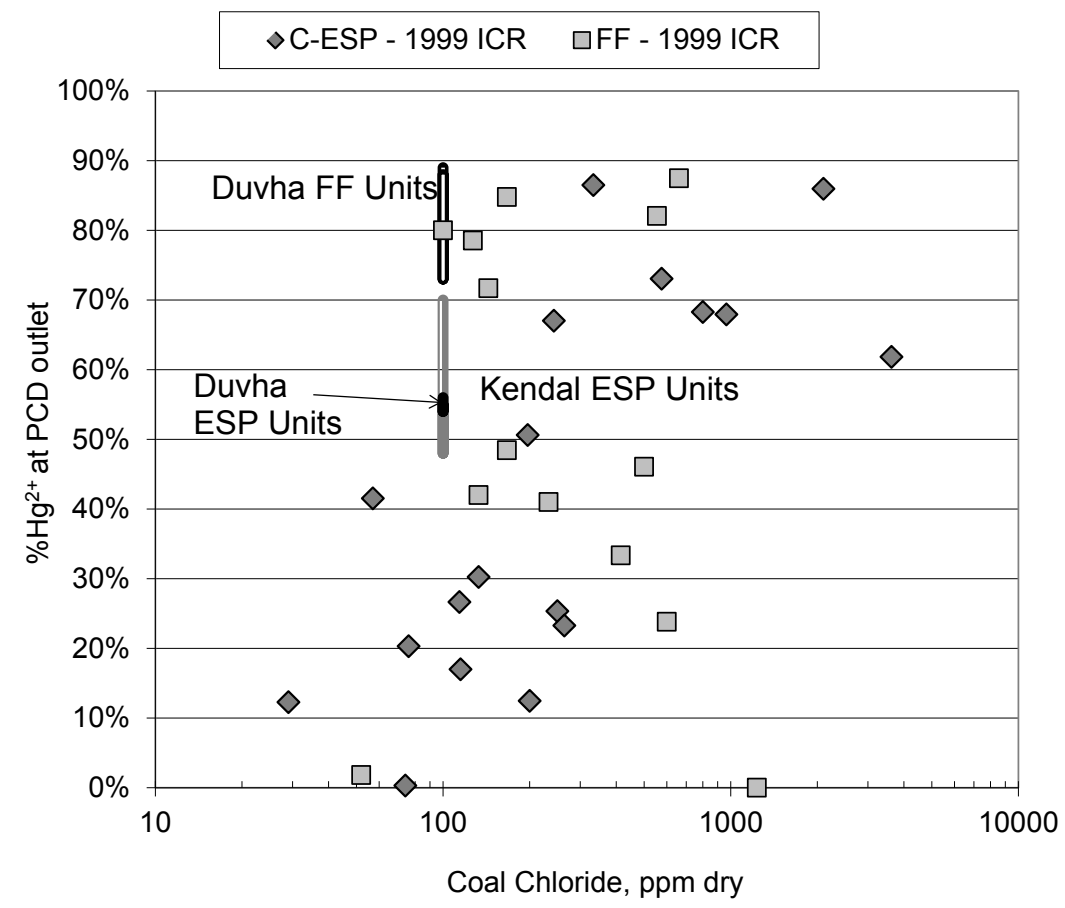

Figure 16. Fraction of oxidized mercury $\left(\mathrm{Hg}^{2+}\right)$ at the particulate control device (PCD) outlet as a function of coal chlorine content (in parts per million [ppm]): comparison of data from Duvha (fabric filter [FF] and cold-site electrostatic precipitator [C-ESP] units) and Kendal power stations with EPA 1999 Information Collection Request (ICR) data.

Oxidation of the elemental $\mathrm{Hg}$ that is present in the flame zone is the key step in the transformation of $\mathrm{Hg}$ into forms that can adsorb and (or) absorb in downstream air pollution control equipment. Gaseous elemental $\mathrm{Hg}$ is oxidized by $\mathrm{Cl}$ radicals in the flue gas at temperatures between $300{ }^{\circ} \mathrm{C}$ and $700{ }^{\circ} \mathrm{C}$, which corresponds to the boiler region from the economizer inlet to the air heater inlet. Gas-phase oxidation cannot explain the amount of gaseous oxidized Hg observed in coal-fired boilers. Heterogeneous oxidation (that is, catalyzed by surfaces) is responsible for the formation of most of the gaseous-oxidized $\mathrm{Hg}$ by $\mathrm{Cl}$ species. 
Significant oxidation of $\mathrm{Hg}$ takes place in the air preheater, and this might be catalyzed by fly ash and (or) the heat exchange surface.

Mercury adsorption on carbon surfaces is used in many applications to capture Hg both from gas and liquid media. In a coal-fired power plant, the fly ash often contains unburned carbon from less-than-complete combustion of the coal, and this unburned carbon can adsorb $\mathrm{Hg}$. The unburned carbon content of the fly ash is often correlated with the removal of $\mathrm{Hg}$ across ESPs (Senior and Johnson, 2005) and FFs (La Marca, and others, 2006). The temperature of the flue gas at the PCD also affects capture of $\mathrm{Hg}$ by fly ash particles and the subsequent removal in the PCD.

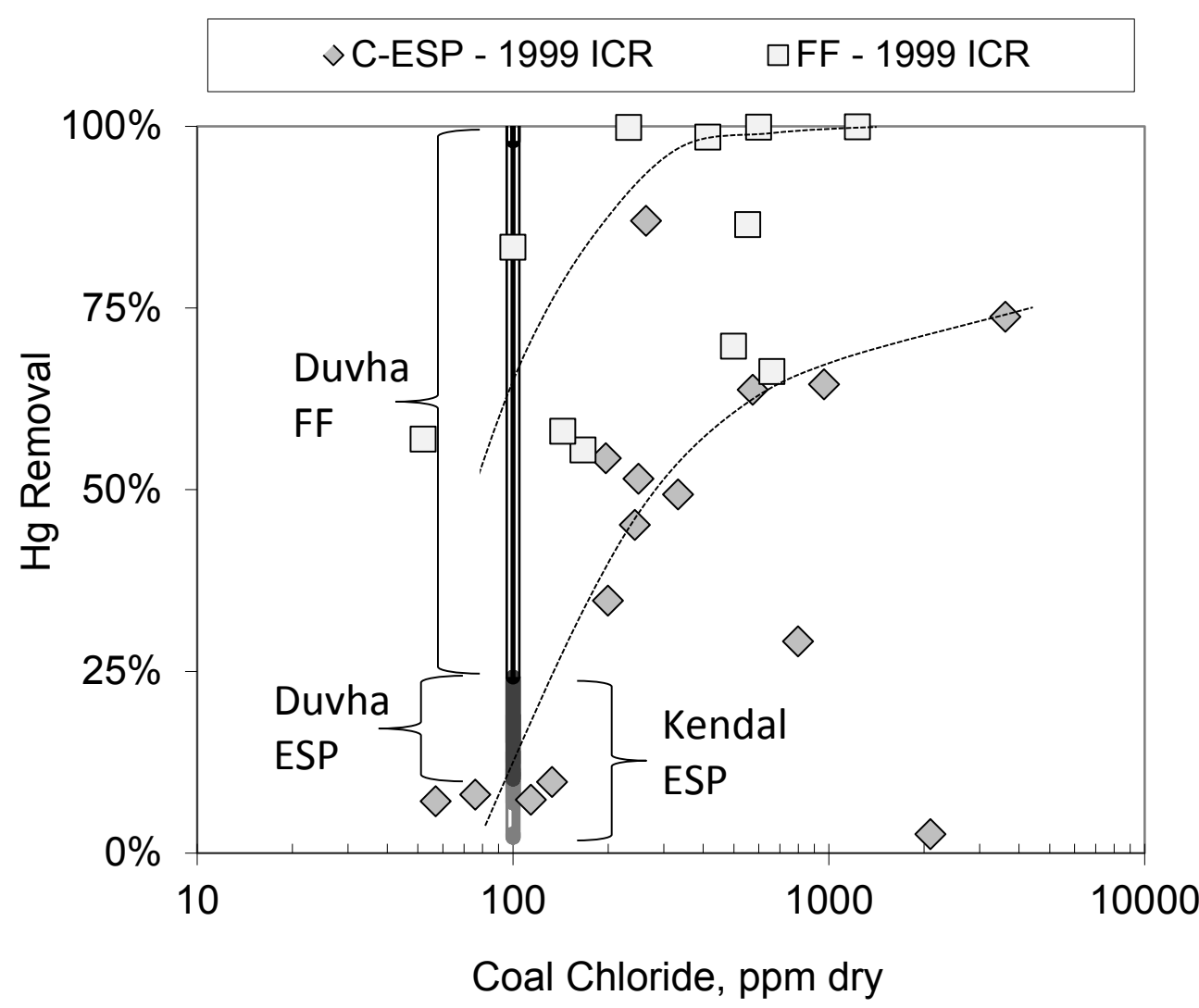

Figure 17. Removal of mercury $(\mathrm{Hg})$ across the particulate control device outlet as a function of coal chlorine content (in parts per million [ppm]): comparison of data from Duvha (fabric filter [FF] and cold side electrostatic precipitator [C-ESP] units) and Kendal power stations with EPA 1999 Information Collection Request (ICR) data.

Certain other constituents in flue gas have negative impacts on the ability of either unburned carbon in fly ash or powdered activated carbon (PAC) to remove $\mathrm{Hg}$. (PAC can be added to the flue gas to enhance $\mathrm{Hg}$ removal.) Sulfuric acid vapor $\left(\mathrm{SO}_{3}\right.$ or $\left.\mathrm{H}_{2} \mathrm{SO}_{4}\right)$ in particular can reduce the effectiveness of carbon surfaces to adsorb Hg. An example of this (pilot-scale testing reported by Pollack, 2009) is shown in figure 18. The test results shown in the figure are from activated carbon injection, but a similar effect would be expected with unburned carbon in 
ash. That is, an increase in $\mathrm{SO}_{3}$ in the flue gas upstream of the PCD would have the effect of reducing the adsorption of $\mathrm{Hg}$ by unburned carbon in ash.

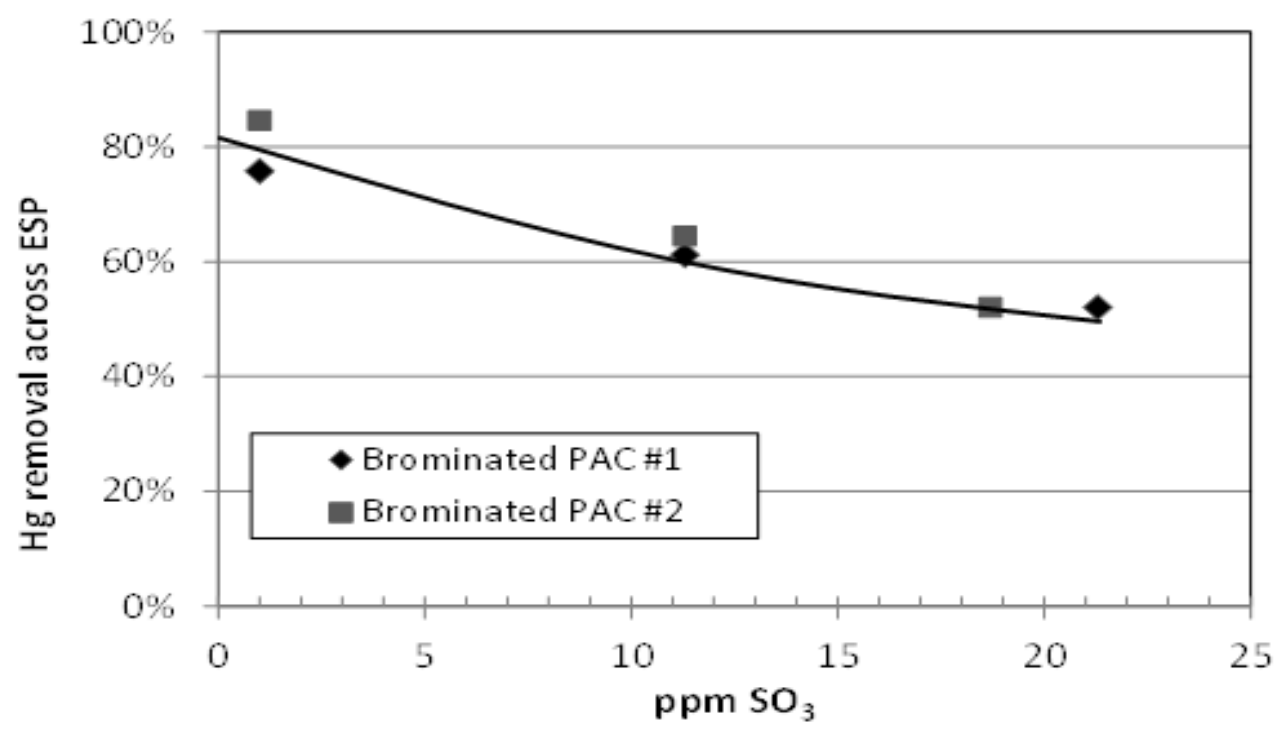

Figure 18. Effect of sulfuric acid vapor $\left(\mathrm{SO}_{3}\right.$; in parts per million [ppm]) addition on performance of brominated activated carbon (PAC) for mercury $(\mathrm{Hg})$ removal across electrostatic precipitator $(\mathrm{ESP})$. Figure shows results from injection of $160 \mathrm{mg} / \mathrm{m}^{3}$ PAC upstream of the air preheater (APH) at the pilot combustor. Temperature at the APH inlet is $150^{\circ} \mathrm{C}$. Test assumes a baseline $\mathrm{SO}_{3}$ concentration of $1 \mathrm{ppm}$ (Source: Pollack, 2009)

Halogen compounds have long been identified as the most important species for oxidizing $\mathrm{Hg}$ in coal combustion systems. Chlorine is the most abundant halogen in coal. Coal $\mathrm{Cl}$ content had a strong influence on the oxidation state of $\mathrm{Hg}$ in the flue gas, as well as on the removal of $\mathrm{Hg}$ in certain APCDs (as previously illustrated in figs. 16 and 17). The longer contact time between ash particles and Hg-containing flue gas in a FF, as compared to an ESP, means that the removal of $\mathrm{Hg}$ by FFs is almost always higher than removal by ESPs.

Some of the scatter in the data may be due to the other factors discussed: level of unburned carbon in the ash, temperature at the $\mathrm{PCD}$, and concentration of $\mathrm{SO}_{3}$ in the flue gas. The units at Duvha with FFs, units 1-3, do not have uniformly high levels of $\mathrm{Hg}$ removal. Unit 1 has a much lower $\mathrm{Hg}$ removal than unit 2 or unit 3 . This is corroborated by the higher gaseous $\mathrm{Hg}$ emission from unit 1 as compared to units 2 and 3 . This is mostly likely due to a combination of two factors: the level of unburned carbon in the fly ash and the temperature of the FF. Neither of these parameters was reported in the 2010 sampling. Coal-fired boilers that are nominally "identical" can exhibit differences in combustion efficiency, which can be manifested as different amounts of unburned carbon in the fly ash. Differences in heat transfer between boilers can result in differences in gas temperatures at the APCDs (Senior, 2015).

Hg removal across ESPs at the different units at Duvha or Kendal also shows considerable variation, from about 2 percent removal to about 22 percent removal. The factors that are likely responsible are unburned carbon in fly ash, ESP temperature, and the concentration of $\mathrm{SO}_{3}$, which is added to the flue gas as a conditioning agent to improve the collection of ash in the ESP. None of these parameters are known for the sampling campaigns at Duvha and Kendal. 


\subsection{Potential for Improving Mercury Capture of Eskom Fleet}

\subsubsection{Coal Selection and Coal Washing}

Combined results from laser ablation ICP-MS of pyrite and bulk analysis of density separates for a Highveld (\#4) coal indicate that reduction of $\mathrm{Hg}$ and As by coal washing of \#4 coal should be straightforward, as both elements reside almost exclusively in pyrite. The extent to which coal washing is effective in reducing pyrite contents should be reflected in the reduction of these elements. Other elements of environmental concern, such as $\mathrm{Mn}, \mathrm{Cr}, \mathrm{Co}, \mathrm{Ni}$, and $\mathrm{Pb}$, while present in pyrite at measurable levels, likely have competing modes of occurrence in the Highveld \#4 coal that make it difficult to predict the extent of their reduction upon coal washing without further investigation. The low overall As content in Highveld coals is explained by relatively low concentrations of As in pyrite, approximately $50 \mathrm{ppm}$ on average. Arsenic is the most abundant minor constituent in iron disulfides in coal, reaching percent levels in some cases, and in many cases measurable with electron beam instruments having detection limits that are poorer than laser ablation ICP-MS used in the present study (Kolker, 2012). Analysis of density separates of South African Highveld (\#4) coal indicate that $\mathrm{Hg}$ input to the boiler can be reduced by discarding the stone fraction as is practiced by Eskom. To the extent possible, retention of as much of the low-ash fraction as is practical will also reduce $\mathrm{Hg}$ input to the boiler, and would potentially have co-benefits in efficiency of operation.

\subsubsection{Optimization of Equipment and Operational Parameters}

In order to decrease emissions of $\mathrm{Hg}$ from a coal-fired boiler (for a given level of $\mathrm{Hg}$ input), both equipment and operational changes can be considered. As noted above, $\mathrm{Hg}$ is removed by adsorption on solids and the subsequent collection of those solids in a PCD or by absorption of $\mathrm{Hg}$ in a FGD scrubber. To increase Hg removal in the Eskom fleet, several approaches are available.

Optimizing operating conditions. Mercury can be adsorbed on the unburned carbon in fly ash. Certain operational changes in the boiler can increase the adsorption of $\mathrm{Hg}$ by the fly ash; these include lowering the air preheater exit temperature, minimizing the concentration of $\mathrm{SO}_{3} / \mathrm{H}_{2} \mathrm{SO}_{4}$ in the flue gas, and increasing the amount of unburned carbon in the ash. As commercial reuse of fly ash in South Africa is extremely limited, increasing its carbon content would not impact ash marketing for beneficial use. Lowering the air-preheater exit temperature will also have a slight positive effect on the boiler efficiency, whereas increasing unburned carbon in fly ash will have a slight negative effect on boiler efficiency, and these effects may offset one another. The presence of $\mathrm{SO}_{3}$ in the flue gas is beneficial to the operation of an ESP.

Addition of FFs. Changes in air pollution control equipment can improve Hg capture. FFs are generally more efficient at removing Hg than ESPs, as demonstrated in Section 4. The ESP can be replaced by a FF, either by installing a FF within the existing ESP casing or by bypassing the existing ESP and installing a separate FF unit.

Use of sorbents. The addition of reagents and (or) sorbents can improve $\mathrm{Hg}$ capture in existing APCDs. For low-Cl coals, such as those from South Africa, the addition of halogens $(\mathrm{Cl}$ and $\mathrm{Br}$, primarily) to the fuel or the boiler will increase the removal of $\mathrm{Hg}$. The equipment for halogen addition is relatively inexpensive, but there will be additional operating costs because of the cost of the halogen compound. Powdered sorbents (for example, activated carbon) can be injected into the flue gas upstream of the PCD to capture additional Hg. The cost of equipment required to inject powdered sorbents is higher than that of a halogen addition system, but it is 
still relatively low. Operating costs will increase, due to the cost of the sorbent, and the increase in operating costs can be significant, depending on the sorbent requirements. Less sorbent will be required if the unit has a FF instead of an ESP. Alternatively, a dedicated FF can be installed downstream of an existing ESP. A Hg control sorbent can be injected into the FF in this arrangement, known as a TOXECON FF (Granite and others, 2015; and references therein). Because the fly ash is almost entirely collected in the ESP, the TOXECON FF can be much smaller (less capital cost) than a FF that is designed to remove fly ash and sorbent.

Addition of FGD. Eskom's current fleet of coal-fired boilers has PCDs, but does not have FGD scrubbers. If FGD scrubbers were installed, they should be able to remove gaseousoxidized $\mathrm{Hg}$ with an efficiency of 90 percent or higher. At Duvha and Kendal, gaseous-oxidized $\mathrm{Hg}$ amounted to about 50 percent at the exit of the ESPs and 70 to 90 percent at the exit of the FFs. Higher levels of $\mathrm{Hg}$ oxidation in the flue gas, particularly on units with ESPs, can be achieved through the addition of halogens to the fuel or boiler. The capital cost of adding a FGD scrubber is higher than that of adding a FF or a sorbent injection system and is probably too high to be justified on the grounds of $\mathrm{Hg}$ removal alone. However, if future regulations require reductions in the emissions of $\mathrm{SO}_{2}$ and FGDs are installed to meet these standards, there will be additional reduction in $\mathrm{Hg}$ emissions.

\section{Conclusions}

Results for feed coals provided for this study by Eskom show input $\mathrm{Hg}$ concentrations that are similar to or slightly less than those in previous results. Input $\mathrm{Hg}$ for the Camden, Grootvlei, and Komati stations returned to service since the previous sampling show that input $\mathrm{Hg}$ for these stations is similar to the range obtained for other Eskom power stations. Results for the Matimba power station burning Waterberg coals show that coal washing currently in use is effective in reducing $\mathrm{Hg}$ levels to the range of those of other Eskom power stations. This finding is promising for supplying the future Medupi power station that will also use Waterberg coals and require a similar approach. Chlorine contents of South African coals are generally low. As such, the extent of $\mathrm{Hg}$ self-capture by PCDs is relatively limited.

Results for density separates of a Highveld (\#4) coal are useful in predicting $\mathrm{Hg}$ variation in coal products used in or exported from South Africa. Results for these separates show a strong mineralogical association of $\mathrm{Hg}$ (and As) with pyrite. Reduction of pyrite by coal washing is very likely to result in reduced $\mathrm{Hg}$ contents, as well as lowering $\mathrm{S}$ emissions. To the extent possible, retention of a greater portion of the low-ash fraction would also reduce $\mathrm{Hg}$ input to the boiler and potentially have co-benefits in efficiency of operation. Additional study is needed to predict the coal-washing behavior of other South African coals.

Helping improve estimates of $\mathrm{Hg}$ emissions is one of the goals of this study. To estimate $\mathrm{Hg}$ emissions, general conclusions about emission factors can be drawn from knowledge of the type of $\mathrm{PCD}$ and the coal composition ( $\mathrm{Cl}$ and $\mathrm{S}$ contents, in particular). However, variation in operating conditions in the boiler and APCDs affect the $\mathrm{Hg}$ emission factors. Greater accuracy in estimation of emission factors can be achieved if differences in these operating conditions are considered. Tracking $\mathrm{Hg}$ capture on a unit-by-unit basis would provide a much better estimate of the $\mathrm{Hg}$ emission rate from the plant than simply assigning a fixed emission factor based on the type of PCD, as has been done in previous estimates. As shown in Section 4, collection of paired coal and fly ash samples provides a simple and inexpensive way to track the relative performance of APCDs in removing $\mathrm{Hg}$. 


\section{References Cited}

AMAP/UNEP, 2013, Technical Background Report for the Global Mercury Assessment 2013: published by Arctic Monitoring and Assessment Programme, Oslo, Norway and UNEP Chemicals Branch, Geneva, Switzerland, 263 p.

ASTM, 2013a, ASTM D3761-13: Standard test method for total fluorine in coal by the oxygen bomb combustion/ion selective electrode method, 4 p., www.astm.org/Standards/D3761.htm, accessed Jan 22, 2014.

ASTM, 2013b, ASTM D4208-13: Standard test method for total chlorine in coal by the oxygen bomb combustion/ion selective electrode method, 4 p., www.astm.org/Standards/D4208.htm, accessed Jan 22, 2014.

Bergh, J.P., Falcon, R.M.S., and Falcon, L.M., 2011, Trace element concentration reduction by beneficiation of Witbank Coalfield no. 4 Seam: Fuel Processing Technology, v. 92, p. 812-816.

Cameron, E.N., 1977, Chromite in the central sector of the Eastern Bushveld Complex, South Africa: American Mineralogist, v. 62, p. 1082-1096.

Dabrowski, J.M., Ashton, P.J., Murray, K., Leaner, J.J., and Mason, R.P., 2008, Anthropogenic mercury emissions in South Africa; Coal combustion in power plants: Atmospheric Environment, v. 42, p. 6620-6626.

Falcon, R.M.S., 1986, Classification of coals in southern Africa, in Annhaesser, C.R., and Maske, S., eds., Mineral deposits of southern Africa, v. II: Geological Society of Southern Africa, p. 1899-1921 [not seen; cited in Wagner and Hlatshwayo, 2005].

Forte, Jr., R., Ryan, J.V., Johnson, T.P., and Kariher, P.H., 2012, The United States Environmental Protection Agency's mercury measurement toolkit; An introduction: Energy \& Fuels, v. 26, p. 4643-4646.

Gericke, G., Surender, D., and Delport, W., 2007, Executive summary of mercury research and trace element behavior: Eskom Report C096501, Eskom, Johannesburg (not seen; results given in Scott, 2011).

Granite, E.J., Pennline, H.W., and Senior, C., eds., 2015, Mercury control; For coal-derived gas streams: Weinhem, Germany, Wiley-VCH, $448 \mathrm{p}$.

Huggins, F.E., and Huffman, G.P., 1995, Chlorine in coal; An XAFS spectroscopic investigation: Fuel, v. 74, p. 556-569.

Hulbert, L.J., and Von Gruenewaldt, G., 1985, Textural and compositional features of chromite in the Lower and Critical Zones of the Bushveld Complex south of Potgietersrus: Economic Geology, v. 80, p. 872-895.

Jeffrey, L.S., 2005, Characterization of the coal resources of South Africa: The Journal of the South African Institute of Mining and Metallurgy, p. 95-102.

Ketris, M.P., and Yudovich, Y.E., 2009, Estimations of Clarkes for Carbonaceous biolithes; World averages for trace element contents in black shales and coals: International Journal of Coal Geology, v. 78, p. 135-148.

Kilgroe, J.D., Sedman, C.B., Srivastava, R.K., Ryan, J.V., Lee, C.W., and Thorneloe, S.A., 2002, Control of mercury emissions from coal-fired electric utility boilers; interim report including errata dated 3-21-02: U.S. EPA Report EPA-600/R-01-109, Office of Research and Development, National Risk Management Research Laboratory, Research Triangle Park, N.C., April 2002.

Kolker, A., 2012, Minor element distribution in iron-disulfides in coal; A geochemical review: International Journal of Coal Geology, v. 94, p. 32-43. 
Kolker, A., and Quick, J.C., 2015, Mercury and halogens in coal, in Granite, E.J., Pennline, H.W., and Senior, C., eds., Mercury control; For coal-derived gas streams: Weinhem, Germany, Wiley-VCH, p. 13-44.

La Marca, C., Bianchi, A., Cioni, C., and Malloggi, S., 2006, Impact of Combustion System on Mercury Speciation and Removal in Coal-Fired Units. Italian Section of the Combustion Institute-Proceedings of the 29th meeting on Combustion, June 2006: Pisa, Italy, $6 \mathrm{p}$.

Leaner, J., Dabrowski, J., Mason, R., Resane, T., Richardson, M., Ginster, M., Euripides, R., and Masekoameng, E., 2009, Mercury emissions from point sources in South Africa, in Pirrone, N., and Mason, R., eds., Mercury fate and transport in the global atmosphere: Springer Verlag, p. 113-130.

Masekoameng, E., Leaner, J., and Dabrowski, J., 2010, Trends in anthropogenic mercury emissions estimated for South Africa during 2000-2006: Atmospheric Environment, v. 44, p. 3007-3014.

Pacyna, J.M., and Pacyna, E.G., 2001, An assessment of global and regional emissions of trace metals to the atmosphere from anthropogenic sources worldwide: Environmental Reviews, v. 9, p. 269-298.

Peatfield, D., 2003, Coal and coal preparation in South Africa-A 2002 review: Journal of the South African Institute of Mining and Metallurgy, July/August 2003, p. 355-372.

Pollack, N.R., 2009, Novel carbon based sorbents for high $\mathrm{SO}_{3}$ applications, in Air Quality VII-Proceedings, October 2009: Arlington, Va., 10 p.

Pretorius, C.C., Boshoff, H.P., and Pinheiro, H.J., 2002, Analysis of coal product samples of South African Collieries, 2001-2002: Bulletin 114, Energy Branch, South African Department of Minerals and Energy, Coal and Mineral Technologies (Pty) Ltd, South African Bureau of Standards, Pretoria, $25 \mathrm{p}$.

Roos, B.L., 2011, Mercury emissions from coal-fired power stations in South Africa: M.S. thesis, University of Johannesburg, $84 \mathrm{p}$.

Sanford, R.F, Pierson, C.T., and Crovelli, R.A., 1993, An objective replacement method for censored geochemical data: Mathematical Geology, v. 25, no. 1, p. 59-80.

Scott, G., 2011, Reducing mercury emissions from coal combustion in the energy sector in South Africa: Final Project Report, UNEP Global Mercury Partnership, Mercury in Coal Project Area, www.unep.org/, 18 p., accessed Dec. 17, 2013.

Senior, C.L., and Johnson, S.A., 2005, Impact of carbon-in-ash on mercury removal across particulate control devices in coal-fired power plants: Energy and Fuels, v. 19, p. 859-863.

Senior, C.L., 2015, Mercury behavior in coal combustion systems, in Granite, E.J., Pennline, H.W., and Senior, C., eds., Mercury control; For coal-derived gas streams: Weinhem, Germany, Wiley-VCH, p. 109-132.

Snyman, C.P., and Botha, W.J., 1993, Coal in South Africa: Journal of African Earth Sciences, v. 16 , no. $1 / 2$, p. $171-180$.

Tewalt, S.J., Belkin, H.E., SanFilipo, J.R., Merrill, M.D., Palmer, C.A., Warwick, P.D., Karlsen, A.W., Finkelman, R.B., and Park, A.J., 2010, Chemical analyses in the world coal quality inventory, version 1: U.S. Geological Survey Open-File Report 2010-1196, http://pubs.usgs.gov/of/2010/1196/, 4 p. and data files, accessed Jan. 22, 2014.

U.S. Environmental Protection Agency (EPA), 2007, Method 7473, Mercury in solids and solutions by thermal decomposition, amalgamation, and atomic absorption spectrophotometry, http://www.epa.gov/wastes/hazard/testmethods/sw846/pdfs/7473.pdf, 17 p., accessed

Feb. 25, 2014. 
U.S. Environmental Protection Agency (EPA), 2008, Method 30B, Determination of mercury from coal-fired combustion sources using carbon sorbent traps, http://www.epa.gov/ttn/emc/methods/method30B.html, 39 p., accessed Feb. 4, 2014.

U.S. Environmental Protection Agency (EPA), 2011, Mercury and Air Toxics Standards (MATS): http://www.epa.gov/mats/pdfs/20111216MATSfinal.pdf, 1117 p., accessed Feb. 4, 2014.

Vosteen, B.W., Winkler, H., and Berry, M.S., 2010, Native halogens in coals from USA, China and elsewhere; Low chlorine coals need bromide addition for enhanced mercury captureProceedings of the 2010 Power Plant Air Pollutant Control "MEGA" Symposium: Baltimore, Md., Paper 103, 22 p.

Wagner, N.J., and Hlatshwayo, B., 2005, The occurrence of potentially hazardous trace elements in five Highveld coals, South Africa: International Journal of Coal Geology, v. 63, p. 228-246.

Wagner, N.J., and Tlotleng, M.T., 2012, Distribution of selected trace elements in density fractionated Waterberg coals form South Africa: International Journal of Coal Geology, v. 94, p. 225-237.

Wilson, S.A., Ridley, W.I., and Koenig, A.E., 2002, Development of sulfide calibration standards for the laser ablation inductively-coupled plasma mass spectrometry technique: Journal of Analytical Atomic Spectrometry, v. 17, p. 406-409.

World Coal Association, 2014, Coal Statistics 2013, http:/www.worldcoal.org/resources/coalstatistics/, 3 p., accessed Feb. 4, 2014. 


\section{Appendix 1. Analytical Quality Assurance and Inter- laboratory Comparisons}

\section{Mercury Analysis}

Mercury contents were determined on sample powders at the USGS Eastern Energy Resources Science Center in Reston, Virginia, using a Nippon MA-3000 instrument, and at the USGS Central Energy Resources Science Center in Denver, Colorado, using a Milestone DMA80 instrument. Both instruments are commercially available, dedicated direct $\mathrm{Hg}$ analyzers. Each instrument employs U.S. Environmental Protection Agency (EPA) Method 7473, in which samples are heated and the evolved $\mathrm{Hg}$ is selectively captured as an amalgam and measured by atomic absorption spectrophotometry (EPA, 2007). The Reston MA-3000 has a detection limit of 0.002 nanograms (ng) of $\mathrm{Hg}$ with automatic switching between low (0 to $10 \mathrm{ng}$ ) and high $(>10 \mathrm{ng}$ ) dynamic measurement ranges. In tests of this instrument for coal samples, a sample size of 50 milligrams was found to insure complete thermal decomposition. The MA-3000 is calibrated using solutions prepared from high-purity mercuric chloride at concentrations ranging from 0 to $200 \mathrm{ng} \mathrm{Hg}$. Using these solutions, calibrations of 0.9999 or better are obtained.

Results for replicate analysis of sample unknowns using the Reston instrument are given in table A1 and analyses of NIST Standard 1632d (trace elements in coal) and NIST Standard $1633 \mathrm{c}$ (trace elements in fly ash) are given in table A2. Reproducibility of the analyses is within 10-20 percent or better and NIST standard values are attained when run as unknowns. These values are typical of what is obtainable with this type of instrumentation. Results are especially good, considering the distribution of pyrite, and of $\mathrm{Hg}$ within pyrite, are heterogeneous within the samples determined, especially the density separates. These heterogeneities can contribute to inconsistent results due to a nugget effect for $\mathrm{Hg}$.

The 42 feed coal samples and 8 density separates run on the Reston instrument were rerun in Denver as part of the USGS multi-element package. These results are compared in figure A1. There is no systematic difference between the two laboratories, and in most cases, the results agree within 20 percent or better. For the feed coals, three samples $(9 \mathrm{~B}, 12 \mathrm{~A}$, and $12 \mathrm{~B})$ give values that deviate by more than 25 percent between the two laboratories (fig. A1). For the density separates, another three samples (14E, 14F, and 14G) show poor agreement between the Denver and Reston determinations (fig. A1). These six samples were reanalyzed by both laboratories and in each case, the reruns show better agreement and the average of multiple determinations is between the two original analyses (table A3).

With the exception of feed coal samples 9B, 12A, and 12B for which averages of 5 available runs are reported, $\mathrm{Hg}$ results presented for the group of 42 feed coals samples in this report are from the Reston laboratory. The 48 samples of coal and fly ash from the 2010 sampling at Kendal and Duvha power stations were analyzed for $\mathrm{Hg}$ only in the Reston laboratory, and interlaboratory comparison with the Denver instrument is unavailable. However, some coal samples from this group were determined in 2010 at EPA laboratories in Research Triangle Park, North Carolina, by using a Lumex Zeeman instrument; as a check, some of the same powders were analyzed in 2011 using the USGS Reston Hg instrument. The results show good interlaboratory agreement and stability of the samples and the instrumentation over time (table A4). 
The relatively greater $\mathrm{Hg}$ heterogeneity shown by the density separates may be attributable to their provision from Eskom as 1-mm-size splits rather than as pulverized coal. These splits were ground to a powder (in an agate mortar) prior to the Reston analysis and subjected to further grinding in Denver. In contrast, feed coal samples consist of pulverized coal and in most cases were analyzed as provided, by both the Reston and Denver laboratories. For the density separates, averages of all available determinations shown in table A3 are reported in table 6 and used in plotting.

Table A1. Replicate mercury $(\mathrm{Hg})$ analysis, USGS Reston laboratory.

\begin{tabular}{llccccc}
\hline \multicolumn{1}{c}{ Sample } & Material & $\begin{array}{c}\text { Sample weight } \\
\text { [grams] }\end{array}$ & $\begin{array}{c}\text { Hg } \\
\text { measurements } \\
\text { [nanograms] }\end{array}$ & $\begin{array}{c}\text { Hg } \\
\text { concentrations } \\
\text { [parts per } \\
\text { billion] }\end{array}$ & Date & $\begin{array}{c}\text { Mean } \\
\text { [parts per } \\
\text { billion] }\end{array}$ \\
\hline KFA-3A & Fly ash & 0.024 & 1.390 & 57.9 & Feb. 2014 & \\
KFA-3A-d1 & Fly ash & 0.023 & 1.225 & 53.3 & Feb. 2014 & \\
KFA-3A-d2 & Fly ash & 0.031 & 1.955 & 63.1 & Feb. 2014 & $58.1 \pm 4.9$ \\
DFC-2A & Coal & 0.051 & 8.82 & 177 & Feb. 2014 & \\
DFC-2A-d1 & Coal & 0.043 & 6.42 & 153 & Feb. 2014 & \\
DFC-2A-d2 & Coal & 0.055 & 8.59 & 160 & Feb. 2014 & \\
DFC-2A-d3 & Coal & 0.046 & 7.31 & 162 & Feb. 2014 & $163 \pm 10$ \\
ESKO 8A-1 & Coal & 0.049 & 9.61 & 196 & May 2013 & \\
ESKO 8A-2 & Coal & 0.057 & 12.40 & 218 & May 2013 & \\
ESKO 8A-3 & Coal & 0.049 & 11.01 & 225 & May 2013 & \\
ESKO 8A-4 & Coal & 0.052 & 13.28 & 255 & May 2013 & \\
ESKO 8A-5 & Coal & 0.05 & 12.83 & 257 & May 2013 & $230 \pm 26$ \\
\hline
\end{tabular}


Table A2. U.S. National Institute of Standards and Technology (NIST) standard mercury (Hg) analysis, USGS Reston laboratory.

\begin{tabular}{|c|c|c|c|c|c|c|}
\hline NIST & $\begin{array}{l}\text { Sample weight } \\
\text { [grams] }\end{array}$ & $\begin{array}{c}\mathrm{Hg} \\
\text { measurements } \\
\text { [nanograms] }\end{array}$ & $\begin{array}{c}\mathrm{Hg} \\
\text { concentrations } \\
\text { [parts per } \\
\text { billion] } \\
\end{array}$ & Date & $\begin{array}{l}\text { Mean [parts } \\
\text { per billion] }\end{array}$ & $\begin{array}{c}\text { Certified } \\
\text { value [parts } \\
\text { per billion] }\end{array}$ \\
\hline $1632 d$ & 0.051 & 4.75 & 95.2 & Feb. 2014 & & \\
\hline $1632 d$ & 0.050 & 4.80 & 98.1 & Feb. 2014 & & \\
\hline $1632 d$ & 0.050 & 4.94 & 101 & Feb. 2014 & & \\
\hline $1632 d$ & 0.046 & 4.34 & 96.2 & Feb. 2014 & & \\
\hline $1632 d$ & 0.052 & 4.55 & 89.3 & Feb. 2014 & & \\
\hline $1632 d$ & 0.049 & 4.27 & 89.0 & Feb. 2014 & & \\
\hline $1632 d$ & 0.043 & 3.95 & 93.8 & Feb. 2014 & & \\
\hline $1632 d$ & 0.047 & 4.63 & 100 & Feb. 2014 & & \\
\hline $1632 d$ & 0.052 & 4.66 & 91.5 & Feb. 2014 & $94.9 \pm 4.2$ & $92.8 \pm 3.3$ \\
\hline $1632 d$ & 0.048 & 4.15 & 88.3 & May 2013 & & \\
\hline $1632 d$ & 0.050 & 5.09 & 104 & May 2013 & & \\
\hline $1632 d$ & 0.050 & 4.17 & 85.1 & May 2013 & & \\
\hline $1632 d$ & 0.050 & 4.74 & 96.7 & May 2013 & & \\
\hline $1632 d$ & 0.050 & 4.69 & 95.9 & May 2013 & & \\
\hline $1632 d$ & 0.052 & 4.91 & 96.4 & May 2013 & & \\
\hline $1632 d$ & 0.046 & 4.21 & 93.5 & May 2013 & & \\
\hline $1632 d$ & 0.052 & 4.69 & 92.1 & May 2013 & & \\
\hline $1632 d$ & 0.050 & 5.23 & 107 & May 2013 & & \\
\hline $1632 d$ & 0.048 & 4.56 & 97.0 & May 2013 & & \\
\hline $1632 d$ & 0.050 & 4.66 & 95.2 & May 2013 & & \\
\hline $1632 d$ & 0.056 & 5.11 & 93.1 & May 2013 & & \\
\hline $1632 d$ & 0.053 & 5.14 & 98.9 & May 2013 & & \\
\hline $1632 d$ & 0.043 & 4.32 & 103 & May 2013 & & \\
\hline $1632 d$ & 0.051 & 4.47 & 89.4 & May 2013 & $95.7 \pm 5.9$ & $92.8 \pm 3.3$ \\
\hline $1633 c$ & 0.017 & 18.9 & 1,112 & Feb. 2014 & & \\
\hline $1633 \mathrm{c}$ & 0.019 & 20.2 & 1,063 & Feb. 2014 & & \\
\hline $1633 c$ & 0.017 & 16.3 & 961 & Feb. 2014 & & \\
\hline $1633 c$ & 0.011 & 11.9 & 1,078 & Feb. 2014 & & \\
\hline $1633 c$ & 0.016 & 17.3 & 1,082 & Feb. 2014 & & \\
\hline $1633 c$ & 0.009 & 8.92 & 991 & Feb. 2014 & & \\
\hline $1633 c$ & 0.011 & 11.9 & 1,078 & Feb. 2014 & & \\
\hline $1633 c$ & 0.010 & 9.61 & 961 & Feb. 2014 & $1,041 \pm 56$ & $1,005 \pm 22$ \\
\hline
\end{tabular}



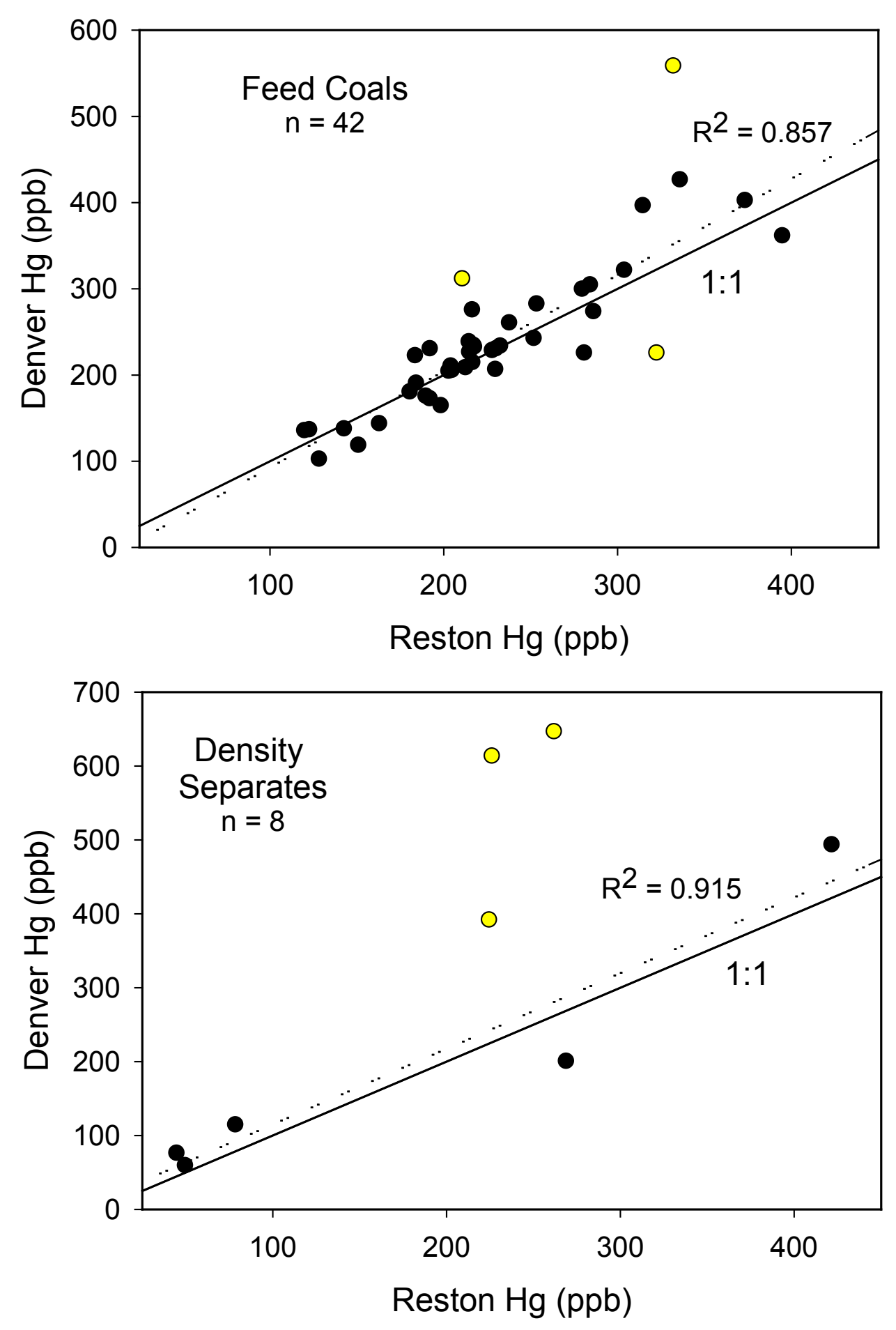

Figure A1. Plots showing correspondence between mercury $(\mathrm{Hg})$ values (ppb, parts per billion) as determined in USGS Reston and Denver $\mathrm{Hg}$ analyzers. Solid lines indicate perfect (1:1) correspondence ( $n$, number of samples; $R^{2}$, correlation). Dashed lines show linear regression, excluding three samples in each group shown in yellow that were reanalyzed by both laboratories (table A3). 
Table A3. Replicate mercury analyses for density separates, and three feed coal samples showing poor initial correspondence between USGS Reston and Denver laboratories (in parts per billion on an asdetermined basis). Densities are as indicated with float designated as $\mathrm{F}$ and sink as $\mathrm{S}$.

\begin{tabular}{llllccc}
\hline Feed coals & $\begin{array}{l}\text { Reston } \\
\text { original }\end{array}$ & $\begin{array}{l}\text { Denver } \\
\text { original }\end{array}$ & $\begin{array}{c}\text { Denver } \\
\text { rerun 1 }\end{array}$ & $\begin{array}{c}\text { Denver } \\
\text { rerun 2 }\end{array}$ & $\begin{array}{c}\text { Reston } \\
\text { rerun }\end{array}$ & Mean \\
\hline 9B & 332 & 559 & 480 & 497 & 449 & $463(5)$ \\
12A & 211 & 312 & 310 & 271 & 285 & $278(5)$ \\
12B & 322 & 226 & 185 & 195 & 239 & $233(5)$ \\
\hline \multicolumn{7}{r}{} \\
\hline 14A 1.4F & 44.6 & 76.5 & Density separates & & \\
14B 1.5F & 49.5 & 59.8 & & & & $60.6(2)$ \\
14C 1.6F & 78.4 & 115 & & & & $54.7(2)$ \\
14D 1.7F & 269 & 201 & & & & $96.7(2)$ \\
14E 1.8F & 224 & 392 & 285 & 321 & 300 & $304(5)$ \\
14F 1.9F & 262 & 647 & 697 & 722 & 631 & $592(5)$ \\
14G 2.0F & 226 & 614 & 544 & 418 & 371 & $435(5)$ \\
14H 2.0S & 421 & 494 & & & & $458(2)$ \\
\hline
\end{tabular}

\section{Trace element analysis by Inductively Coupled Plasma-Mass Spectrometry}

With the exception of $\mathrm{Hg}$ (and Se), which are determined on whole coal, coal samples for trace element analysis are first prepared by heating 0.2 grams of material at $525^{\circ} \mathrm{C}$ for 36 hours to obtain laboratory ash. The ash is digested using a method similar to ASTM D 6357-04 in which the prepared sample is digested in a heated 3-acid (nitric, hydrochloric, and hydrofluoric) mixture. Calibration standards for ICP-MS analysis are prepared from stock solutions and calibration coefficients of 0.995 or better are obtained for standards before running unknowns. Samples are run at dilutions that fall within the range of the calibration standards. Results are corrected for mass and polyatomic interferences by selection of alternate isotopes, or if necessary, by use of preprogrammed correction factors. A standard or replicate is run for every 10 unknowns to check for instrument drift. Sample moistures are obtained at the time of analysis using a method similar to ASTM D3173-03 in which samples are first weighed, heated to $107^{\circ} \mathrm{C}$ for 2 hours, and weighed again in the dried condition. These moistures, and not the values compared in the following section, are used in calculating trace element results determined on an ash basis to a whole-coal basis (table 6). 
Table A4. Comparison of mercury data for 2010 mill feed coal samples; Kendal and Durha power stations versus previously unpublished determinations on the same splits.

[In parts per billion, on an as-determined basis; --, not determined).

\begin{tabular}{|c|c|c|c|c|c|c|}
\hline $\begin{array}{l}\text { Power } \\
\text { station }\end{array}$ & Unit & Sample & Material & $\begin{array}{l}\text { This study } \\
\text { Feb. } 2014\end{array}$ & $\begin{array}{c}\text { USGS } \\
\text { Sept. } 2011\end{array}$ & $\begin{array}{l}\text { EPA } \\
2010 \\
\end{array}$ \\
\hline Kendal & 1 & KFC-1A & Coal & 188 & 176 & 200 \\
\hline Kendal & 1 & KFC-1B & Coal & 167 & 170 & --- \\
\hline Kendal & 2 & KFC-2A & Coal & 196 & --- & 205 \\
\hline Kendal & 2 & KFC-2B & Coal & 249 & 201 & --- \\
\hline Kendal & 3 & KFC-3A & Coal & 199 & --- & 225 \\
\hline Kendal & 3 & KFC-3B & Coal & 205 & 211 & --- \\
\hline Kendal & 4 & KFC-4A & Coal & 188 & --- & 190 \\
\hline Kendal & 4 & KFC-4B & Coal & 174 & 176 & -- \\
\hline Kendal & 5 & KFC-5A & Coal & 347 & --- & 324 \\
\hline Kendal & 5 & KFC-5B & Coal & 361 & 340 & --- \\
\hline Kendal & 6 & KFC-6A & Coal & 359 & --- & 323 \\
\hline Kendal & 6 & KFC-6B & Coal & 348 & 339 & 314 \\
\hline Duvha & 1 & DFC-1A & Coal & 150 & 133 & 132 \\
\hline Duvha & 1 & DFC-1B & Coal & 137 & 186 & -- \\
\hline Duvha & 2 & DFC-2A & Coal & 177 & --- & 148 \\
\hline Duvha & 2 & DFC-2B & Coal & 175 & 148 & --- \\
\hline Duvha & 3 & DFC-3A & Coal & 158 & --- & 150 \\
\hline Duvha & 3 & DFC-3B & Coal & 166 & 152 & --- \\
\hline Duvha & 4 & DFC $-4 A$ & Coal & 261 & --- & 248 \\
\hline Duvha & 4 & DFC-4B & Coal & 306 & 236 & --- \\
\hline Duvha & 5 & DFC-5A & Coal & 206 & --- & 206 \\
\hline Duvha & 5 & DFC-5B & Coal & 221 & 182 & --- \\
\hline Duvha & 6 & DFC-6A & Coal & 285 & --- & 246 \\
\hline Duvha & 6 & DFC-6B & Coal & 253 & 243 & --- \\
\hline
\end{tabular}

\section{Coal Quality Determinations}

A suite of analyses - including short proximate (consisting of ash, S, moisture, and calorific value), $\mathrm{S}$ forms (consisting of organic, pyritic, and sulfate), and halogens (consisting of total $\mathrm{Cl}$, fluorine, and $\mathrm{Br}$ ) — was performed by Geochemical Testing, Inc., of Somerset, Pennsylvania, a commercial laboratory under contract to the USGS (USGS Contract Lab). The following ASTM methods were used: (1) Moisture, D3302; (2) Ash, D3174; (3) Sulfur, D4239; (4) Calorific Value, D5865; (5) forms of Sulfur, D2492; (6) Chlorine, D4208; (7) Fluorine, D3761; and Bromine (no ASTM method available).

Results for ash yield and moisture obtained from Geochemical Testing, Inc., are compared with values provided by Eskom in figures A2 and A3, respectively. For ash yield, all but one sample (9C) show an acceptable correspondence and there are no systematic differences in results between the two laboratories. For moisture, approximately half of the samples plot along a 1:1 line of correspondence and half of the samples do not. This resulted in some divergence between the linear regression and line of 1:1 correspondence (fig. A3). There are no systematic differences apparent between the two laboratories. Moisture content is inherently 
variable as coal samples may lose or adsorb moisture in response to environmental conditions. Overall moisture contents of the samples are low and may reflect some loss of moisture relative to the coals received at each power station.

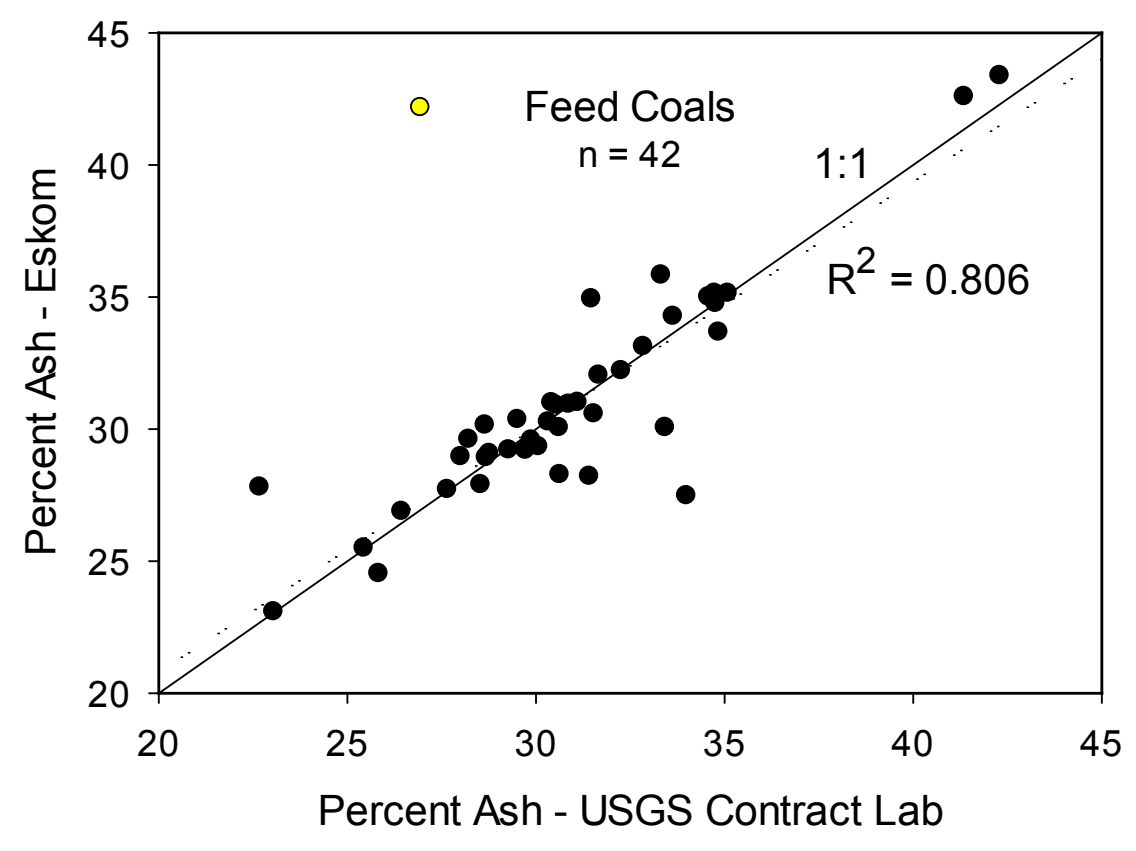

Figure A2. Plot of ash yield determinations (on a dry basis; $n$, number of samples; and $\mathrm{R}^{2}$, correlation) for USGS contract laboratory and results provided by Eskom. One sample shown in yellow (9C) is omitted from the linear regression. Eskom ash value for this sample is used in table 4. 


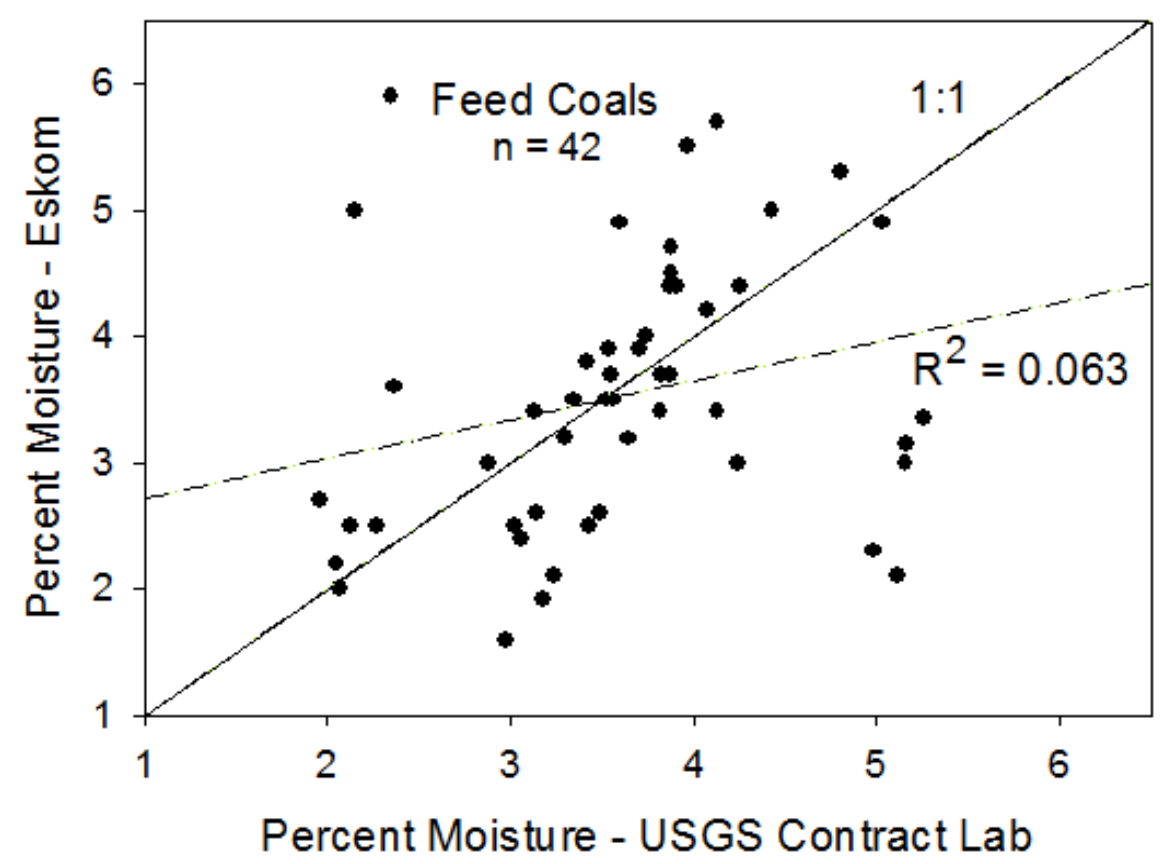

Figure A3. Plot of moisture determinations ( $\mathrm{n}$, number of samples; $\mathrm{R}^{2}$, correlation).

\section{Revisions to Trace Element Results}

All 50 samples in this study were redetermined by Actlabs (Ancaster, Ontario, Canada) using their Ultratrace-4 sample digestion procedure. This procedure, along with the suite of elements obtained, most closely replicates the USGS approach originally used in this study. Prior to analysis, coal samples were first ashed by Actlabs at $525{ }^{\circ} \mathrm{C}$ for 36 hours, replicating the procedure used in the USGS laboratories. The prepared coal ash was then digested using Actlabs' 4-acid (nitric, hydrochloric, hydrofluoric, perchloric) Ultratrace-4 procedure. In this digestion procedure, loss of $\mathrm{Cr}$, As, and $\mathrm{Sb}$ may occur by volatilization during sample dry-down; for this reason, results for these three elements determined by Actlabs are considered unreliable.

To further insure the validity of trace element data contained in the revised version of this report, all samples were redetermined at USGS laboratories in Denver using appropriate ICP-MS protocols. In these re-analyses, coal samples prepared by ashing at $525{ }^{\circ} \mathrm{C}$ for 36 hours were digested using the USGS 3-acid (nitric, hydrochloric, hydrofluoric) procedure. Trace element results (by ICP-MS) given in table 6 reflect values obtained from Actlabs except for Cr, As, and $\mathrm{Sb}$, for which USGS determinations were substituted in table 6 due to the potential for loss of these elements in the Actlabs digestion procedure. Together, these redetermined results replace the original determinations by ICP-MS included in table 6 of the previous version of this report. In both the Actlabs and USGS redeterminations, conversion of results to a whole-coal dry basis was calculated using moisture values obtained from Geochemical Testing, Inc., a USGS contract laboratory (table 4; appendix 1). Note that results for mercury given in table 6 are unchanged from those given in the previous version of this report, except for minimal adjustments to express 
the results on a whole-coal dry basis. Results for halogens, determined by Geochemical Testing, Inc., using ion-selective electrodes, were already expressed on a dry basis in the previous version of this report and are unchanged here.

Comparison of ICP-MS results obtained in redeterminations by Actlabs and by the USGS is given in table A5, showing correlation by element expressed as $\mathrm{R}^{2}$ values for the combined suite of feed coals and density separates. Overall, agreement between the two sets of redeterminations is very good. Correlations tend to be less robust for elements having sub-ppm concentrations (for example, $\mathrm{Tl}, \mathrm{Sb}$ ), which is expected as method detection limits are approached. Differences found for $\mathrm{Cr}$ (seven samples) and Sb (two samples) are consistent with loss of these elements in the Actlabs determinations, and USGS results for these elements are substituted in table 6 of the revised version of this report. USGS results for As are also reported in table 6 because of the potential for As loss in the Actlabs digestion procedure. For As, however, results for the two laboratories agree well $\left(\mathrm{R}^{2}=0.83\right)$ and no systematic differences were found.

Table A5. Linear regression results $\left(R^{2}\right)$ comparing values obtained by USGS contract laboratory Actlabs and USGS Denver laboratories in 2015 ICP-MS reruns of Eskom feed coals and density separates described in this report.

\begin{tabular}{cccc}
\hline & & & \\
Element & Regresssion $\left(\mathbf{R}^{2}\right)$ Actlabs vs. USGS & Number of Samples & Source of Data used in Table 6 \\
\hline $\mathrm{Be}$ & 0.869 & 50 & Actlabs \\
$\mathrm{Cr}$ & 0.478 & 50 & USGS \\
$\mathrm{Mn}$ & 0.957 & 50 & Actlabs \\
$\mathrm{Co}$ & 0.959 & 50 & Actlabs \\
$\mathrm{Ni}$ & 0.912 & 50 & Actlabs \\
$\mathrm{Zn}$ & 0.888 & 50 & Actlabs \\
$\mathrm{As}$ & 0.829 & 50 & USGS \\
$\mathrm{Mo}$ & 0.699 & $49^{1}$ & Actlabs \\
$\mathrm{Pb}$ & 0.812 & 50 & Actlabs \\
\hline
\end{tabular}

${ }^{1}$ Sample $14 \mathrm{H}$ is excluded from linear regression for Mo. 
ISSN 2331-1258 (online)

http://dx.doi.org/10.3133/ofr20141153 